\title{
IN TEMPI DI GUERRA E DI PESTE HORREA E MOBILITÀ DEL GRANO PUBBLICO TRA GLI ANTONINI E I SEVERI
}

\author{
Federico De Romanis*
}

\section{DI ALCUNI HORREA MAGHREBINI DI II SEC. D.C.}

1. L'identificazione e la cronologia proposte da E. Papi e F. Martorella per quello che a Thamusida ora si rivela un granaio annesso al porto, capace di contenere poco più di 1,000 tonnellate di grano, rappresentano acquisizioni tanto inattese quanto importanti ${ }^{1}$.

Inattese, perché sebbene fosse già stato sospettato, sulla scorta dell'editto banasitano di Caracalla ${ }^{2}$, che " la culture céréalière, déja importante en Césarienne sous les rois berbères, y fut encouragée sous l'Empire ainsi peut-être qu'en Tingitane pour les besoins de l'annone $"^{3}$, non molti, finora, avevano osato includere la Tingitana tra le province i cui tributi granari siano stati adoperati, dall'amministrazione imperiale, al di fuori dei confini provinciali. Ora sappiamo invece che in età severiana, e forse già qualche decennio prima, si decise di trasferire sull'oceano (e dunque, con ogni probabilità, al Mediterraneo) una quota non irrilevante della produzione granaria della valle del Sebou.

Ciò consente una contestualizzazione nuova dell'editto banasitano di Caracalla: i debita fiscalia frumentaria siue pecuniaria da cui sono liberati, tra

\footnotetext{
* Università degli Studi della Tuscia (Viterbo).

1. Papi E. e Martorella F., Grano della Tingitana, 2007, p. 85-96. Peraltro, questo edificio si distingue da un altro granaio, dalla capienza di 300 tonnellate, a uso delle truppe di stanza.

2. IAM 2, 100.

3. CORBIER M., Discours du prince, 1977, p. 216 [= Donner à voir, donner à lire, 2006, p. 202].
}

10 dicembre 215 e 9 dicembre 216, i contribuenti delle due Mauretanie (e non ultimi, tra questi, i Banasitani $)^{4}$ si accumulano negli stessi anni in cui dalla valle del Sebou, tramite gli horrea di Thamusida, si realizzano importanti trasferimenti di grano, certamente pubblico, verso il Mediterraneo.

4. Rispetto alla pur raffinata interpretazione dell'editto banasitano (ri)proposta da CORBIER M., Discours du prince, 1977, p. 211-232 [= Donner à voir, donner à lire, 2006, p. 197-213], farei mie alcune delle obiezioni già mosse da Di ViTa-Evrard G., L'édit de Banasa, 1988, p. 287-304. Interpretare come conversione in prestazioni di caelestia animalia quella che si presenta come una remissione dei debita fiscalia frumentaria siue pecuniaria presuppone la volontà, da parte dell'estensore del testo, di dissimulare i concreti contenuti dell'editto. Mi sembra però che, almeno per quanto riguarda le misure fiscali, in esso non vi sia alcuna ambiguità. Vici e prouinciae sono bene de rep. merentes perché, indipendentemente dagli obblighi alle annuae pensitationes siue in frumento seu in pecunia, danno (nel presente come già nel passato e, auspicabilmente, nel futuro : il participio presente merentium (1. 12) ha un valore indeterminato) uiri fortes e, tramite le loro siluae, caelestia animalia. L'indulgentia imperiale ispirata dall'obsequium e dalla fides dei provinciali - Caracalla ne è certo sarà ripagata con ulteriore obsequium quando i beneficiari avranno investito su di lui il meritum ("ricompensa, beneficio" : cfr. ThlL VIII 814, 11.1 sgg.) appena ottenuto (cum... meritum apud me conlocaueritis). Non leggerei in tutto ciò un'obliqua richiesta a essere pagato in uomini e bestie anziché in grano e danaro, perché l'imperatore è molto esplicito nel dichiarare quali siano, a seguito di questo beneficium, le sue aspettative in materia fiscale : hoc beneficio meo praesumo omnes de cetero annuas pensitationes siue in frumento seu in pecunia eo promptius daturos quo me reputabitis non expectasse quin ultro offerrem neque petentibus uobis neque sperantibus noua remedia et magnificam indulgentiam. Frumento e danaro, dunque, come in precedenza. 
La novità non è di scarso rilievo. Quella del Sebou, infatti, è una valle importantissima per l'economia della Mauretania Tingitana. Lo rivela la precoce colonizzazione augustea di Banasa ${ }^{5}$, precedente all'annessione del regno di Mauretania e più antica di quella, solo claudiana, di Lixus ; lo dimostra la navigabilità, esaltata da Plinio il Vecchio, del "magnifico " Sububus ${ }^{6}$; lo dimostrano, all'età di Caracalla, le risonanze volubilitane all'editto banasitano or ora evocato. Un'eco della gratitudine dei contribuenti della Tingitana per il condono dei debiti fiscali di Caracalla è stata giustamente colta nella glorificazione, sulle iscrizioni dell'arco di Volubilis ${ }^{7}$, datate alla ventesima tribunicia potestas di Caracalla (dal 10 dicembre 216 fino alla notizia della sua morte, avvenuta l'8 aprile 217), della singularis eius erga uniuersos et noua supra omnes retro principes indulgentia, ciò che suggerisce come lungo la valle del Sebou, da Banasa a Volubilis, a un relativamente omogeneo paesaggio agrario caratterizzato dalla cerealicoltura si applicasse una medesima politica fiscale, con il risultato di un diffuso indebitamento dei contribuenti di questa parte della Tingitana.

La proiezione mediterranea degli horrea di Thamusida e del grano che da essi passa consente di inquadrare la storia della fiscalità della valle del Sebou in quella della faticosa lievitazione del tributo granario africano all'annona di Roma dall'età tardo-repubblicana a quella severiana. Più in particolare, quanto può dedursi dall'editto banasitano di Caracalla permette di accostare la situazione venutasi a determinare lungo la valle del Sebou in età severiana ad altri fenomeni dispersi su un orizzonte geografico molto più vasto, ma riconducibili tutti a un coerente indirizzo di politica fiscale, tendente a massimizzare $\mathrm{i}$ proventi in grano e in olio.

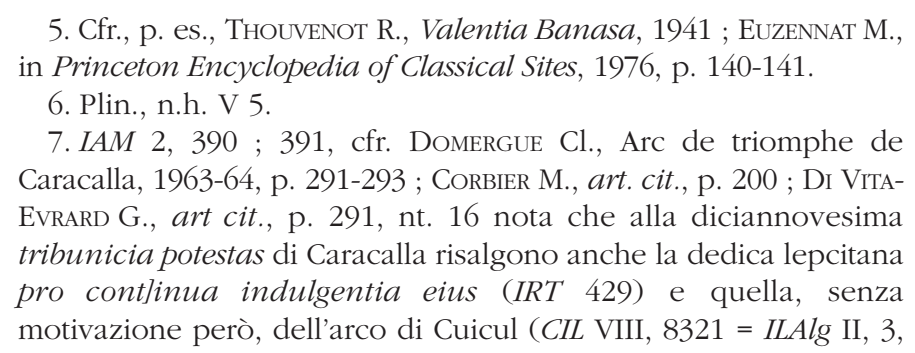

7. IAM 2, $390 ; 391$ cfr. Domergue Cl., Arc de triomphe de Caracalla, 1963-64, p. 291-293 ; CORBIER M., art. cit., p. 200 ; Di VITAEvRARD G., art cit., p. 291 , nt. 16 nota che alla diciannovesima tribunicia potestas di Caracalla risalgono anche la dedica lepcitana pro contlinua indulgentia eius (IRT 429) e quella, senza motivazione però, dell'arco di Cuicul (CIL VIII, 8321 = ILAlg II, 3, 7818).
Ripetiamo : all'età di Caracalla, quando a Thamusida si trovavano (da alcuni decenni ?) costruiti degli horrea atti a facilitare trasferimenti al Mediterraneo di cereali prodotti lungo la valle del Sebou, gli arativi compresi nel tratto che va da Thamusida a Banasa e a Volubilis dovettero essere sottoposti a un tale livello di pressione fiscale, che nel 216 si riconobbe necessario, pur senza concedere una strutturale revisione dell'imposizione, condonare i debiti che fino ad allora ne erano derivati. In questo senso, direi che, pur non avendo caratteri di unicità, l'editto banasitano di Caracalla non è affatto un documento banale, tanto più che la sua portata africana ma interprovinciale - e quindi estesa come minimo alle due Mauretanie ${ }^{8}$ - lascia in qualche misura presumere l'esistenza di debita fiscalia e di causae pendentes anche al di fuori della valle del Sebou e della Mauretania Tingitana.

Del resto, a valutare in più ampio contesto quanto avviene nella valle del Sebou invitano anche altri borrea del Maghreb, la cui cronologia in qualche modo si avvicina a quella degli borrea di Thamusida.

2. Il beneficium di Caracalla doveva riguardare anche l'altipiano della regione di Sitifis, nella Mauretania Caesariensis, dove tuttavia, malgrado la marcata vocazione cerealicola del territorio", non sono state finora riscontrate tracce di una gratitudine dei contribuenti. È possibile che l'estensione delle proprietà imperiali ${ }^{10}$ abbia reso quest'area meno sensibile alle diverse modulazioni della politica fiscale riguardo gli arativi cerealicoli. Nondimeno, anche da quest'area doveva trasmettersi grano al Mediterraneo e anche in quest'area si trovano borrea funzionali alla raccolta, lo stoccaggio e la movimentazione di grano pubblico.

Il fatto che il toponimo Caput Saltus Horreorum sia già attestato agli inizi del $193^{11}$, dimostra che le strutture che esso presuppone e, più in generale, la valorizzazione delle potenzialità produttive e contributive di quest'area, precedono l'avvento della dinastia severiana.

8. GASCOU J., Vici et provinciae 1992 p. 161-172 ; diversamente però Christol M., Rome et les tribus indigènes, 1988, p. 305-337, ripubblicato (con un addendum) in Christol M., Regards, 2005, p. 23. 9. Cfr. Fentress E.W.B., Economy, 1990, p. 117-128.

10. CRAWFORD-Thompson D.J., Imperial Estates, 1976, p. 58-59.

11. CIL VIII, $8425 ; 8426$ = ILS 6890, da Aïn Zada, cfr. Gsell S., $A A A$, fo 16,319 . 
Se è corretta la localizzazione di Horrea ad Aïn Rua proposta da S. Gsell ${ }^{12}$, proprio la non piccola distanza, circa venti chilometri, tra questo luogo e Aïn Zada (Caput Saltus Horreorum) dà un'idea delle considerevoli proporzioni del saltus in questione e dell'importanza della struttura che, pur periferica rispetto al suo caput, gli dà nome. Come del resto conferma la circostanza che Horrea risulta essere una tappa della via da Sitifis a Saldae ${ }^{13}$, la dislocazione limitanea di Horrea/Aïn Rua rispetto all'estensione del saltus è ovviamente funzionale al trasferimento a mare delle derrate prodotte dal saltus imperiale ${ }^{14}$.

Nell'impossibilità di precisare la loro cronologia oltre il terminus ante quem indicato, ci si dovrà limitare a inserire gli borrea di Caput Saltus Horreorum entro l'arco temporale disegnato dal processo evolutivo che muove dalle deduzioni coloniarie, tra Nerva e Traiano, di Sitifis, Mopthi, Cuicul ${ }^{15}$, prosegue con la costruzione, nel 124, delle strade che da Sitifis si dirigono verso nord-ovest e verso nord-est ${ }^{16}$ e comprende la costituzione delle proprietà di Matidia ${ }^{17}$ e dell'amministrazione della ratio

12. Gsell S., $A A A$, fo 16,78

13. Itin. Anton. 31, 6-32, 3 : item a Sitifi Saldas m.p. LXXVIIIIS Orrea m.p. XVIII ; Lesbi m.p. XVIII ; Tubusuptus m.p. XXV ; Saldis m.p. XVIII.

14. Logica vorrebbe che complementari a quelli di Caput Saltus Horreorum ci fossero, sul mare, degli altri horrea : secondo Fentress E.W.B., Economy, 1990, p. 118, il porto annonario dell'altopiano di Sitifis sarebbe stato Tubusuctu, che nell'antichità sarebbe stato collegato al mare da uno Oued Soummam allora navigabile. In età tetrarchica a Tubusuctu furono costruiti horrea (ILS 645) per i rifornimenti dei contingenti militari impegnati contro i Quinquegentani, cfr. Di VITA-EvRard G., Dédicace des horrea, 1992, p. 843-864; non sappiamo in che relazione fossero con gl horrea di Caput Saltus Horreorum quelli di Muslubium, attestati da Tab. Peut. seg. III (Musulubio Horreta) e Geogr. Rau. 40, 23 (Mulusbion orea) ; 88, 19 (Musluuion.orea) ; 132, 28 (Musluuium orea). Per una via che collegava Sitifis e Muslubium, cfr. Gsell S., $A A A, f^{\circ} 7,57$; per la possibile menzione di nauicularii da Muslubium nelle iscrizioni del mosaico di Piazzale delle Corporazioni a Ostia cfr. $A E$ 1913, 99; dubbi tuttavia in CIL XIV, 4549, 11.

15. Février P.-A., Aux origines, 1967, p. 51-64 ; Gascou J. Politique, 1972, p. 108-115 ; ID., Politique municipale, 1982, p. 166$168 ; 177-178$.

16. CIL VIII, 10363 ; 22406 ; cfr. Salama P., Voies romaines de Sitifis à Igilgili, 1980, p. 123

17. CIL VIII, 8812 (p. 1946) = ILS 5965 ; 9382 ; cfr. ECK W., s.u. Matidia, in $R E$ Supplb. XV, coll. 133, secondo cui la proprietà potrebbe anche risalire già a Matidia maggiore ; BOATWRIGHT M.T., priuata (attestata già all'età di Antonino $\mathrm{Pio}^{18}$ ), lo stabilimento dei possessores e cultores che nel 180 pongono una dedica al Genius Decumanae Aug. ${ }^{19} \mathrm{e}$ dei coloni domini nostri che nel 191 pongono una dedica a Commodo ad Ain Melloul ${ }^{20}$.

Pertanto, quando i coloni Perdicenses pongono una dedica a Severo e Caracalla Augusti e Geta Cesare $^{21}$, la trasformazione del paesaggio agrario della regione di Sitifis è iniziata da un pezzo. Essa non si arresta, però, con l'inizio dell'età severiana : è nel 213 che i coloni di Caput Saltus Horreorum, i Kalefacelenses e i Pardalarienses costituiscono il castellum Aurelianense Antoninianense ${ }^{22}$, dando così inizio a uno sviluppo ${ }^{23}$ che nell'area si espanderà nei decenni successivi e che riflette, oltre che attriti con le comunità indigene, la generale crescita di quelle unità produttive ${ }^{24}$.

E dunque : se gli horrea di Thamusida, costruiti all'incirca nella seconda metà del II sec. d.C., si affiancano a quelli di Caput Saltus Horreorum, costruiti non prima di Traiano e non dopo Pertinace, i debita fiscalia frumentaria condonati da Caracalla nel 216 sono paralleli a tutto ciò che è implicito nella costituzione del castellum Aurelianense Antoninianense ${ }^{25}$.

3. A insinuare il sospetto che l'editto banasitano di Caracalla abbia riguardato anche la Numidia è, al momento, la sola vicinanza cronologica tra l'arco di Volubilis e quello di Cuicul ${ }^{26}$, appena oltre i confini della Mauretania Caesariensis, in un territorio contiguo e in larga parte omogeneo rispetto alla regione di Sitifis. Pure va rilevato, però, per quanto riguarda i tributi granari della Numidia in età severiana, che a

Matidia the Younger, 1992, p. 25-26 ; MratscheK-Halfmann S. Divites et praepotentes, 1993 , p. 70-71 ; 377 n. 326. Matidia minore onorata a Cuicul : $A E$ 1911, $109=$ ILAlg II, 3, 7775.

18. CIL VIII, $8810 ; 8811=$ CIL VIII, $20618=$ ILS 5964.

19. $A E 1966,549=A E 1967,599$

20. CIL VIII, 8702

21. $A E 1966,592$.

22. CIL VIII, $8426=$ ILS 6890

23. FÉvRIER P.-A., Inscriptions inédites, 1966, p. 217-228 BÉnabou M., Résistance africaine, 2005, p. 186-199.

24. "Troubles de croissance ", secondo la felice formulazione di Christol M., Regards, 2005, p. 45.

25. CIL VIII, $8426=$ ILS 6890 .

26. Cfr. supra, nt. 7 
Cuicul erano stati costruiti degli horrea neppure due decenni prima dell'editto di Caracalla ${ }^{27}$.

Diversamente da quanto deve essere accaduto a Caput Saltus Horreorum, dove gli horrea sorgono già prima del 193 all'interno di un saltus imperiale e presumibilmente per iniziativa dell'amministrazione imperiale, diversamente anche da quanto accadrà $a$ Carales nell'età di Elagabalo, dove gli horrea dell'imperatore sono (ri ?)costruiti a solo dal praefectus prouinciae Sardiniae $^{28}$, gli horrea di Cuicul, dedicati soltanto tra il 10 dicembre 198 e il 9 dicembre 199 , risultano eretti per iniziativa della res publica Cuiculitanorum, all'interno dello stesso tessuto urbano della colonia ${ }^{29}$. Ciò non deve portare a ritenere, tuttavia, che essi non fossero funzionali alle esigenze dell'annona imperiale, ma solo a quelle della stessa colonia ${ }^{30}$.

L'importanza di Cuicul come centro di immagazzinamento delle derrate fiscali è infatti confermata, per l'età alto-imperiale, dalla dedica all'annona Augusta da parte del pontifex T. Flauius Nepos Marcianus ${ }^{31}$, e ribadita, quasi due secoli dopo la costruzione degli horrea, dalla collocazione delle misure fiscali - sextarius uini, capitum hordei, modius tritici - certificate dal consularis Herodes ${ }^{32}$.

Seppur non dichiaratamente ispirata dall'auctoritas imperiale, l'iniziativa della res publica Cuiculitanorum va confrontata con quella, presa ex auctoritate imp. Caesaris Traiani Hadriani Aug. tra 124 e 126 dalla res publica Cirtensium, relativa alla costruzione dei ponti lungo la uia noua Rusicadensi ${ }^{33}$, a sua volta strata,

27. $A E$ 1911, 106 = ILAlg II, 3, 7806. Gli horrea menzionati sono stati identificati con l'edificio a pianta trapezoidale subito dopo la porta di Cirta da AllaIs Y., Greniers publics, 1933, p. 259-268 : si tengano presente però le perplessità di E. Papi cfr. supra, p. 171-186

28. ILSard 51. Sull'identificazione dell'imperatore con Elagabalo, cfr. OgGianu M.G., Contributo, 1991, p. 881. Alla 1. 7, l'integrazione restituit, spesso proposta, non si impone di necessità, potendosi anche ammettere, p. es., extruxit.

29. Se gli horrea menzionati nell'iscrizione fossero quelli identificati dalla Allais (cfr., supra, nt. 27), andrebbe rilevato come essi si trovassero in posizione liminale al momento della loro erezione, cfr. FÉVRIER P.-A., Notes sur le développement urbain, 1964 , p. 3-26

30. Ciò sembra adombrare Rostovzev M., Storia economica e sociale, 1933 , p. 424 , nt. 20

31. $A E 1925,74=$ ILAlg II, 3, 7636

32. $A E 1921,46=I L A l g$ II, 3, 8023 sempre nello stesso periodo e per impulso imperiale a spese dei possessores territori Cirtensium ${ }^{34}$. A Cirta come a Cuicul sono le comunità cittadine (con i loro ceti dirigenti in prima fila) a realizzare infrastrutture funzionali alla mobilità dei tributi in natura del loro territorio. E come a Cirta la uia noua Rusicadensis e suoi ponti preludono all'ascesa sociale di Frontone e dei plurimi senatori cirtensi d'età antonina ${ }^{35}$, così anche a Cuicul - su scala assai più modesta, s'intende ${ }^{36}-$ gli investimenti per la costruzione degli borrea accompagnano le carriere di L. Alfenus Senecio, legato di Coele Syria e Britannia all'età di Settimio Severo e Caracalla ${ }^{37}$, omonimo del cuiculitano L. Alfenus Senecio procuratore di Mauretania Caesariensis e Belgica $^{38}$, di Ti. Claudius Subatianus Proculus, legato di Numidia tra 208-210 e console nel 210, probabile cuiculitano $^{39}$ e probabile fratello di Ti. Claudius Subatianus Aquila, primo prefetto di Mesopotamia e quindi prefetto d'Egitto tra 206 e 211, nonché possibile consanguineo di Claudius Subatia[---] proconsole di Cipro del 197-19840. Non lontano da

\section{ILS 5872 .}

34. ILS 5873.

35. Front., epist. II 11, 2, p. 189 Hout = p. 199 Hout $^{2}$ Cfr. Leglay M., Sénateurs, 1982, p. 755-770.

36. Per una valutazione complessiva del rilievo dell'élite di Cuicul, cfr. JacQues Fr., Privilège de liberté, 1984, p. 549-553.

37. PIR A 521 ; Leglay M., Sénateurs, 1982, p. 771 ; Leunissen P.M.M., Konsuln und Konsulare, 1989, p. 97 ; 159 ; 231-2 ; 263 $267 ; 338 ; 363$

38. PIR ${ }^{2}$ A 520 ; Pflaum H.G, CP, n. 176 * Di lui, però, andrà rilevata l'iscrizione non alla tribù Papiria, quella di Cuicul, ma alla Quirina, ciò che suggerisce un'origine da una città della confederazione cirtense.

39. Leglay M., Sénateurs, 1982, p. 758 ; Salcedo de Prado I., Los Claudii, 2006, p. 539-554 ; diversamente, prospetta un'origine da Pompeiopoli di Paphlagonia Salomies O., Die Herkunft, 1997, p. $245-248$

40. PIR ${ }^{2}$ S 935 ; 937 ; 938 . Anche se il Subatianus Aquila di $P O x y$ 40. PIR ${ }^{2}$ S $935 ; 937 ; 938$. Anche se il Subatianus Aquila di POxy
2708 fosse il padre dei due fratelli e avesse raggiunto la epistrategia della Tebaide nel 168/169 (ma non si può escludere un diverso legame tra i personaggi e una datazione al 200/201 del documento, cfr. ECK W., RE Supplb. XV, coll. 569-570; PIR ${ }^{2}$ S 936), sarebbe 2006, p. 548, che le promozioni del fino ad allora cavaliere Ti. Claudius Subatianus Proculus da subpraefectus classis Misenensis a quaestor urbanus e quindi a tribunus (plebis) candidatus, a praetor urbanus candidatus, a legatus legionis VI Ferratae Fidelis Constantis, a curator Atheniensium et Patrensium, a legatus Auggo. pro praetore splendidissimae prouinciae Numidiae e finalmente a 
questi anni, inoltre, potrebbe collocarsi anche l'approdo al clarissimato del cuiculitano Cosinius Maximus o della sua famiglia ${ }^{41}$.

All'accelerato dinamismo della società cuiculitana in età severiana fanno riscontro più precise articolazioni della geografia amministrativa e fiscale della Numidia, ora divenuta provincia autonoma. Il più sistematico sfruttamento delle potenzialità contributive in grano $\mathrm{d}$ questo lembo occidentale della provincia contribuisce infatti a far emergere una scansione duale della Numidia che produce e paga le proprie tasse in frumento. Ciò è evidente nella procuratela ad fusa frumenti et res populi per tr[actum] utriusque Numidiae ${ }^{42}$ e nella netta divisione tra una procuratela per Numidiam e una procuratela tractus (Hipponensis et) Theuestini ${ }^{43}$.

Per comprendere la funzionalità degli horrea di Cuicul non è sufficiente guardare alla geografia fisica della regione o agli assi viarii - ben quattro, secondo la Tabula Peutingeriana ${ }^{44}$ - che su Cuicul convergono. Anzi, ciò rischia di essere fuorviante, se non si tiene in primo luogo conto dell'appartenenza di Cuicul non alla provincia di Mauretania Caesariensis, cui pure essa è vicinissima, ma alla provincia di Numidia. In forza di questa pertinenza amministrativa, i suoi horrea saranno da connettere non già alla rete logistica che lega gli borrea di Caput Saltus Horreorum a Saldae (o Muslubium o Tubusuctu), ma a quella che proietta sui porti di Chullu o, forse meglio, Rusicade-Astyra ${ }^{45}$ il territorio di Mileu e l'entroterra sud-occidentale della Numidia ${ }^{46}$.

console tradiscono il costante sostegno di Settimio Severo, un sostegno che avrà parallelamente scortato Ti. Claudius Subatianus Aquila alla prefettura di Mesopotamia (la prima!) e a quella d'Egitto 41. $P I R^{2}$ C 1531. A proposito di Cosinius Marcianus u.c. leg. Aug. pr. pr. all'età di Gordiano III di $A E$ 1967, 563, cfr. Leglay M., Sénateurs, 1982, p. 774

42. ILS 9017 ; Pflaum H.G., $C P$, n. 274

43. ILS 1438 ; Pflaum H.G., CP, n. 275.

44. Tab. Peut., seg. II

45. Conduce probabilmente a Chullu e/o Rusicade la via munita a Mileuitanis - de uectigali rotari all'età di Antonino Pio (CIL VIII, $10327 ; 10328 ; 22391)$ : cfr. Gsell S., $A A A$, fo 8,$29 ; 135 ; 136$; fo 17,59 , dove si ricorda la testimonianza di al-Ya'kūbī secondo la quale una delle porte di Mileu era detta la porta di Iskida (Rusicade). Per l'importanza di Rusicade come porto annonario, cfr. CIL VIII, 7960 $=$ ILAlg II, 1, 5 ; CIL VIII, $7975=19852=$ ILS $5910=$ ILAlg II, 1, 379 Gsell S., AAA, fo 8, 194 ; 196.

46. È il caso di ricordare che in età severiana Cuicul e Mileu
E improbabile che gli arativi che inviavano agli borrea di Cuicul i propri tributi granari si estendessero a nord della colonia stessa, dove il territorio mal si presta alla cerealicoltura. Verso occidente, essi dovevano arrestarsi a non più di un paio di decine di chilometri da Cuicul, dove iniziava, col territorio della res publica Mopth., la provincia di Mauretania Caesariensis ${ }^{47}$. Più ampiamente essi dovevano invece dispiegarsi a sud di Cuicul, almeno fino a raggiungere il pagus Thigillauensium $^{48}$ e le dei[.Jesnsiones i cui em $<p>$ tores pongono, all'età di Settimio Severo, una dedica al Genius Subtabarti ${ }^{49}$. È probabile, inoltre, che inviassero a Cuicul i propri tributi granari anche le terre della res publica gentis Suburburum ${ }^{50}$, i cui legami con la colonia di Cuicul ${ }^{51}$ si rivelano anche dalla circostanza che è da Cuicul che si misurano le distanze della strada (o del reticolo di strade) che la stessa res publica Cuiculitanorum (almeno fino all'undicesimo miglio da Cuicul) e la res publica gentis Suburburum col(onorum ?) (almeno a partire dal diciannovesimo e fino al venticinquesimo miglio da Cuicul) si affannano a restaurare tra la diciottesima e la diciannovesima tribunicia potestas di Caracalla e poi di nuovo sotto Severo Alessandro ed Emiliano ${ }^{52}$.

costituiscono un unico distretto amministrativo dei IIII publica Africae : ILAlg II, 3, 7808, dove Pastor è uilicus Cuiculi et Milei. Per la cronologia dell'iscrizione, cfr. Dupus X., Les IIII publica Africae, 2000, p. 281-284.

47. Gsell S., $A A A$, fo 16, 183 ; Galand L., Fouilles de Mons, 1949,

p. 35-91 ; Eingartner J., Mopth(...) - Mons, 1998, p. 309-320.

48. Gsell S., $A A A$, fo 16, 269 ; ILAlg II, 3, p. 759.

49. Gsell S., $A A A$, fo 16, $422 ; A E$ 1906, $98=A E$ 1907, 158.

50. $A E 1904,144=I L A \lg$ II, 3,$7529 ; 7534$

51. In base all'elevato numero di praefecti pro duouiris attestati a Cuicul, Dupuis X., Cuicul, 1999, p. 133-134 ipotizza che essi fossero nominati "dans le cadre d'une situation administrative et juridique normale " e che fossero incaricati di amministrare "des territoires attribués comme pouvait l'être celui des Suburbures ".

52. Alquier P., RSAC, 59, 1928-29, p. 398-400, nn. 113-114 (da Aïn Djira, con indicazione di una distanza di 11 miglia da Cuicul : cfr. Gsell S., $A A A$, fo 16,$295 ; 297$ ) ; $A E$ 1942-43, 68 (da Oued Djermane, con indicazione di una distanza di 19 miglia da Cuicul); CIL VIII, 10335 (da Bordj Mamra, con indicazione di una distanza di 21 miglia da Cuicul); Cagnat R., Sabinius, 1903, p. 101 (da Mechta Zebabcha, con indicazione di una distanza di 25 miglia da Cuicul : cfr. Gsell S., $A A A$, fo 16, 468) ; $A E$ 1911, $101 ; 104$ (entrambe da Cuicul) : cfr. Dupus X., Cuicul, 1999, p. 129-138. 
La ragione dell'ubicazione degli horrea di Cuicul diventa così più chiara : in essi si raccolgono i tributi granari prelevati negli arativi a sud della colonia, fino alle terre dei Suburbures. Di qui, il frumento era poi trasmesso a Mileu lungo la via segnata, sulla Tabula Peutingeriana, dalle stazioni di Caput Budelli, Modolana, Berzeo, fons Camerata, Nobas fusciani ${ }^{53}$ e, sul terreno, dal rinvenimento di quattro miliari ${ }^{54}$. Da Mileu, infine, esso era portato ai porti di Chullu o Rusicade : ancora una volta, sul Mediterraneo.

\section{SUlLe CAPIENZE DEGLI HORREA DI TRANSITO}

1. Come abbiamo detto, la consonanza tra l'editto banasitano di Caracalla e le iscrizioni dell'arco di Volubilis lascia intravedere lungo tutta la valle del Sebou ampie distese cerealicole sottoposte a tassazione in grano. Assai meno ampie, anche se comunque non disprezzabili, sono quelle che si ricavano dall'indicazione della distanza da Cuicul delle strade che attraversano il territorio della res publica gentis Suburburum col(onorum ?). L'ampiezza dei territori che a essi si riferiscono invita dunque a non vedere nella capienza degli horrea rispettivamente di Thamusida e di Cuicul la semplice misura del tributo granario della valle del Sebou e del territorio di Cuicul e dei vicini Suburbures Anche se si fossero estesi per soltanto $500 \mathrm{~km}^{2}$ (sui circa 36,000 dell'intero bacino del fiume) e fossero stati tassati, come capitava nella Sicilia tardo-repubblicana o nell'Egitto tardo-antico, a circa 2,500 modii italici per $\mathrm{km}^{2}$, gli arativi della valle del Sebou avrebbero prodotto un tributo granario superiore a 1,000,000 di modi $^{55}$,

53. Tab. Peut., segg. II-III : Culchul colonia, VII Caput Budelli, VII Modolana, IIII Berzeo, IIII fons Camerata, IIII Nobas fusciani, XII $<$ nomen omissum $>$, VII Mileu colonia. È probabilmente un diverso itinerario quello indicato in Itin. Anton. 28, 3-29, 1 : Mileum XXV Idicra XXV Cuiculi. Cfr. Gsell S., $A A A$, fo 17, 59.

54. CIL VIII, $22393 ; 10329=22394 ; 22395 ; 22396$; cfr., rispettivamente Gsell S., $A A A$, fo 17,$57 ; 41 ; 22 ; 21$.

55. De Romanis F., Per una storia, 2003, p. 692-695. Nonostante i debita fiscalia frumentaria contratti dai contribuenti della valle del Sebou, tenderei a escludere che gli arativi della Tingitana fossero tassati quanto il nomo Arsinoite all'età di Commodo, sui cui eccezionali prelievi cfr. infra. quasi sette volte la capienza stimata da Papi e Martorella per gli horrea di Thamusida.

Parimenti inadeguati sarebbero risultati gli horrea di Cuicul se avessero dovuto contenere, tutti contemporaneamente, i pur assai più modesti tributi granari del territorio della colonia e della res publica gentis Suburburum col(onorum). Da tutto ciò, però, non si deve dedurre che soltanto un'infima parte dei tributi granari fosse trasferita dalle rispettive aree. Infatti, la capacità degli horrea di transito, di quegli horrea, cioè che, come a Thamusida, ospitano temporaneamente il grano in attesa che sia ridiretto verso la destinazione finale, può essere notevolmente inferiore ai volumi complessivi depositati nel corso di un anno. Oltre che dalla massa totale del grano da trasferire, infatti, la capienza di questo tipo di horrea dipende anche dal tempo per cui si estendono le operazioni di trasferimento del grano e dal modo in cui corrispondono le entrate e le uscite di esso : la possibilità di diluire su tempi più lunghi i trasferimenti di grano e di coordinare le sue entrate e uscite dagli horrea di transito consentono di ridurre notevolmente i volumi di questi ultimi.

Poiché quello che determina le dimensioni degli borrea non è tanto la massa totale, quanto il flusso delle derrate, non si può neppure immaginare che vi sia stata una proporzione uniformemente rigida tra capienza degli horrea di transito e volumi del grano complessivamente di passaggio in un anno. Tutto al contrario, è verosimile che quella proporzione sia stata la più varia. Purtroppo, la documentazione a nostra disposizione non consente di illustrare puntualmente questo principio. Varrà tuttavia la pena di evocare rapidamente dei casi in cui horrea o complessi di horrea dovevano essere attraversati, nel corso di un anno, da flussi di grano di gran lunga superiori alla loro capacità.

2. Le tavolette di Murecine consentono di stabilire delle capienze minime per talune strutture puteolane. Sappiamo infatti che la dodicesima cella degli borrea Bassiana publica media poteva contenere, essa sola, almeno 7,000 modii ${ }^{56}$. Se le celle I-XI erano, come è lecito attendersi, di dimensioni pari alla XII, gli borrea Bassiana publica media dovevano contenere almeno

56. TPSulp $45 ; 52$ (cfr. 51). 
84,000 modii. Questo minimo, però, potrebbe allontanarsi dalla capienza effettiva, nella misura in cui la capienza delle singole celle poteva superare 7,000 modii, gli horrea Bassiana publica media potevano contare assai più di dodici celle e agli almeno 84,000 modii degli horrea Bassiana publica media si aggiungevano poi gli horrea Bassiana publica ima (dove però non appare che vi fossero celle e che si stoccasse grano $^{57}$ ) e gli horrea Bassiana publica superiora ${ }^{58}$.

Sempre a Puteoli, una sola delle almeno ventisei celle degli horrea nei praedia Barbatiana superiora di Domitia Lepida poteva accogliere almeno 13,000 modi $i^{59}$. Anche in questo caso, se le celle I-XXV erano all'incirca delle stesse dimensioni della XXVI, la capacità minima delle celle I-XXVI sarà stata di 338,000 modii, all'incirca il doppio di quanto stoccabile a Thamusida. Se poi la numerazione si riferisse non già a tutti gli horrea dei praedia Barbatiana, ma ai soli horrea dei praedia Barbatiana superiora ${ }^{60}$ e si dovessero presupporre praedia Barbatiana sottostanti (solo inferiora? O invece anche media e ima ?) con ancora altre celle, ecco che dovremmo elevare considerevolmente la già rispettabile capienza minima dei praedia Barbatiana.

Con ogni probabilità, i praedia Barbatiana sono così chiamati perché appartenuti o a M. Valerius Messalla Barbatus, marito, nella prima età tiberiana, di Domitia Lepida, proprietaria, nel 40, degli horrea e de praedia in cui essi insistono, oppure già a M. Valerius Messalla Barbatus, console nel 12 a.C. ${ }^{61}$ Se gli horrea non sono stati edificati prima che i praedia si qualificassero come Barbatiana e sono dunque più tardi, p. es., dei granaria già evocati da Cicerone ${ }^{62}$, la loro costruzione sarà da considerarsi in relazione con

57. TPSulp 45

58. Si ritiene che i tre livelli - ima, media e superiora - degl horrea Bassiana publica non corrispondano a tre piani elevati uno sull'altro su una medesima superficie, ma a tre diverse sezion giacenti su tre diverse quote di un'area scoscesa, cfr. Sommella P., Forma e urbanistica, 1978, p. 90, nt. 90 ; CAMODECA G., Puteoli, 1994, p. 109.

59. TPSulp $46 ; 79$

60. Così VIRLouvet C., Denrées alimentaires, 2000, p. 137.

61. Cfr., rispettivamente, $P_{I R}^{2}$ V 88 e 89 . Confonde i due personaggi Camodeca G., Puteoli, 1994, p. 108

62. Cic., de fin. II 84 . le esigenze avvertite a seguito del trasferimento a Roma, a partire dall'età augustea, dell'enorme tributo granario egiziano ${ }^{63}$ oppure del successivo ampliamento, in età tiberiana ${ }^{64}$, delle quote occupate dal frumento provinciale nei consumi di Roma.

Delle gigantesche capacità di stoccaggio della Puteoli giulio-claudia le tavolette di Murecine riportano solo un'immagine assai parziale e sfocata. Di esse tuttavia si intende la necessità funzionale. Quelle ciclopiche possibilità di riserva si giustificano sia per la scala considerevole (diverse decine di milioni di modii all'anno) dei quantitativi di grano provinciale scaricato a Puteoli, sia per la grave aritmia tra gli ingressi e le uscite di esso. Sbarcato in grandi quantità dalle navi alessandrine, i cui approdi si concentravano soprattutto nei mesi estivi, il grano stoccato a Puteoli veniva trasferito a Roma con navi di assai più piccolo tonnellaggio, capaci anche di risalire il Tevere, lungo un arco temporale che, almeno a partire dall'età di Claudio, comprendeva anche i mesi invernali ${ }^{65}$. Tuttavia, poiché quei trasferimenti saranno iniziati già negli stessi mesi estivi, con parziale decongestione degli horrea puteolani, ecco che la capienza di questi ultimi poteva essere sensibilmente inferiore al totale dei tributi granari che vi affluivano.

3. L'iscrizione tardoantica ${ }^{66}$ incisa su un lato di una delle loro porte mostra come all'età di Teodosio I la funzione degli horrea di Myra fosse ormai quella di raccogliere le derrate fiscali (cereali, olio e vino) prelevate nei territori della stessa Myra e di Arneai, nelle immediate vicinanze. All'età di Adriano, quando quegli borrea furono costruiti, la loro funzione doveva essere diversa. Credo di aver dimostrato altrove che gli horrea di Myra, come anche quelli della vicina Patara, costruiti all'incirca nello stesso torno di tempo, servissero a stoccare temporaneamente quote di frumento pubblico egiziano, che l'imperatore poteva offrire in vendita a città orientali (Efeso tra le prime), quando l'andamento della piena del Nilo avesse lasciato prevedere un

63. Cfr. infra, nt. 83

64. Tac., ann. VI 13

65. Pomey P. e Tchernia A., Tonnellaggio massimo, 1980-81, p. $35-45$

66. GrÉGOIRE H., Recueil des inscriptions grecques chrétiennes d'Asie mineure, 1922, n. 290. 
soddisfacente raccolto cerealicolo e un conseguentemente normale prelievo fiscale in grano ${ }^{67}$.

Certamente, Adriano avrà accordato alle città dell'Oriente mediterraneo una quota relativamente modesta del grano pubblico egiziano. Condizionata al buon andamento del raccolto in Egitto, in mancanza del quale essa sarebbe stata sospesa, la concessione imperiale si limitava a quanto, in quelle occasioni, diveniva superfluo per la città di Roma : azzardando una stima, difficilmente si sarà trattato di un quantitativo superiore al $10 \%$ del tributo granario d'Egitto. La capienza degli horrea di Myra e Patara appare d'altra parte relativamente ragguardevole : sommata insieme, la superficie dei due edifici ${ }^{68}$ è di quasi $4,000 \mathrm{~m}^{2}$, poco più della metà di quella $\left(7,200 \mathrm{~m}^{2}\right)$ dei Grandi Horrea ostiensi ${ }^{69}$, più del quadruplo di quella di Thamusida.

Sia pur con le dovute differenze di scala rispetto alla Puteoli giulio-claudia, anche a Myra e a Patara le dimensioni degli horrea sono condizionate dall'aritmia tra entrate e uscite del grano. Sbarcato nei porti di Lycia in relativamente grandi quantità dalle navi alessandrine durante il loro viaggio verso l'Italia ${ }^{70}$, il grano egiziano doveva essere poi redistribuito a quelle città che, secondo importanza ed esigenza, ne potevano far acquisto, su più piccole navi, per limitati contingenti $e$ in tempi scaglionati, con la possibilità dunque che il grano dovesse giacere negli borrea diverse settimane, prima di trovare una nave che lo ridirigesse alla sua destinazione finale

Tuttavia, anche qui, come a Puteoli, è probabile che una parte del grano entrato in quegli horrea ne uscisse relativamente presto, prima che tutto il quantitativo destinato alle città d'Oriente vi facesse ingresso. ̀̀ verosimile, di conseguenza, che la quota di frumento pubblico che Adriano poteva preventivare di mettere a

67. La costruzione degli horrea di Myra e Patara va connessa alla

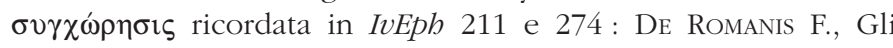
horrea, 2002, p. 279-298 ; un diverso inquadramento in CAVALIER L. Horrea d'Andriakè et Patara, 2007, p. 51-65.

68. Gli horrea di Myra si estendono per circa $2,000 \mathrm{~m}^{2}$; quelli di Patara occupano un'area di $1,890 \mathrm{~m}^{2}$.

69. La capienza del loro primo piano è valutata a 6,960 tonnellate da Hermansen G., Ostia, 1982, p. 228-231.

70. Già prima di Adriano, a Myra e Patara le navi che correvano l'Egeo si incontravano con quelle in viaggio per (o provenienti da) il bacino orientale del Mediterraneo : Act. Apost. 21, 1 ; 27, 5-6. disposizione delle città orientali, per quanto modesta rispetto al totale del tributo granario egiziano, superasse la capienza degli horrea di Myra e Patara e che questi si rivelassero sufficienti allo scopo solo perché via via svuotati.

4. Per molti aspetti, la spedizione del tributo granario egiziano alla Costantinopoli giustinianea poteva sembrare una corsa contro il tempo. Oltre che nella multa di un solido per ogni tre artabe minacciata all'Augustale che non avesse spedito da Alessandria entro la fine di agosto tutti gli otto milioni di artabe dell' $\dot{\varepsilon} \mu \beta 0 \lambda \eta^{71}$, la cura con cui l'imperatore ha cercato di assicurare la tempestività degli arrivi di grano egiziano a Costantinopoli è dimostrata anche dalla costruzione degli borrea di Tenedo, un'opera provvidenziale, secondo Procopio, tanto per la città di Costantinopoli quanto per i nauicularii della flotta alessandrina ${ }^{72}$, proprio perché permetteva di ridurre i rallentamenti nella trasmissione del grano dovuti alle difficoltà di navigazione nello stretto dei Dardanelli $\mathrm{i}^{73}$.

Degli horrea di Tenedo, dove a suo giudizio si sarebbe potuto depositare il carico dell'intera flotta alessandrina, Procopio sa precisare la superficie, che avrebbe misurato non meno di 90 piedi per 280

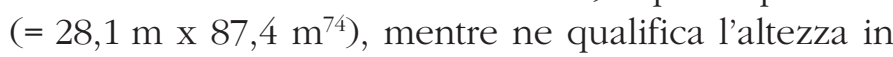
maniera genericamente iperbolica (ひ้ $\psi \varsigma \varsigma$ - ó $\varphi \alpha \tau o v)^{75}$.

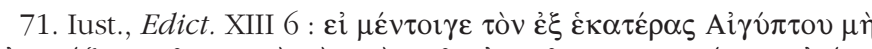

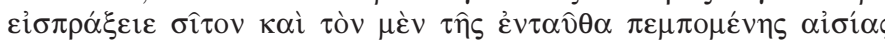

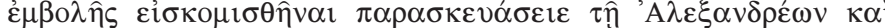

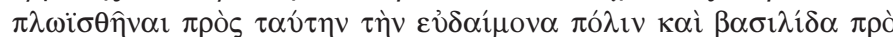

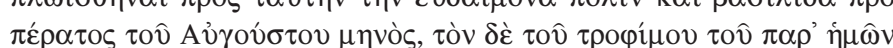

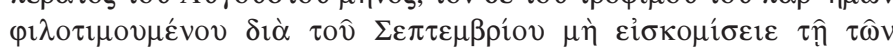

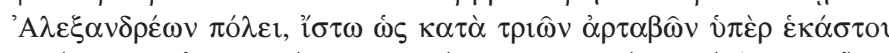

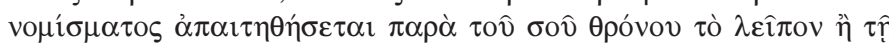

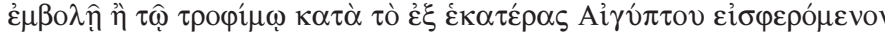

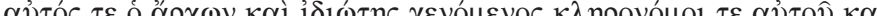
a

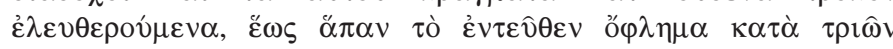

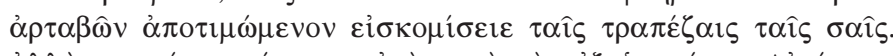

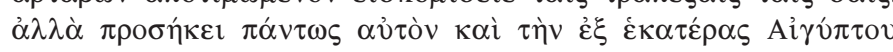

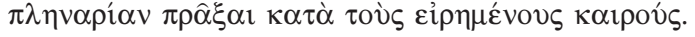

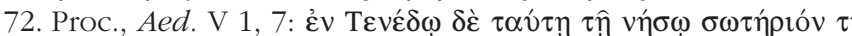

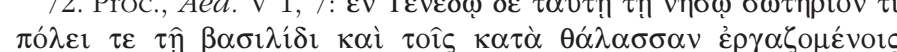

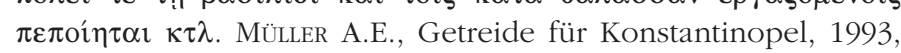
p. 1-20 ; Belke K., Prokops "De Aedificiis ", V, 2000, p. 115-117.

73. ARnaud P., Routes de la navigation, 2005, p. 228-229.

74. MÜLLER A.E., Getreide für Konstantinopel, 1993, p. 7.

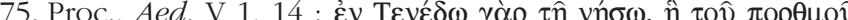
ár 
È difficile prendere alla lettera tali affermazioni, se si

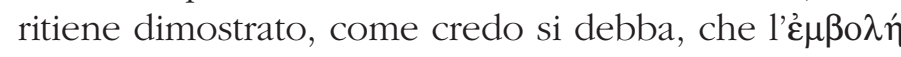
egiziana per Costantinopoli fosse di 8,000,000 di artabe e cioè di 36,000,000 di modii italici $^{76}$. Trasmessa nei circa 120 giorni che vanno dalla mietitura in Egitto fine alla fine di agosto, termine ultimo per le spedizioni da

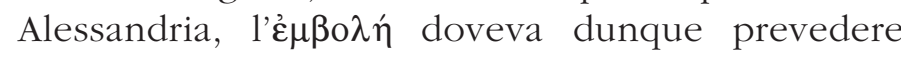
partenze (e arrivi) di grano al ritmo medio di 300,000 modii al giorno. L' ineffabile " altezza degli horrea di Tenedo avrà certo reso notevole la loro capienza, ma non fino al punto da contenere l'intero carico della flotta egiziana ${ }^{77}$ : anche tenendo conto del fatto che ciascuna nave deputata al trasporto dell'є̇ $\mu \beta 0 \lambda \eta$ compiva tre viaggi all'anno ${ }^{78}$ (tra un carico e un altro dovevano quindi passare 40 giorni) e che dunque il tonnellaggio complessivo dello $\sigma \tau o ́ \lambda$ os si aggirava intorno non a 36,000,000, ma a soli $12,000,000$ di modii italici, $100,000 \mathrm{~m}^{3}$ di grano, all'incirca equivalenti appunto a 12,000,000 di modii italici, costretti entro una superficie di $2,460 \mathrm{~m}^{2}$, si sarebbero dovuti elevare per più di 40 metri.

Se dunque l'altezza degli horrea di Tenedo, pur indicibile come afferma Procopio, non era tuttavia tale da consentire di immagazzinare 12,000,000 di modii in un edificio dalla pianta di $2,460 \mathrm{~m}^{2}$, si deve ammettere non solo che una parte della flotta alessandrina riusciva, trovando vento da sud, a risalire direttamente

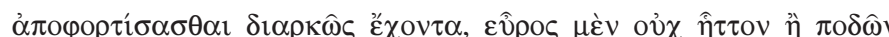

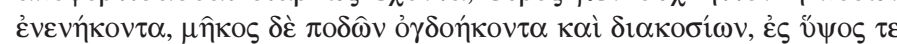

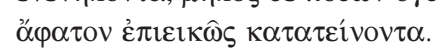

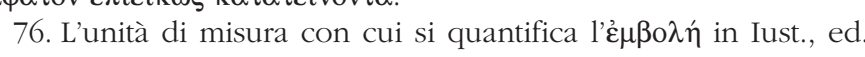
XIII 8 è la stessa con cui si misura il grano fiscale in PCairo Maspero I 67057 iii, 8, cfr. Gascou J., Table budgétaire, 1989, p. 286-287 ; CARRIÉ J.-M., Institution annonaire, 2003, p. 166-172 ; 186 ; Zuckerman C., Du village à l'empire, 2004, p. 194; 186 ; ZUCKERMAN C., Du village à lempire, 2004, p.
diversamente, SIRKS B., Some observations, 2003, p. 213-219.

77. MÜLLER A.E., Getreide für Konstantinopel, 1993, p. 8, ipotizza un'altezza di $10 \mathrm{~m}$ e un volume complessivo di $20,000 \mathrm{~m}^{3}$, che ritiene capace di immagazzinare 15,000 t di grano.

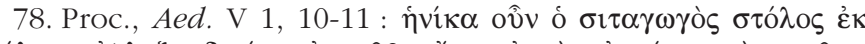

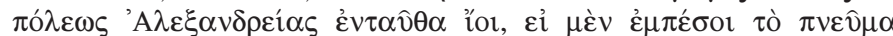

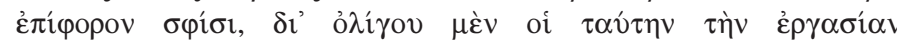

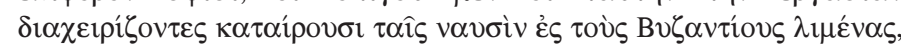

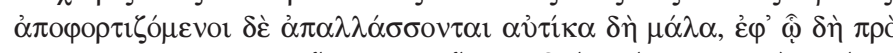

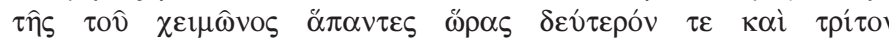

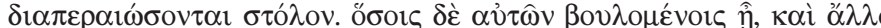

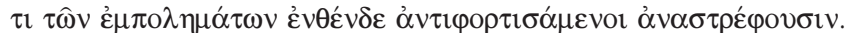

gli stretti dei Dardanelli, senza fermarsi a Tenedo ${ }^{79}$, ma anche che tra Tenedo e Constantinopoli vi doveva essere un'assai efficace organizzazione dei trasporti, pronta a sfruttare tutte le occasioni favorevoli per trasferire nella capitale il grano stoccato sull'isola ${ }^{80}$, sì che più volte, durante i quattro mesi del trasferimento dell'żußo $\lambda \hat{\eta}$, gli horrea di Tenedo dovevano riempirsi e svuotarsi.

5. Anche la capienza degli horrea di Thamusida e Cuicul, trattandosi, come s'è detto, di horrea di transito, doveva essere proporzionale ai flussi del grano più che alla massa complessiva di esso. Tuttavia, converrà notare alcune diversità rispetto ai casi citati in precedenza, dove il grano arriva sempre dal mare e ed entra sempre con una velocità assai maggiore (perché portato con navi più grandi) di quanto non esca.

Gli borrea di Thamusida facilitavano il raccordo tra trasporti fluviali, continui, ma di flusso modesto, e trasporti marittimi, intermittenti, ma di assai maggiore capacità, i quali erano in grado, con pochi convogli e in breve tempo, di smaltire gli stoccaggi faticosamente accumulati. La velocità acquistata dal grano in uscita limitava dunque i tempi di permanenza del grano negli horrea e rendeva superflui grandi volumi, riducendo di conseguenza la proporzione tra capienza degli horrea e massa totale del grano in transito : i 150,000 modii stoccabili nel granaio di Thamusida mostrano solo che durante il periodo di navigazione le partenze di navi onerarie da Thamusida per (Gades e quindi ?) il Mediterraneo non erano così rare da dover richiedere una capacità di immagazzinamento superiore ai 150,000 modii.

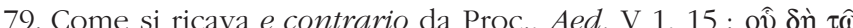

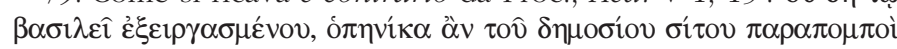

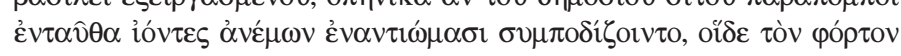

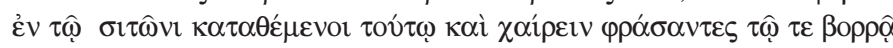

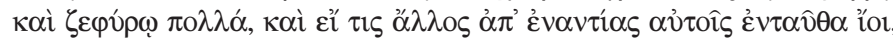

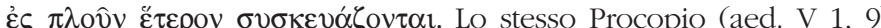
precisa che era impossibile risalire i Da elli, quando non soffiava

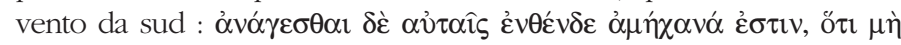

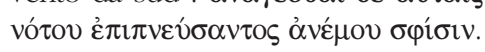

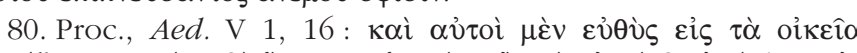

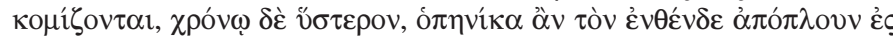

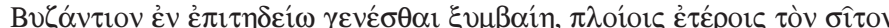

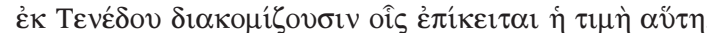


Quanto agli borrea di Cuicul, essi rappresentano un punto di snodo di una movimentazione tutta terrestre. La loro capienza, dunque, sarà stata proporzionale ai flussi modestissimi di quel tipo di trasporti, soggetti ad assai meno lunghe interruzioni invernali, ma certo assai meno agili dei trasporti su acqua, sia fluviali che marittimi. Il prelievo delle derrate fiscali sarà stato scaglionato lungo l'intero arco dell'anno ed esse saranno state trasmesse con periodicità pressoché costante. Anche per questo, dunque, oltre che per il fatto di riferirsi a un territorio assai più limitato, saranno state necessarie capienze inferiori a quelle di Thamusida.

Tra i trasferimenti di grano richiesti dall'organizzazione annonaria romana, quelli facilitati dagli horrea di Thamusida, Caput Saltus Horreorum e Cuicul rappresentano dei miracoli di volontarismo. Pur in assenza di più esplicita documentazione, l'ubicazione atlantica di Thamusida e, ancor di più, la mancanza di vie d'acqua che collegassero Caput Saltus Horreorum e Cuicul al Mediterraneo danno la misura del grande dispendio di energie che il trasporto del grano pubblico per l'annona di Roma poteva talvolta comportare.

Di quegli sforzi arrivano a noi solo echi flebili : alle reticenti testimonianze date dallo sterminato dossier epigrafico relativo alla rete viaria africana si aggiunge solo un vago accenno, nella letteratura gromatica, alle controversie che sorgono in Africa a proposito di uecturae e di copiae deuehendae ${ }^{81}$. Paradossalmente, la documentazione più significativa circa la gravosità dei trasporti su terra del frumento pubblico è stata restituita dalla provincia in cui questi dovevano essere meno onerosi che in tutte le altre : a essa converrà dunque riferirsi per meglio apprezzare lo sforzo fatto dalle provincie maghrebine per portare a mare il grano fiscale prelevato nell'interno.

81. Front., de contr. agr. p. 45 Th. = p. 53 L. Il verbo deueho, il cui primo significato è "de superiore loco in inferiorem uehere (ThlL V 848), è anche altrove usato per trasporti dall'interno dell'Africa al mare : Liu. XXIX 31, 11 ; XLIII 6, 11 .

\section{Tributi granari E DEMOgRAFIA DELL'EgITTO ROMANO E BIZANTINO}

1. La soluzione del dilemma circa la non specificata

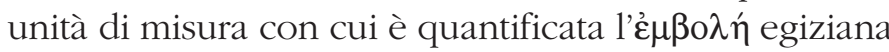
nell'Editto XIII di Giustiniano ${ }^{82}$ pone a sua volta un altro problema : se in età giustinianea dall'Egitto riuscivano a trarsi ben $8,000,000$ di artabe $(=36,000,000$ di modii italici) di grano all'anno per l'annona di Costantinopoli, come mai in età augustea e per tutta l'età giulio-claudia se ne inviavano a Roma non più di 20,000,000 di modii ${ }^{83}$ ? I dati a nostra disposizione,

\section{Cfr. supra, nt. 76}

83. La credibilità della testimonianza offerta, per l'età augustea, da Epit. de Caes. 1, 3-6 è " difficilmente revocabile in dubbio " per Geraci G., Alessandria, 2003, p. 635. Che per tutta l'età giulioclaudia il tributo granario egiziano non si sia molto allontanato da livelli augustei è dimostrato dal fatto che ancora da Flavio Giuseppe esso è stimato solo pari a un terzo del fabbisogno della

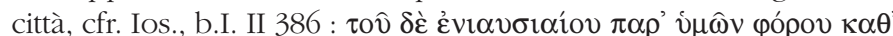

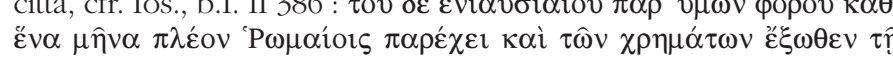

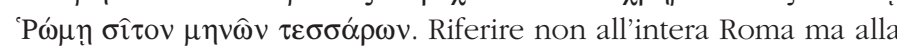
sola plebe frumentaria i quattro mesi di grano inviati dall'Egitto rappresenta una violazione della lettera del testo, che oltretutto comporterebbe un'assai poco probabile riduzione (dai 20,000,000 augustei ai 3,000,000 d'età flavia) del tributo granario egiziano. Un augustei ai $3,000,000$ deta flavio del tributo fabbisogno di $60,000,000$ di modii, quale si ricava dall combinazione del dato tramandato dall'Epitome de Caesaribus con l'indicazione di Flavio Giuseppe, non deve essere considerato eccessivo per la Roma giulio-claudia, se la sua popolazione si aggirava intorno al milione di abitanti e se il grano che si rivendeva in città doveva anche soddisfare $\mathrm{i}$ consumi di un suburbium non iente quanto a cereali, come scia del Beloch, molti studiosi, pur non presupponendo una Roma (molto) meno affollata, propongono spesso valutazion notevolmente più basse (fino a 30,000,000 di modii) del suo fabbisogno granario, fondandosi su stime del consumo individuale calcolate in base al fabbisogno calorico di un uomo sedentario e ai contenuti energetici del grano. Sulla fallacia di questo metodo, gravemente distorsivo della realtà della Roma alto-imperiale, ho insistito altrove : De Romanis F., Pane di similago, 2003, p. 145-172. Sul piano del metodo, osservo che indipendentemente da me, in base ad altre fonti e in riferimento ad altro contesto, anche Zuckerman C., Du village à l'empire, 2004, p. 160-170, spec. p. 169 ha rilevato che occorre tener conto delle perdite dei valori nutritivi nel passaggio dal grano al pane. Quanto al caso specifico della Roma alto-imperiale, vanno sottolineate le peculiarità di una panificazione in cui predomina il pane di similago, caratterizzato da un rapporto tra peso del grano e peso del pane attestato sui valori $1: 0,55$, ben al di sotto dunque del rapporto $1: 0,85$, che si rileva in altri ambiti, geografici o cronologici (BAGNALL R.S., A Heavy 
dall'età altoimperiale a quella bizantina, non lasciano ravvisare né un proporzionale aggravio della pressione fiscale per unità di superficie né un sostanziale ampliamento delle superfici degli arativi sottoposti a tassazione ${ }^{84}$. Si può inoltre presumere che gli imperatori giulio-claudi, assillati dalla precarietà del sistema di approvvigionamento granario di Roma, avrebbero volentieri avvicinato ai livelli giustinianei il tributo granario egiziano, solo che ne avessero avuto la possibilità. Perché, dunque, solo 20,000,000 di modii?

E possibile che la differenza tra i tributi granari egiziani alla Roma augustea e alla Costantinopoli giustinianea si debba in parte alla maggiore lentezza e laboriosità dei trasferimenti Alessandria-Roma rispetto a quelli Alessandria-Costantinopoli. Abbiamo sopra ricordato come la flotta granaria alessandrina dell'età di Giustiniano dovesse riuscire a sbarcare, prima

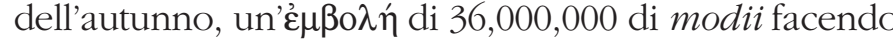
fare a ognuna delle sue unità ben tre viaggi nei circa 120 giorni dedicati a quelle navigazioni. La complessiva capacità di carico delle navi granarie alessandrine in quell'età doveva pertanto essere di circa 12,000,000 di modii e un viaggio Alessandria-Costantinopoli (Tenedo)-Alessandria doveva durare circa 40 giorni. In età giulio-claudia, i più lunghi tempi della rotta Alessandria-Puteoli-Alessandria non permettevano di compiere, a tutta la classis Alexandrina, tre viagg all'anno ; è anzi dubbio che tutte le navi riuscissero a farne due. Così, per trasportare a Roma 36,000,000 di

Artaba, 2001, p. 7-11 ; Zuckerman C., op. cit., p. 166-167). D conseguenza : le indicazioni sul tributo granario egiziano fornite dall'Epitome de Caesaribus e da Flavio Giuseppe sono tra loro coerenti e ne dimostrano la sostanziale stabilità dall'età augustea a quella flavia. - Naturalmente, io ritengo che il passo di Flavio Giuseppe (e altri passi come Sen., breu. uit. 18, 5; Tac., ann. XII 43 ; hist. IV 52) provino che l'amministrazione dell'annona aveva una conoscenza sufficientemente precisa - al punto che una data quantità di grano poteva essere valutata a " sette o al massimo otto giorni " - del ritmo del consumo granario dell'intera città di Roma chi sostiene che questo invece fosse "unknown and unknowable " (van Minnen P., Agriculture, 2000, p. 210, nt. 22), non tiene conto né dei passi qui (ri)citati, né dell'organizzazione necessaria alla sussistenza di una città come la Roma imperiale.

84. Anzi, i dati a nostra disposizione, sia pur molto parziali, danno semmai indicazioni in senso opposto : BAGNALL R.S., Agricultural Productivity, 1985) p. 289-308 ; ID., Egypt, 1996, p. 155156 ; ID., P.Oxy. 4527, 2000, p. 288-292. modii sarebbe occorsa una flotta con una capacità di carico di più di 18,000,000, mentre per trasportarne 20,000,000 poteva bastarne una dalle capacità di carico all'incirca uguali o non di molto superiori a quella giustinianea. In un'età in cui si ricorre a navi paragonabili alla Isis poi descritta da Luciano solo per il trasporto degli obelischi e in cui il porto traianeo di Ostia è ancora di là da venire ${ }^{85}$, è possibile che il trasferimento dell'intera capacità contributiva in grano dell'Egitto comportasse, nell'immediato, costi talmente elevati da far ritenere non economica quella opzione.

2. È anche possibile, però, che non sia questa la vera o almeno la sola ragione della diversità di scala tra due tributi granari. Se già in età giulio-claudia fossero stati effettivamente incamerati $36,000,000$ di modii all'anno di grano pubblico egiziano, dovremmo poter rinvenire, da qualche parte, tracce della circolazione e/o del consumo della quota eccedente i 20,000,000 di modii inviati a Roma. Secondo D. Rathbone, ben 6,000,000 di modii all'anno sarebbero stati annualmente rivenduti fuori dell'Egitto, e più precisamente nelle provincie orientali dell'impero ${ }^{86}$. Implicitamente, lo studioso esclude che i 7,000 e i 13,000 modii di grano alessandrino che le tavolette di Murecine dimostrano essere stoccati a Puteoli rispettivamente nel 37 e nel $40^{87}$ siano di origine contributiva e/o rappresentino una quota minima di quantitivi molto più grandi. Riterrei nella sostanza giusta una tale presunzione : con ogni probabilità, quelle giacenze, se non di grano sin dall'origine privato, saranno da ricondursi alle retribuzioni in natura date ai trasportatori di frumento publico da Alessandria a Puteoli, e dunque saranno state una frazione relativamente modesta dei 20,000,000 di modii inviati a Roma. Per quanto riguarda le province orientali, sulle quali Rathbone farebbe riversare 6,000,000 di modii all'anno, occorre aver presente un discrimine cronologico. Le iscrizioni efesine $I v E p h 211$ e 274 dimostrano che solo a partire dall'età di Adriano limitate ${ }^{88}$ quantità di grano pubblico

85. Pomey P. e TChernia A., Tonnellaggio massimo, 1980-81, p. 55. 86. Rathbone D., Ancient Economy, 1989, p. 173. 87. TPSulp $51 ; 52 ; 46 ; 79$.

88. Un'iscrizione di Tralleis (IvTrall 80) dell'età di Adriano ricorda l'acquisto di 60,000 modii di grano egiziano ; relativamente eccezionali saranno stati gli acquisti di grano egiziano che hanno 
egiziano cominciarono a essere abitualmente vendute a città dell'Oriente mediterraneo, peraltro solo negli anni in cui una soddisfacente piena del Nilo avesse assicurato prelievi granari sufficientemente abbondanti ${ }^{89}$. Prima di allora, permessi di acquistare grano pubblico egiziano erano concessi solo eccezionalmente, rispondevano a situazioni di assoluta emergenza e spesso, quando venivano concessi, imponevano interventi straordinari per assicurare lo stesso rifornimento granario di Roma ${ }^{90}$.

3. Poiché, quindi, si deve escludere che in età giulioclaudia uscissero abitualmente dall'Egitto quantità significative di grano in aggiunta ai 20,000,000 di modii destinati a Roma e poiché si deve d'altra parte ammettere che la pressione fiscale non fosse più lieve che in età tardoantica, si è portati a ritenere che una buona parte dei tributi granari fosse riassorbita all'interno stesso della provincia. A distogliere gli imperatori giulio-claudi da una più cospicua esportazione di grano pubblico dalla valle del Nilo potrebbe essere stata pertanto determinante la $\pi \circ \lambda v \alpha \nu \theta \rho \omega \pi i \alpha$ che caratterizza l'Egitto nella prima età imperiale $^{91}$ e che in qualche misura si attenua successivamente, a seguito delle epidemie di II e III secolo. Dimostrato dalla frequenza delle carestie nello stesso Egitto tardo-tolemaico e giulio-claudio ${ }^{92}$, il delicato equilibrio tra produzione e fabbisogno di grano potrebbe riflettersi sia nella disperazione della rivolta della Tebaide, suscitata, subito dopo l'istituzione della

verosimilmente permesso l'erogazione a Efeso, intorno al 166, in coincidenza con la permanenza in città di truppe di ritorno dall spedizione partica, di 201,200 medimni $(=1,207,200$ modii $) \mathrm{d}$ grano : IvEph $672 ; 3080$

89. IvEph 211.

90. Cfr. De Romanis F., Gli horrea, 2002, p. 291-292.

91. Stimata a 7,500,000 di abitanti esclusa Alessandria da Flavio Giuseppe (b.I. II 385), sulla base dell'ammontare de $\dot{\eta} \kappa \alpha \theta$

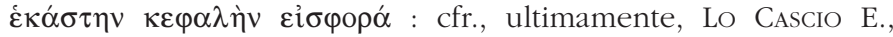
Popolazione, 1999, p. 425-447 ; SCHeIDEL W., Death on Nile, 2001, p. 184-250. Scettici, però, sul valore della testimonianza di Flavio Giuseppe Rathbone D., Villages, 1990, p. 105-106 ; BagNall R.S e Giuseppe RATHBONE D., Villages, 1990, p. 105-106 ; BAG
FrIER B.W., Demography of Roman Egypt, 1994, p. 53-56.

92. Casanova G., Epidemie e fame, 1984, spec. p. 191-195. L'ottimismo straboniano (XVII 1,3) è ridimensionato da Plin., n.h. V 58 : una piena di dodici cubiti comporta la fames della provincia ; solo quattordici cubiti ne assicurano la bilaritas. provincia, da una pressione fiscale forse ancora mal tarata $^{93}$, sia nel ricorso ai prestiti di grano per la semina da parte di un contadiname minuto, che stenta ad assolvere ai propri obblighi fiscali ${ }^{94}$. La necessità di mantenere quell'equilibrio potrebbe aver dunque suggerito, soprattutto in alcune aree della provincia, sopportabili conversioni in danaro (oppure in derrate alternative) di una parte delle imposte sugli arativi cerealicoli95

Di ciò qualche traccia potrebbe forse essere individuata. È infatti possibile che i proventi fiscali dell'Alto e del Basso Egitto non contribuissero all'approvvigionamento granario della Roma giulio-claudia in misura esattamente proporzionale. Nell'enumerare i genera di triticum importati a Roma, Plinio il Vecchio ricorda quello Alexandrinum, ma da esso distingue il Thebaicum $^{96}$, in quella lista non incluso. Ciò induce a sospettare che le tasse in grano della Tebaide fossero almeno in parte convertite in danaro o comunque non sostenessero, abitualmente, l'annona di Roma. Ci si può chiedere, inoltre, se dal nomo Arsinoite d'età giulioclaudia si potesse estrarre già quantità di grano pubblico comparabili a quelle che si richiedevano, $\mathrm{p}$. es., all'età di Commodo. A fronte delle 270,808 artabe che risultano esportate, verso la fine di Mesore del 42, da (una parte del?)le merides di Themistos e Polemon ${ }^{97}$ e che probabilmente rappresentano il grosso, se non la totalità, dei tributi granari di quell'area in quell'anno, nel 185 ben 814,862 artabe di grano, come vedremo, si richiedevano alla meris di Herakleides ${ }^{98}$.

Tornando al rapporto tra produzione e fabbisogno di grano in Egitto, indizi di un suo miglioramento si rilevano per la media età adrianea. Allora, infatti, capita

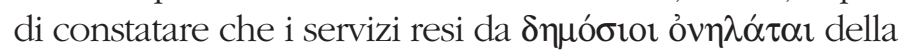

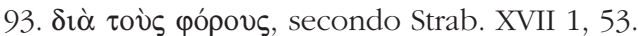

94. Foraboschi D. e Gara A., Economia dei crediti in natura, 1982, p. 69-83.

95. Possibilità su cui giustamente insiste RathBone D., Ancient Economy, 1989, p. 174 : " It seems, therefore, that we must suppose either that around one third of the taxes due in wheat was never paid or was creamed locally, or - more plausibly - that this was paid in another form, partly in barley, hay and other produce, but in another form, partly in barley, hay and other produce, but
probably mostly in cash through the process known as adaeratio ". 96. Triticum Alexandrinum : Plin., n.h. XVIII 66 ; triticum Thebaicum : ibid. 68

97. $B G U 802$.

98. POxy 4527.
} 
kome di Thallos in merito al trasporto dei prelievi dal raccolto del dodicesimo anno (127/128) vengono pagati il 3 Mechir del quattordicesimo anno (28 gennaio 130) con quel grano fiscale prelevato dal raccolto del decimo anno (125/126), che, depositato da quattro

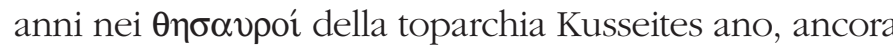

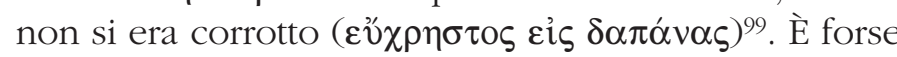
a partire da quello stesso torno di tempo che il trasporto di grano pubblico dal nomo Arsinoite al Nilo comincia a richiedere l'ausilio di forza lavoro esterna al nomo ${ }^{100}$. Soprattutto : è a partire da quegli anni che una parte del frumento pubblico egiziano, pur non andando a Roma, esce tuttavia dall'Egitto, per essere stoccata prima negli borrea di Myra e Patara e assegnata poi a città dell'Oriente mediterraneo ${ }^{101}$.

Ancora successivamente, una diminuzione della pressione demografica a seguito delle epidemie di II secolo, percentualmente tanto più leggera quanto più accentuata sarà stata la $\pi \circ \lambda v \alpha v \theta \rho \omega \pi i ́ \alpha$ egiziana di I secolo, potrebbe aver ridotto il fabbisogno interno più di quanto non abbia compromesso le potenzialità produttive e contributive della provincia ${ }^{102}$. Un eventuale assestamento della popolazione egiziana a un livello inferiore di alcune centinaia di migliaia di unità rispetto all'età giulio-claudia potrebbe aver reso possibili, a sostanziale parità di pressione fiscale su superfici coltivate non di molto inferiori, prelievi in natura sensibilmente superiori ai 20,000,000 di modii augustei.

99. PWürzb $10=$ PSarap 1bis, su cui KruSE Th., Der königliche Schreiber, 2002, p. 377-378.

100. $S B$ 12168, datato a un 15 Mechir (= 9 febbraio), probabilmente del 130 (Youtie H., P. Mich. Inv. 974, 1978, p. 247).

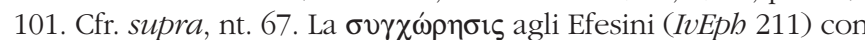
ogni probabilità risale alla primavera del 129, quando Adriano visita la città (Halfmann H., Itinera principum, 1986, p. 192-193). Dalla dedica degli horrea di Myra (ILS 5908) si ricava solo una posteriorità al terzo consolato di Adriano ; frammentaria è l'iscrizione su quelli di Patara (CIL III, $12129=$ TAM II, 397). In base alla pettinatura della raffigurazione di Sabina, data intorno a dopo il 130 gli horrea di Myra : BORCHHARDT J., Myra, 1975, p. 66-74.

102. Evoca una possibilità del genere : Bagnall R.S., P.Oxy. 4527 , 2000, p. 291 : "Is it possible for population to have fallen significantly without a concomitant decline in wheat production? That depends in considerable part on the population level before the plague relative to the labor needed for farming the land ".

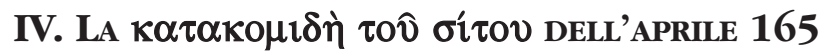

1. Si diceva che in Egitto, diversamente da quanto accade in altre province, i trasferimenti del grano pubblico risultano agevolati dal fatto di poter essere effettuati quasi interamente su acqua, salvo per quei tratti in cui esso deve essere prima portato ai $\theta \eta \sigma \alpha v \rho o u ́$ locali e quindi ai punti di imbarco. Malgrado la loro brevità, però, quei trasporti terrestri potevano risultare problematici, in determinate circostanze.

Il tempestoso incontro, durante il quale il prefetto d'Egitto Flauius Titianus ebbe a minacciare alcuni strateghi, perché quanto prima animali da soma fossero inviati al nomo Arsinoite per il trasporto del grano pubblico, è rievocato in una lettera inviata il 24 Pharmouthi del quinto anno di Marco Aurelio e Lucio Vero (= 19 aprile 165) al basilikos grammateus facente funzione di stratego del nomo Ossirinchite ${ }^{103}$. In quella missiva, lo stratego delle merides di Themistos e Polemon faceva presente che dei 411 asini venuti lì a lavorare dal nomo Ossirinchite soltanto 156 erano rimasti ${ }^{104}$. Con atto di insubordinazione tanto temerario quanto inopportuno, i restanti 255 , di cui nel verso del papiro si specifica il villaggio di origine ${ }^{105}$, erano stati portati via, senza il permesso dello stratego, dai relativi

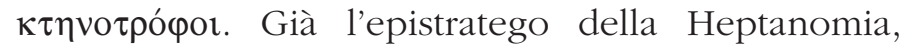

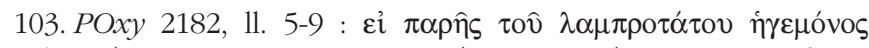

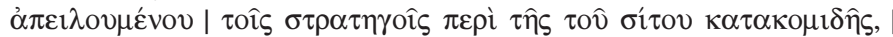

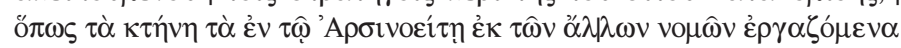
$\pi \lambda \varepsilon \varepsilon \hat{\sigma} \tau \alpha$ ö $\sigma \alpha \pi \varepsilon \mu \varphi \theta \hat{\eta} \mid v \alpha t$. Per la datazione, cfr. BL VIII, 254.

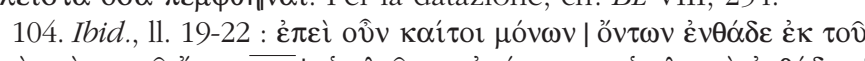

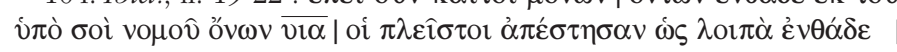

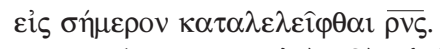

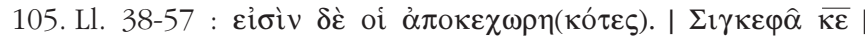

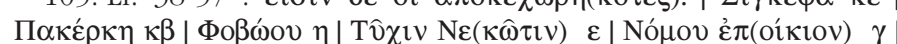

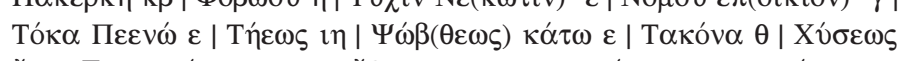

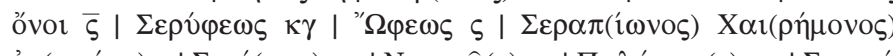

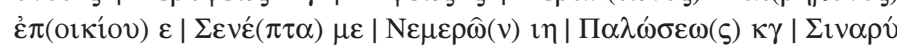

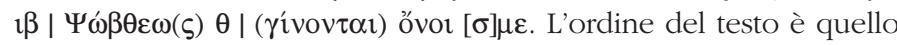
che risulta dalla numerazione delle linee nell'edizione : in base all specificazione Xúcos ovor $\bar{c}$ ella soprallineatura distintiva de specificazione $X v \sigma \varepsilon \omega \varsigma$ ovot $\bar{\zeta}$ e alla soprallineatura distintiva dei
numerali, apposta solo in due casi (evidentemente i primi scritti) e quindi tralasciata, mi pare però che l'elenco sia stato impaginato (e

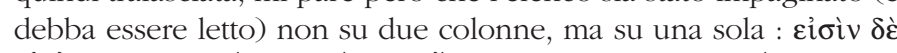
oi ஷ̊̉. $\kappa \tau \lambda$. Poiché l'aritmetica lascia a desiderare, dovrebbe essere stato tralasciato qualche addendo. 


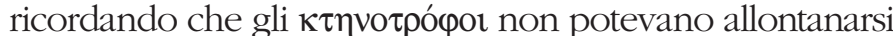
senza il permesso dello stratego, aveva intimato al basilikos grammateus del nomo Ossirinchite di consegnare disertori ${ }^{106}$ : ora lo stratego delle merides di Themistos e Polemon lo invitava a inviare un numero pari di asini e uomini in sostituzione dei fuggitivi, perché il grano potesse essere trasportato fintanto che il fiume, che già aveva cominciato a ritirarsi, continuava a essere navigabile ${ }^{107}$.

Nell'introduzione e nel commento al testo, l'editrice, E.P. Wegener, ha presunto che il grano per il cui trasporto erano stati mobilitati 411 asini dal nomo Ossirinchite fosse quello del raccolto dello stesso quinto anno di Marco Aurelio e Lucio Vero ${ }^{108}$ e che il limite temporale alla navigabilità del $\pi$ o $\tau \alpha \mu$ ó $\varsigma$ fosse dato dalla piena del Nilo, durante la quale la navigazione sarebbe stata sospesa ${ }^{109}$. Conseguentemente, la studiosa è stata indotta a giudicare eccessiva l'allarmata premura

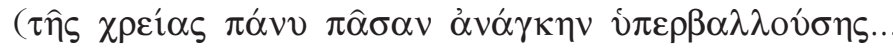

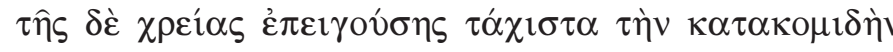

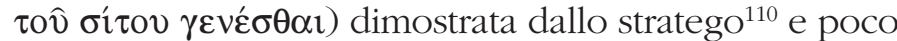

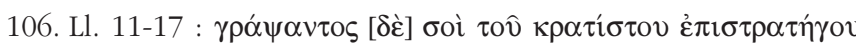

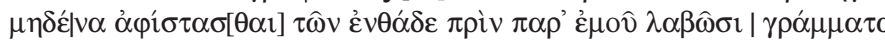

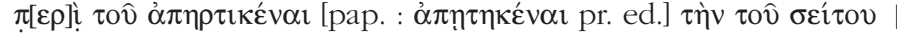

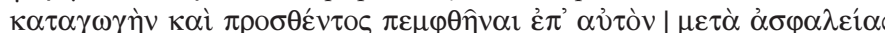

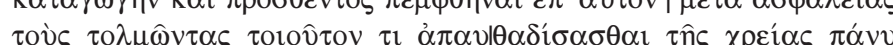

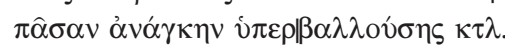

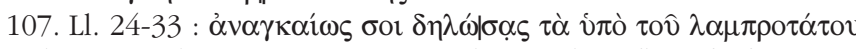

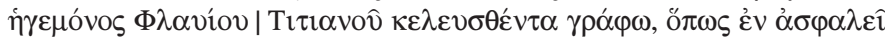

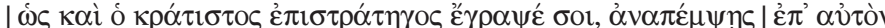

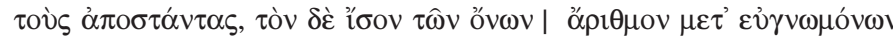

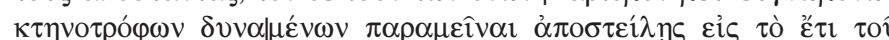

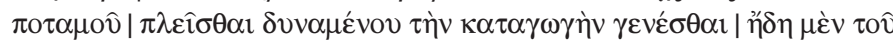

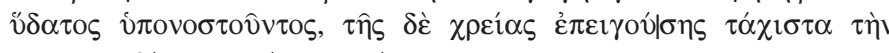

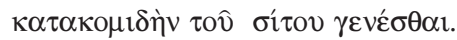

108. Ad POxy XVIII 2182, p. 127.

109. Ibid p. 130, ad 32 : "We know that the Nile is rising from 10-15 August till 20-5 September [...], during which time navigation was suspended (cf. WILCKEN U., Grundz., p. 33) ". Non ho trovato nella pagina di Wilcken indicata la giustificazione di tale affermazione. Mi domando se essa, a chiunque si debba, non derivi da un'indebita generalizzazione di Plin., n.h. V 57 : cum crescit, reges aut praefectos nauigare eo nefas indicatum est.

110. Ad POxy XVIII 2182, 127 : «[...] it appears that the donkeydrivers had to be already in service at the beginning of the harvest [...] Although the corn could be shipped to Alexandria at least up till Epeiph 23 (July 17) [...], or in any case before the end of August, when the flood reaches its highest point (cf. Edict XIII 6), i.e. there were still three or four months, the strategus in his anxiety to get the donkeys exaggerates and writes that the time is pressing ".

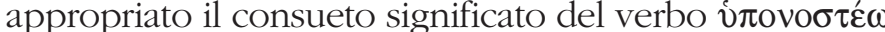
("ritirarsi ") per la ricorrenza alla 1. 32, che qui sarebbe invece da intendersi, all'opposto, come " imperceptibly return, i.e. rise $" 111$.

Quest'ultima inferenza è stata già contestata ${ }^{112}$, e senza dubbio a ragione : assegnare allo í di 1.32 un senso opposto a quello che correntemente ha il verbo diventa tanto meno necessario, quando si constata che la sua restituzione all'accezione più banale e largamente attestata risulta coerente con l'imminenza, rispetto alla data della lettera, della magra del fiume. All'altezza del nomo Arsinoite, il Nilo toccava il livello più basso all'incirca agli inizi di giugno, per iniziare di nuovo a crescere, ma sensim modiceque, una ventina di giorni dopo ${ }^{113}$. È evidente, pertanto, che a partire da un giorno compreso tra il 19 aprile e i primi di giugno il trasporto del grano pubblico delle merides di Themistos e Polemon era complicato dalla temporanea impraticabilità delle vie d'acqua che collegavano al Nilo molti dei punti di imbarco ${ }^{114}$. Ed è parimenti evidente che lo stratego vorrebbe che prima di quel

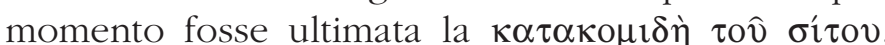
Comprensibile e appropriato è dunque il tono d'urgenza della sua richiesta.

111. Ibid., p. 130 ad 1. 32 : "The meaning is 'to retire'. [...] Consequently on April 19 [...] the water is neither rising nor falling. The strategus, however, looking forward to the time when the corn cannot be shipped, although there is plenty of time, exaggerates 作 for $\dot{v} \pi$ ovo $\sigma \dot{\varepsilon} \omega$ the meaning "imperceptibly return i.e. rise" ".

112. YouTIE H.C., Oxyrhynchus Papyrus 2182, 1944, p. 163-165 = Scriptiunculae II, p. 869-872 ; BONNEAU D., Crue du Nil, 1964 , p. 51-52 ; 111-112 ; Kruse Th., Der königliche Schreiber, 2002 , p. 353, nt. 921 ; ancora incerto, invece, ADAMs C., Land Transport, 2007, p. $19 ; 178$.

113. Cfr. Plin., n.h. V 57 : incipit crescere luna noua quaecumque post solstitium est, sensim modiceque cancrum sole transeunte, abundantissime autem leonem, et residit in uirgine isdem quibus adcreuit modis. BONNEAU D., Crue du Nil, 1964, p. 23.

114. Sull'impossibilità di navigare nei canali durante l'ó $\pi$ óß $\alpha \sigma 1 \varsigma_{\text {, }}$ (implicitamente anche $P O x y$, 4004); PLond 1346 ;

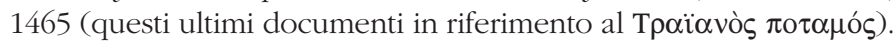
Vale la pena di ricordare che i lavori di manutenzione del Tpaïavòs $\pi$ o $\alpha \mu$ ó $\varsigma$ erano eseguiti, presumibilmente quando esso non era navigabile, nei due mesi di Pachon e Payni (PCairlsid 81, del 297) oppure per un periodo di tre mesi, entro i quali ci saranno stati i 60 giorni di Pachon e Payni (PSI 689, del 423). 
2. Dalla corretta interpretazione delle 11. 26-32 di POxy 2182 discendono conseguenze di rilievo, finora, mi pare, non adeguatamente sottolineate. Se i 411 asini dal

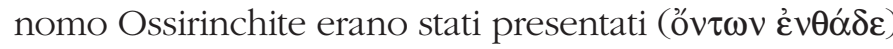
a trasportare grano nelle merides di Themistos e Polemon del nomo Arsinoite già prima del 24

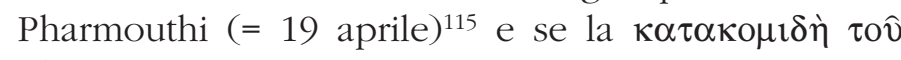

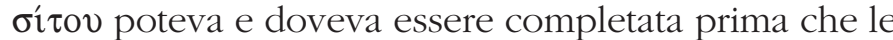
vie d'acqua che andavano dall'interno del nomo Arsinoite al Nilo avessero cessato di essere navigabili1 ${ }^{116}$, si deve assolutamente escludere che il grano da trasportare fosse quello del raccolto del quinto anno di Marco Aurelio e Lucio Vero, la cui mietitura era forse iniziata, ma probabilmente ancora non terminata, il 19 aprile $^{117}$ e il cui trasporto al fiume certo non si sarebbe potuto realizzare entro i primi giorni di giugno.

Neppure sotto la pressione di eventi assolutamente eccezionali si può attribuire al prefetto d'Egitto o, peggio ancora, a uno degli strateghi del nomo Arsinoite l'assurda pretesa che fossero incamerati e poi trasportati ai punti di imbarco i proventi granari dell'intero nomo in un mese o poco più e con poche migliaia di asini. Come vedremo, almeno in determinate circostanze (e nel 165 quelle circostanze dovevano esserci tutte), dal nomo Arsinoite potevano prelevarsi, in quel periodo, all'incirca un milione e mezzo di artabe ${ }^{118}$. Compresso in 30 giorni, al ritmo di circa 50,000 artabe al giorno, l'immagazzinamento e il trasferimento di tutto quel grano avrebbe comportato, ogni giorno, più di 15,000

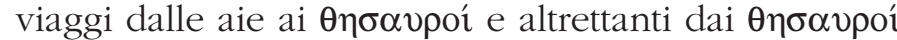
ai punti di imbarco ${ }^{119}$ : anche se gli asini a disposizione fossero stati 10,000, essi avrebbero dovuto comunque compiere tre viaggi al giorno ciascuno. Molto

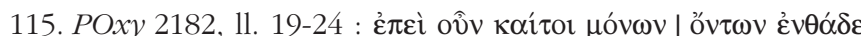

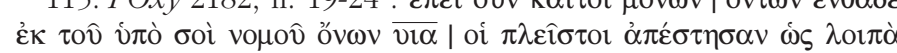

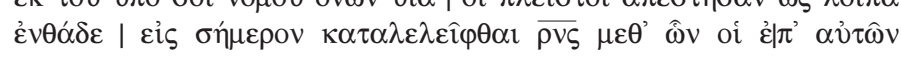

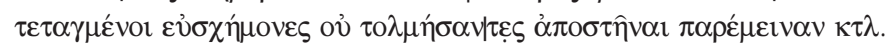

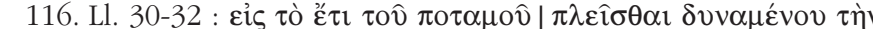

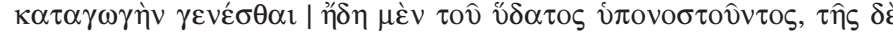

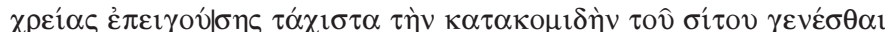

117. Cfr. SCHNEBEL M., Die Landwirtschaft, 1925, p. 162-165.

118. Come può stimarsi dai proventi granari della sola meris di Herakleides nell'anno 185, su cui cfr. infra, p. 000.

119. Sui carichi degli asini nella documentazione papiracea, cfr. WilcKen U., Griechische Ostraka, I, 1899, p. 754 ; ADAMS C., Land Transport, 2007, p. 77-79. difficilmente, però, sarà stato disponibile un così grande numero di animali, se l'intero nomo Ossirinchite dà solo 411 asini alle merides di Themistos e Polemon. E molto difficilmente avrebbe potuto compiere, ciascuna bestia, tre viaggi al giorno : non compiono più di un viaggio al giorno i quasi cento asini del nomo Kynopolite che dal 21 al 26 ottobre 210 portano ad Alsos da Lagis e Trikomia solo 1,730 artabe ${ }^{120}$.

Inoltre : nei documenti dei sitologi non solo di II, ma anche di III e IV secolo, non troviamo attestazioni

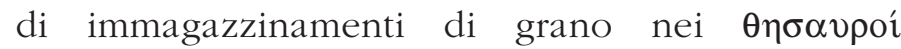
dell'Arsinoite che risalgano già al mese di Pharmuthi. Un punto che sembra fermo nella peraltro variabile tempistica della trasmissione del grano pubblico del nomo Arsinoite è che il grano era immagazzinato nei

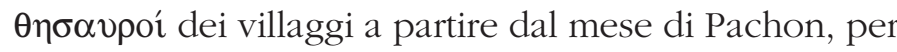
essere poi trasportato ai punti di imbarco nei mesi successivi ${ }^{121}$. Non c'è ragione di ritenere che i prelievi dal raccolto del quinto anno di Marco Aurelio e Lucio Vero fossero incamerati e soprattutto trasmessi così anticipatamente, tanto più che PBerlLeihg 4 recto $(=S B$ 7196 recto) ci dà la certezza che almeno a Theadelphia, nella meris di Themistos, dal 16 di Payni al 4 di Epeiph 165 non solo si incamerassero 5,427 artabe e 21/24 di grano del raccolto di quell'anno, le quali si aggiungevano alle 1,884 artabe e 1/2 già in precedenza depositate nei granai, ma anche che di tutta quella quantità di grano, in quello stesso periodo, si trasmettessero al porto di Alsos solo 564 artabe e $1 / 2^{122}$. Appare pertanto necessario ammettere che il grano pubblico di cui il 19 aprile 165 lo stratego delle merides di Themistos e Polemon voleva al più presto completato il trasporto fosse ancora quello prelevato dal raccolto del quarto anno di Marco Aurelio e Lucio Vero $(163 / 164)$.

3. Nella misura in cui le condizioni generali della trasmissione del grano pubblico del nomo Arsinoite nel 164/165 desunte da POxy 2182 offrono delle linee guida anche per l'interpretazione di casi particolari, possiamo tentare una lettura dei dati offerti da

120. PHamb 17

121. Bagnall R.S., P.Col. VII, p. 97 ; TSIParis C., O. Lund., 1979, p. 62. Reiter F., Vorschläge, 2001, p. 194.

122. PBerlLeihg 4. 
PBerlLeihg 1 (= SB 7193). Oltre alle giacenze in precedenza depositate, in questo papiro i sitologi di Theadelphia registrano le entrate e le uscite di grano pubblico dal 1 Thoth (= 29 agosto) 164 al 16 Tybi (= 11 gennaio) 165. In questo lasso di tempo, entrano nei granai del villaggio all'incirca 829 artabe, che si aggiungono a circa altre 1,651 rimaste depositate dai mesi precedenti. Delle 2,480 artabe totali, 2,100 sono prestate per la semina del quinto anno, mentre neppure un'artaba viene portata al Nilo per essere convogliata ad Alessandria. È dunque ovvio che il grano pubblico prelevato a Theadelphia il quarto anno di Marco Aurelio e Lucio Vero e inviato fuori dell'Egitto - a Roma o agli eserciti in Siria - o è stato tutto già raccolto e inviato prima del 29 agosto 164, e ciò rappresenterebbe un'eccezione rispetto alla generale tendenza del nomo Arsinoite, per cui si dovrebbe dedurre che la trasmissione del grano pubblico lì procedesse in maniera non uniforme, o deve essere ancora in una certa misura incamerato l'11 gennaio 165 , ciò che aiuterebbe a comprendere, qualche mese dopo, sia l'irritazione del prefetto d'Egitto sia la preoccupazione dello stratego delle merides di Themistos e Polemon.

4. In parte, l'ampiezza del ritardo accumulato nel trasferimento di una così larga parte del grano fiscale del nomo Arsinoite prelevato dal raccolto del quarto anno di Marco Aurelio e Lucio Vero è la conseguenza della progressiva riduzione del numero di animali e uomini che vi avrebbero dovuto lavorare. Per quanto riguarda il nomo Ossirinchite, questa flessione della forza lavoro poté essere avvertita già all'inizio delle operazioni di trasferimento del frumento pubblico del quarto anno, quando si rilevò che da quel nomo furono inviati nelle merides di Themistos e Polemon

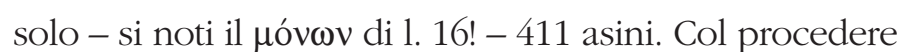
dei mesi però quel già ridotto contingente si assottigliò

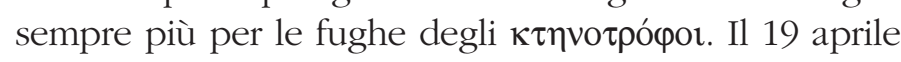
165 restavano solo 156 asini, dei 411 iniziali : 255 di essi, il $62 \%$, non erano più disponibili. Quanti altri

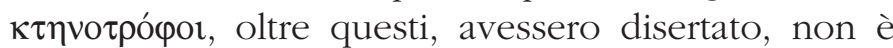
possibile precisare. Le lettere circolari e le minacce $\kappa \alpha \tau$ ' ő $\psi$ tv che il prefetto d'Egitto Flauius Titianus indirizza agli strateghi di nomi diversi dall'Ossirinchite dimostrano però che molti nomi (tutti quelli della Heptanomia ?) ${ }^{123}$ avevano inviato al nomo Arsinoite

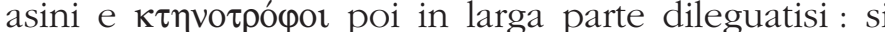
tratta, insomma, di una diserzione di assai vaste

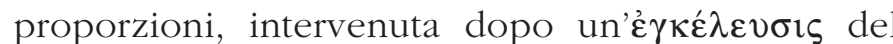
prefetto $^{124}$.

La convinzione che il grano da trasportare fosse già quello del quinto anno di Marco Aurelio e Lucio Vero ha fatto sì che non si avvertisse l'esigenza di dare una spiegazione al basso numero di asini dal nomo Ossirinchite al lavoro il 19 aprile 165 nelle merides di Themistos e Polemon. Ma se l'arrivo di soli 411 asini e la loro successiva riduzione a 156 dà comunque un'idea della più generale riduzione della forza lavoro umana e animale addetta al trasporto del grano nel nomo Arsinoite, questa forse richiede una spiegazione non banale.

È difficile evincere dalla lettera dello stratego delle merides di Themistos e Polemon le ragioni per cui la

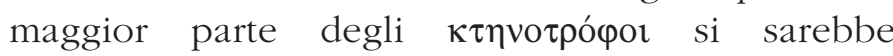
progressivamente eclissata coi relativi asini. È probabile che esse dipendessero semplicemente dall'accresciuta onerosità di quelle prestazioni, che poté sembrare eccessiva - non sapremmo però dire perché - dopo una particolare ordinanza del prefetto. Come si vedrà, sin dalla fine del 162 la campagna partica di Lucio Vero doveva aver imposto periodi di servizio assai più lunghi del solito, che l'amministrazione, oltretutto, spesso stentava a indennizzare. Nondimeno, converrà qui evocare anche la possibilità di una connessione delle

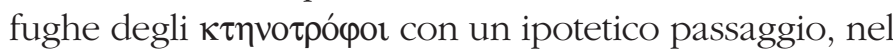
Fayum, dell'epidemia che in quello stesso anno arriva a investire anche Nisibi e Smirne ${ }^{125}$, dove tra l'altro colpisce, il particolare merita di essere qui sottolineato, anche le bestie da soma ${ }^{126}$. Naturalmente, perché un tale collegamento sia ammissibile, sarebbe necessario che il passaggio in Egitto della prima ondata della

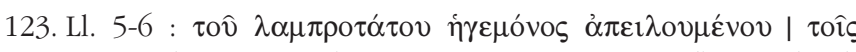

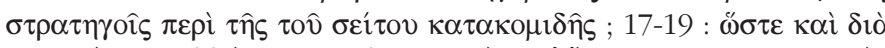

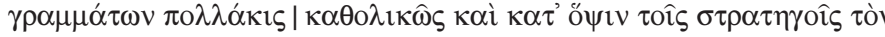

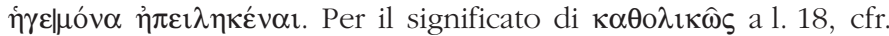
KATZOFF R., Law as 'katholikos', 1986, p. 124.

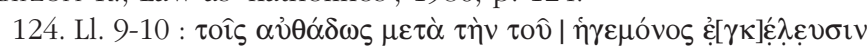

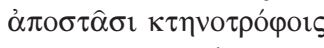

125. Lucian., hist. conscr. 15 ; Ael. Arist. 51, 25

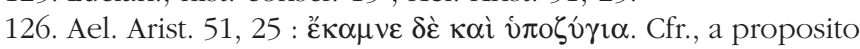
dell'epidemia sotto Commodo, Herod. I 12, 1 : [...] $\pi \mathrm{o} \lambda \lambda \eta \dot{\eta} \tau \varepsilon$ $\tau 1 \varsigma$

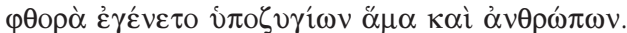


peste risalga già a qualche anno prima del documento che la ricorda ${ }^{127}$, ciò che, a sua volta, potrebbe ammettersi senz'altro, se il racconto di Crepereius Calpurnianus non dovesse a tucididismo d'accatto, come invece Luciano lascia intendere, il particolare dell'origine della pestilenza ỏ $\pi$ ò Aïıı $\pi i \alpha \varsigma^{128}$.

\section{Fiscalità di gUERRA E MOBILITÀ DEL GRANO NEL NOMO ARSINOITE}

1. La laboriosità delle operazioni di trasmissione del frumento pubblico del nomo arsinoite prelevato dal raccolto del quarto anno di Marco Aurelio e Lucio Vero non dipendeva però soltanto dal via via sempre più scarso numero di bestie al lavoro. In parte, l'enorme ritardo allora accumulato era causato anche dal più alto livello dei prelievi in natura che la campagna partica rendeva necessari ${ }^{129}$. Da POxy 2182 risulta chiaramente

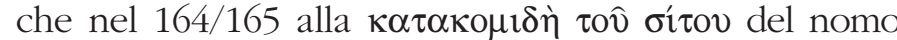

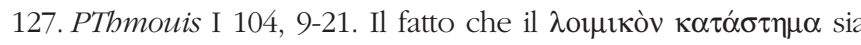
ricordato solo dopo le violenze dei Nicociti tra le cause dello spopolamento di Kerkenouphis induce a ritenere relativamente limitato l'impatto dell'epidemia su quella comunità. Il passaggio dell'epidemia, dunque, potrebbe anche essere stato non immediatamente precedente allo sgravio concesso dal komogrammateus nel nono anno di Marco Aurelio e Lucio Vero (168/169).

128. FGrHist 208 F 3. I confini tra Egitto ed Aïro $\pi$ í $\alpha$ sono ancora infestati da un'epidemia in età severiana : Cass. Dio LXXV 13, 1. Su Crepereius Calpurnianus, cfr. Jones C.P., Culture and Society, 1986 p. 161-166.

129. Quanto afferma la Expositio totius mundi et gentium 36 a proposito delle guerre contro i Persiani nel IV secolo (Constantinopolis enim Thraciae ab ea [sc. Aegypto] quam plurime pascitur : similiter et orientales partes, maxime propter exercitum imperatoris et bellum Persarum : propterea non posse aliam sufficere nisi diuinam Aegyptum), vale anche per la campagna partica di Lucio Vero, quando si dovettero rifiutare pagamenti in danaro di tasse in grano e procedere all'acquisto di $\pi v$ ò̀

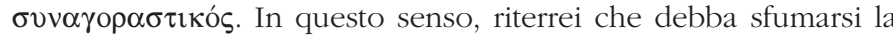
posizione di MrtThof Fr., Annona militaris, 2001, I, p. 51 " Allerdings gibt es bislang für das 1 , und 2 . Jh in der papyrologischen Dokumentation keine konkreten Hinweise dafür, daß Ägypten zur Versorgung eines im Orient engagierten Expeditionskorps beigetragen hätte. Es steht daher zu vermuten, daß solche Lieferungen den regulären Steureinnahmen der Provinz entnommen wurden, ohne daß die Bevölkerung mit zusätzlichen Requisitionen behelligt worden wäre ».
Arsinoite dovevano collaborare un numero considerevole di uomini e animali provenienti da altri nomi : ben 411 asini erano venuti (e ancora di più ne erano stati auspicati) dal solo nomo Ossirinchite alle sole merides di Themistos e Polemon. Altri asini, da altri nomi, dovevano essere stati inviati nelle stesse merides di Themistos e Polemon e nella meris di Herakleides.

Ciò non era una novità assoluta. Per quel che possiamo vedere, già all'età di Adriano ai villaggi del

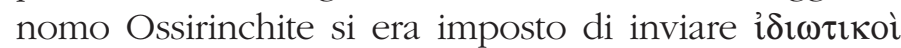

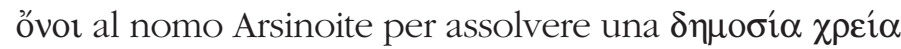
che avrà certamente riguardato il trasporto del grano pubblico $^{130}$. È assai dubbio, però, che il trasporto del grano pubblico del nomo Arsinoite abbia richiesto sempre tanta forza lavoro esterna quanta fu necessaria trasferire in occasione del trasporto dei prelievi dal raccolto del quarto anno di Marco Aurelio e Lucio Vero.

Dalle ricevute che componevano un tomos synkollesimos della banca pubblica di Arsinoe non sembra infatti di poter dire che dieci anni prima fosse stato necessario dispiegare una simile mobilitazione :

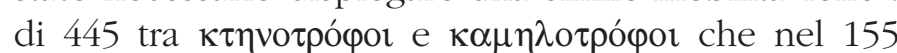
sottoscrivono (o fanno sottoscrivere) 64 ricevute per i

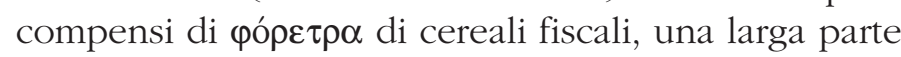
di essi, ben 385, viene dalla stessa meris di Polemon di cui si trasportano i tributi ; altri 53 (43 della meris di Herakleides, 10 della meris di Themistos) sono comunque del nomo Arsinoite : solo 6 provengono dal vicino nomo Herakleopolite ${ }^{131}$. Neppure negli anni immediatamente successivi alla campagna di Lucio Vero sembra che avesse luogo una mobilitazione comparabile a quella degli anni di guerra: gli

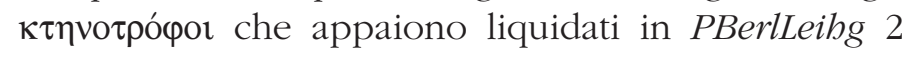
verso (= SB 7194 verso $)^{132}$, vengono tutti dalle merides di Themistos e Polemon, così come anche, in PCol II 1 recto 5, i 148 asini che trasportano il grano pubblico del nomo Arsinoite nei giorni 10 e 11 di un mese e di un anno imprecisati, all'incirca alla metà del II secolo.

\section{SB XIV 12168}

131. KamBitsis S., Papyrus Graux III, 1997, p. 30-32

132. PBerlLeihg 2 verso (= SB 7194 verso), 1.1 ripete il totale PBerlLeihg 2 recto (= SB 7194 recto) 1. 19, raggiunto l'11 Mechir dell'ottavo anno di Marco Aurelio e Lucio Vero : è dunque probabile che i pagamenti che di seguito si registrano si riferiscano a trasporti del grano pubblico prelevato dal raccolto del settimo anno. 
2. $\mathrm{E}$ anche possibile che in anni normali il trasporto del grano del nomo Arsinoite, oltre a richiedere meno uomini e meno animali, richiedesse anche meno tempo. Sebbene realizzato con forze esterne di gran lunga inferiori a quelle dispiegate nel 164/165, il trasferimento dei tributi granari della meris di Polemon del raccolto dell'anno diciassettesimo di Antonino Pio doveva essere già stato ultimato nel mese di febbraio

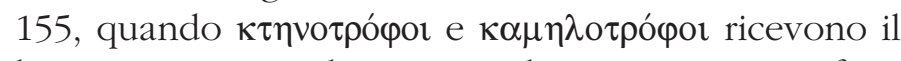
loro compenso, in danaro, a Ptolemais Euergetis. Infatti,

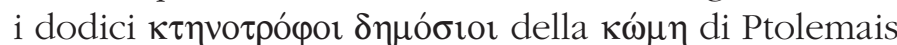
Nea che vengono liquidati con poco più di 821 dracme il 14 Mechir del 155, hanno effettuato i loro servizi nei soli due mesi precedenti di Hathyr e Hadrianos ${ }^{133}$.

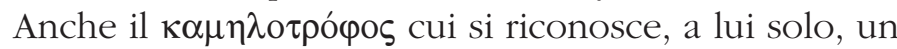
indennizzo per poco meno di 107 artabe ha terminato il suo servizio prima del 4 Phamenoth $155^{134}$. Per non parlare, andando un po' più indietro nel tempo, del

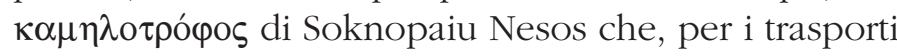
del grano fiscale eseguiti a partire da Pachon 138, viene liquidato, con ben 460 artabe, prima dell'ultima delle Epagomenai dello stesso anno ${ }^{135}$.

Negli anni della campagna partica di Lucio Vero, ai molto più numerosi addetti al trasporto del grano pubblico del nomo Arsinoite dovette richiedersi un servizio assai più lungo. Si è visto sopra come, malgrado le diverse centinaia, anzi migliaia di asini inviate dagli altri nomi della Heptanomia, il 24 Pharmouthi 165 dovesse essere ancora terminata la

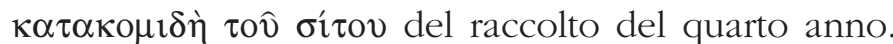
Quasi due anni prima, il 28 di Payni 163, due

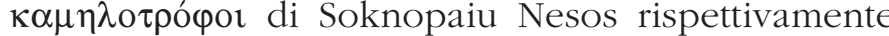
ricevono, da una banca privata di Ptolemais Euergetis $^{136}, 296$ e 600 dracme sulla garanzia del loro credito nei confronti dell'amministrazione per i servizi di trasporto di grano pubblico dalla meris di Herakleides espletati, senza o con assai poco

133. In PFrisk 1 col. 14

134. PCol II col. 16, 18

135. BGU 2699. Per la datazione, cfr. Bastianini G. e Whitehorne J., Strategi and Royal Scribes, 1987, p. 46 ; NACHTERGAel G., Papyrologica. II, 2005, p. 231. Per altri aspetti, cfr. Kruse Th., Der königliche Schreiber, 2002, p. 369-372 ; 981-982, nt. 119.

136. BOgaert R., Liste géographique, 1995, p. 142

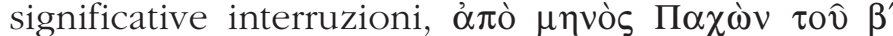

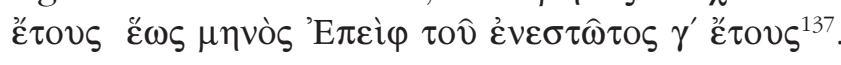

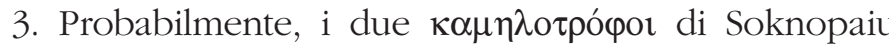
Nesos, e il banchiere che eroga loro il prestito, speravano in una celere liquidazione dei servizi in buona parte già resi. Per la verità, il tomos synkollesimos della banca pubblica di Arsinoe mostra che anche nei paciosi anni di Antonino Pio questo non sempre avveniva ${ }^{138}$. Molto meno spesso, però, ciò doveva verificarsi negli anni della campagna partica di Lucio Vero

In PBerlLeibg 2 recto (= SB 7194 recto) sono registrati i pagamenti in grano, effettuati il 26 Tybi e l'11 Mechir del 168, per servizi resi da alcuni gruppi di

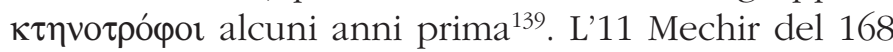

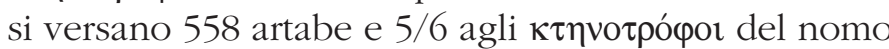
Kynopolite per i trasporti dei prelievi dal raccolto dell'anno terzo $(162 / 163)$ nella meris di Polemon ${ }^{140}$.

137. BGU 607, 11. 13-29 : ع́x $\tau \hat{\omega} v$ ỏ

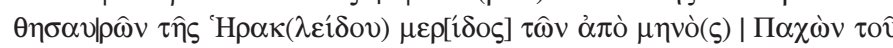
$\beta$ (ह̌兀

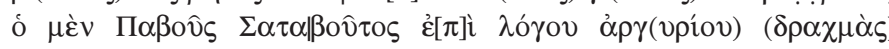

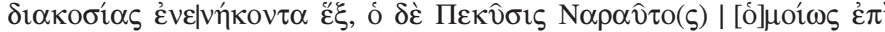

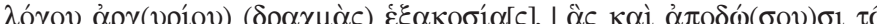


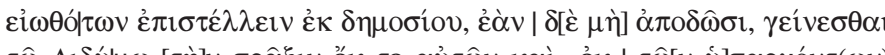

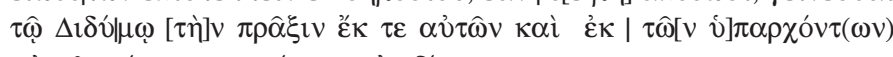

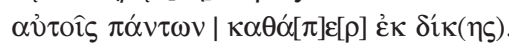

138. Alcuni dei trasporti liquidati nello stesso diciottesimo anno di Antonino Pio riguardano grano del raccolto dell'anno i dell'anno quattordicesimo e quindicesimo (150/151 e 151/152) : PFrisk 1 col. 4 ; dell'anno quindicesimo (151/152) : PFrisk 1 col. 15 ; col. 31 ; dell'anno sedicesimo (152/153) : BGU 2270. Più che di trasporti di rimanenze dei prelievi di anni precedenti, riterrei che si tratta di pagamenti posticipati di conti rimasti in sospeso : cfr. Kambitsis S., Papyrus Graux III, 1997, p. 18. Trasporti di grano pubblico pagati con anni di ritardo anche in $B G U 2269$, del primo anno di Antonino Pio e in PWürzb $10=$ PSarap 1bis, in cui trasporti di prelievi dal raccolto dell'anno dodicesimo di Adriano sono pagati nell'anno quattordicesimo con grano prelevato dal raccolto del decimo anno.

139. Si deve escludere che i trasporti di cui il documento certifica il pagamento nell'ottavo anno, siano stati realizzati nello stesso ottavo anno (diversamente, Johnson A.Ch., Roman Egypt, 1959, p. 415): piuttosto che trasporti di grano lasciato per anni nei $\theta$ $\sigma \alpha v p o i ́$ della meris, si deve ammettere, con KALÉN T., Berliner Leihgabe Griechischer Papyri, 1932, p. 84 e Kruse Th., Der königliche Schreiber, 2002, p. 386, che il testo si riferisce a trasporti pagati con anni di ritardo. 140. PBerlLeihg 2 recto (= SB 7194 recto), 11. 11-18. 
Ancora prima, il 26 Tybi 168, dalle stesse autorità

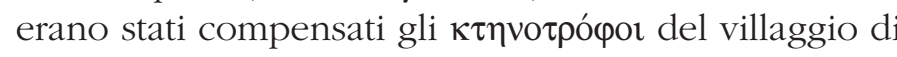
Sobthis, del nomo Herakleopolite, per i servizi resi ne

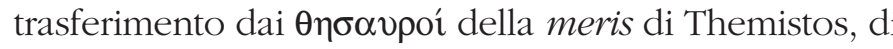
prelievi dai raccolti degli anni 161/2, 162/3, 163/4, $164 / 5$ e $165 / 6^{141}$. Poiché queste remunerazioni in grano saranno state proporzionali alla combinazione delle quantità trasportate con le distanze percorse, varrà la pena di prestare attenzione ai loro dislivelli. Gli

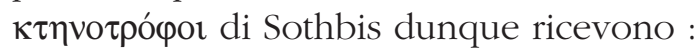

a. per il trasporto dei prelievi dal raccolto del secondo anno $(161 / 2)$ : 81,25 artabe ;

b. per il trasporto dei prelievi dal raccolto del terzo anno $(162 / 3)$ : 147,25 artabe ;

c. per il trasporto dei prelievi dal raccolto del quarto anno $(163 / 4)$ : 160 artabe ;

d. per il trasporto dei prelievi dal raccolto del quinto anno $(164 / 5)$ : 198 artabe ;

e. per il trasporto dei prelievi dal raccolto del sesto anno (165/6) : $\quad 33$ artabe.

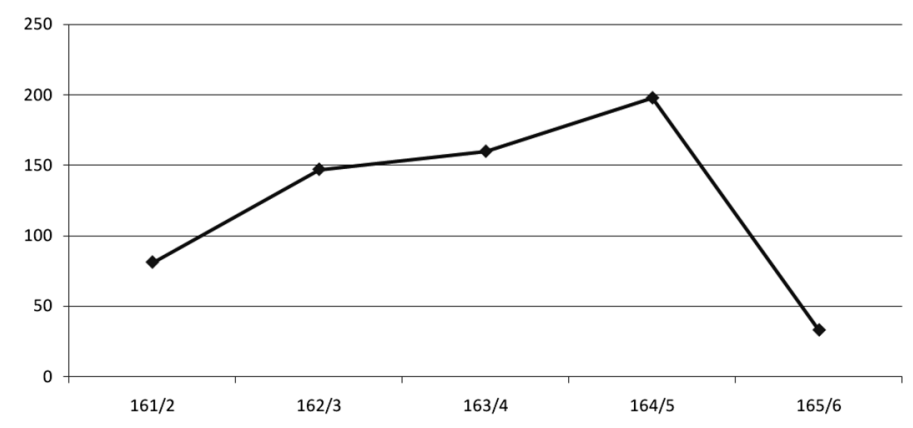

È evidente la disparità tra i compensi per i raccolt del terzo, quarto e quinto anno rispetto a quello per il raccolto del secondo e soprattutto del sesto, quando questi scendono esattamente a $1 / 6$ dell'anno precedente. Se la radicale riduzione dei compensi allora sopraggiunta è la spia anche di una certa anche se non proporzionale - riduzione dei prelievi in grano, dovremo concludere che fu la campagna partica, per la quale Lucio Vero si trovava in Siria già alla fine del $162^{142}$, a determinare il loro aumento a partire dai prelievi del raccolto del secondo anno ${ }^{143} \mathrm{e}$

141. PBerlLeihg 2 recto (= SB 7194 recto), 11. 1-10 142. HalfmanN H., Itinera principum, 1986, p. 210

143. Vale la pena di sottolineare che, in connessione coi prelievi dai raccolti del quarto e del quinto anno, nel momento di massimo che fu la fine delle ostilità e il ritorno nelle sedi di stanza delle truppe mobilitate a permetterne, nell'estate del $166^{144}$, la riduzione.

Nella primavera-estate del 166, interrotte le ostilità e rinviate alle loro sedi le truppe, non c'era più bisogno di sottoporre a stress fiscale la meris di

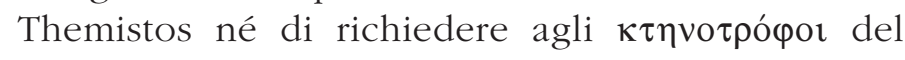
villaggio di Sobthis del nomo Herakleopolite la mole di lavoro imposta l'anno precedente : di conseguenza, anche i compensi per i trasporti dei prelievi dal raccolto dell'anno 165/166 si ridussero notevolmente.

\section{DOPO LA PESTE : MOBILITÃ DEL GRANO PUBBLICO NELLA HePTANOMIA SEVERIANA}

1. Saltiamo ora a un momento non lontano da quello in cui a Cuicul si dovette prendere la decisione di costruire degli borrea che facilitassero il trasferimento al Mediterraneo del frumento pubblico della regione. In una lettera circolare inviata agli strateghi della Heptanomia e dell'Arsinoite (esclusa l'Oasi) il 17 di Epeiph (= 11 luglio) 197, il prefetto d'Egitto Q. Aemilius Saturninus si trova a deplorare una grave negligenza

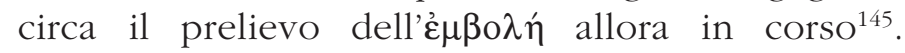

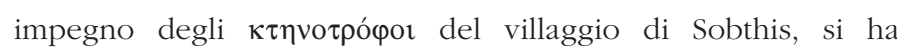

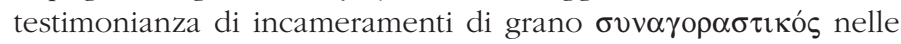
merides di Themistos e Polemon (PStras 191 ; PBerlLeihg 1; BGU

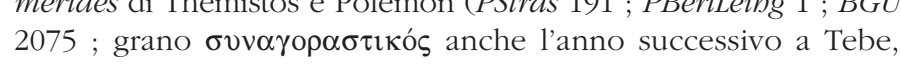
però : OBodl 1471) : cronologicamente ciò dovrebbe coincidere, se non anche già con la carestia in Italia (H.A., MAnt 11, 3; 12, 13-14), certo con il $\lambda$ uós patito, in quello stesso periodo, dall'esercito di Lucio Vero (Cass. Dio LXXI 2, 4).

144. Halfmann H., op. cit., p. 210.

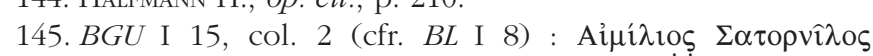

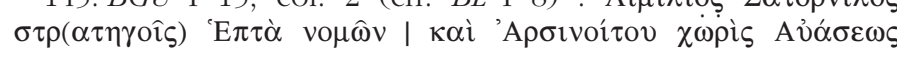

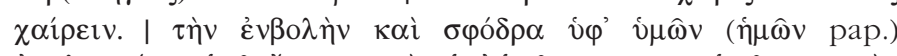

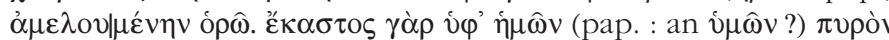

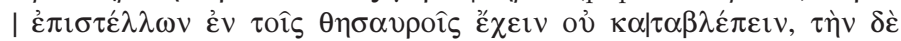

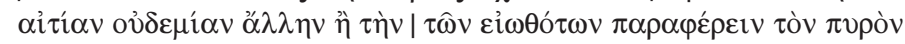

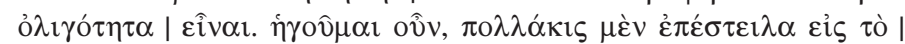

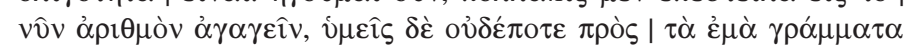

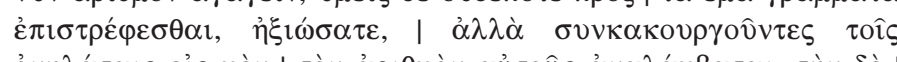

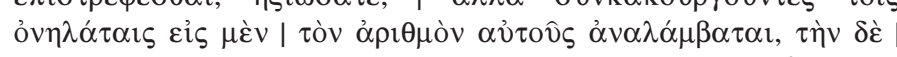

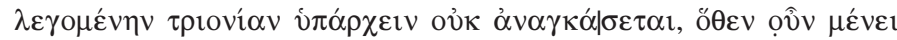

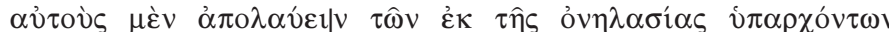

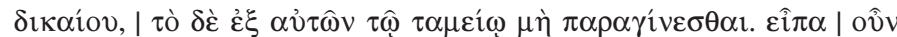


I destinatari della sua missiva gli hanno infatti comunicato di constatare di non avere grano nei

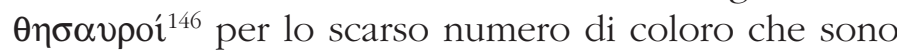
soliti portarvi grano. Di un disservizio così ampio e generalizzato, il prefetto attribuisce tutte le responsabilità agli strateghi, i quali non si sarebbero neppure degnati di guardare le ripetute lettere in cui aveva raccomandato loro di portare gli effettivi degli

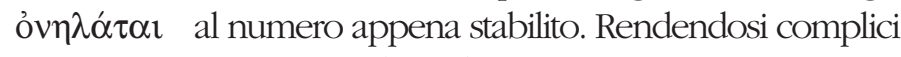

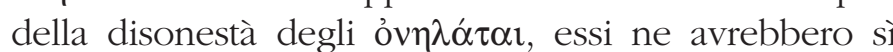
ampliato gli organici, ma senza assicurarsi che ciascuno di essi potesse indipendentemente assolvere all'obbligo della $\tau p ı v i ́ \alpha$, potesse mettere cioè a disposizione tre diversi asini per il trasporto del grano fiscale. Una parte degli

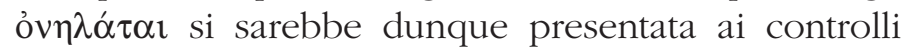
amministrativi con asini presi temporaneamente in prestito

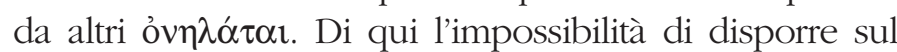
momento della desiderata mobilità e la necessità di ricorrere in futuro al rimedio di marchiare ogni asino, in modo tale da impedire la sua contemporanea attribuzione

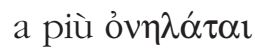

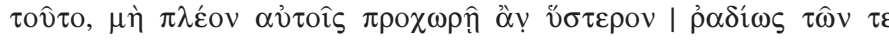

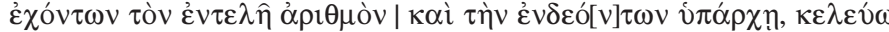

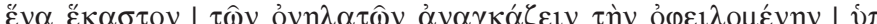
$\alpha$

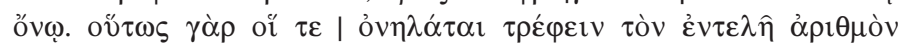

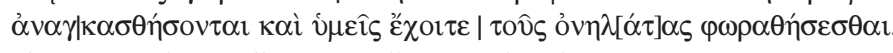

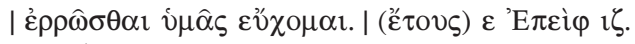

146. Anche se il senso generale rimane comunque chiaro, la malferma sintassi rende difficile la comprensione precisa delle 11. 4-8. Lo $\eta \mu \hat{\omega} v$ di 1.3 viene comunemente (e giustamente) interpretato come

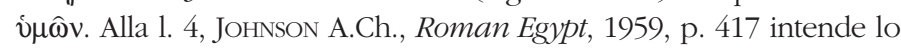

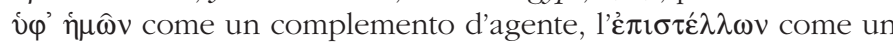
passivo e il $\kappa \alpha \tau \alpha \beta \lambda \varepsilon \dot{\pi} \varepsilon \imath v$ come un indicativo : "For each of you commanded by us to have wheat in the storerooms disregards our command " (simile la traduzione di ADAms C., Land Transport, 2007. p. 174). Preferirei intendere $\dot{\varepsilon} \pi \iota \sigma \tau \dot{\varepsilon} \lambda \lambda \omega v$ come un attivo e far

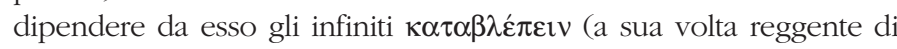

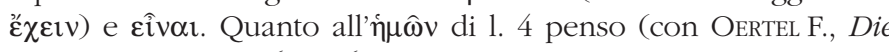
Liturgie, 1917, p. 116, nt. 6) che come a 1. 3, debba intendersi come un $\dot{v} \mu \hat{\omega} v$ e che $\dot{v} \varphi^{\prime} \hat{v} \mu \hat{\omega} v$ sia in realtà il partitivo richiesto da

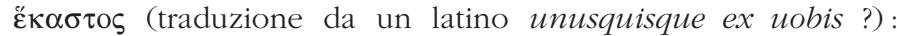
"Ciascuno di voi scrive di constatare di non avere grano nei granai e che (di ciò) non v'è nessuna altra causa oltre la scarsità di coloro che sono soliti trasportare il grano ". Oltre al già citato OERTEL F., op. cit., p. 116-121, sulla ỏv $\lambda \alpha \alpha \sigma i \alpha$, cfr. LewIs N., Compulsory Public Services, 1997, p. 38 ; DreColl C., Die Liturgien im römischen Kaiserreich, 1997, p. 186-187. Più in generale, sul trasporto del grano pubblico in Egitto, cfr. ultimamente ADAMs C., op. cit., p. 159-195.
2. Malgrado ne restino oscuri molti contorni, di questo importante episodio della storia amministrativa dell'Egitto romano può essere comunque tentato un inquadramento, partendo dal carattere preventivo degli interventi di Q. Aemilius Saturninus. È infatti evidente che nel 197 non si riteneva accettabile la velocità con cui, nella Heptanomia e nell'Arsinoite, era stato incamerato e trasmesso il frumento pubblico negli anni precedenti. Certo, la circostanza che proprio nel $197 \mathrm{si}$ sentisse il bisogno di velocizzare quelle operazioni non può non considerarsi in connessione con i preparativi della seconda campagna partica, avviata di lì a poco aestate exeunte $e^{147}$. Varrà tuttavia la pena di sottolineare, a fronte della straordinarietà dell'evento bellico che lo sollecita, il carattere strutturale dell'aumento, insistentemente richiesto, del numero

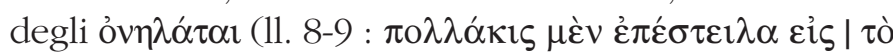
vôv $\alpha \rho \imath \theta \mu o ̀ v ~ \alpha ่ \gamma \alpha \gamma \varepsilon \hat{\imath} v)$ : anche dopo la fine delle

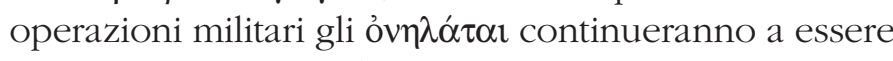

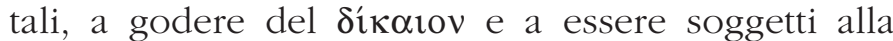

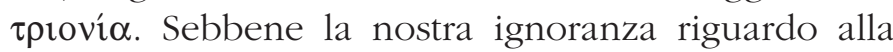
consistenza di questo aumento non ci consenta di apprezzarne fino in fondo l'importanza, il fatto che gli interventi del prefetto abbiano riguardato l'intera Heptanomia (esclusa l'Oasi), che una loro presunta elusione potesse essere addotta come unica spiegazione per l'insoddisfacente ritmo dell'incameramento del grano pubblico e che, viceversa, il loro scrupoloso adempimento potesse immaginarsi risolutivo di ogni problema, basta a escludere che si trattasse di un provvedimento di scarso rilievo. D'altra parte, l'insoddisfazione di Q. Aemilius Saturninus per i deludenti risultati constatati l'11 luglio 197, in un momento così delicato per l'impero e per la sua carriera ${ }^{148}$, dimostra che non era semplice ottenere le performances auspicate.

Se guardiamo più da vicino la situazione lamentata da Q. Aemilius Saturninus nel 197, constatiamo che essa è molto diversa da quella in cui si trova Flauius

147. H.A., S 16,1

148. Nel mese di Pachon dello stesso 197 si rivolge a lui un

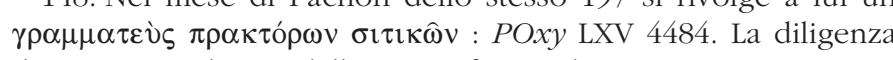
dimostrata negli anni della sua prefettura d'Egitto, estesasi per tutta la durata della seconda campagna partica di Severo, valse a Q. Aemilius Saturninus la promozione, per lui poi rovinosa, prefetto al pretorio, collega di Plauziano : Cass. Dio LXXV 14, 2. 
Titianus nel 165. Verificato già il 17 Epeiph (= 11 luglio), il ritardo constatato da Saturninus riguarda anche (e forse soprattutto ${ }^{149}$ ) le operazioni di primo immagazzinamento del grano pubblico. Il ritardo registrato da Flauius Titianus il 24 Pharmouthi (= 19 aprile), quando si è ormai a ridosso del nuovo raccolto, riguarda invece la sola trasmissione ai canali di imbarco

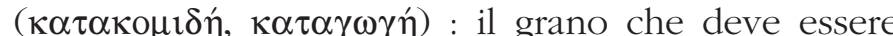

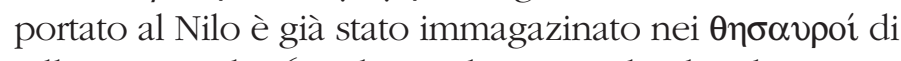
villaggio. Nel 165, il ritardo riguarda il solo nomo Arsinoite, dove si vogliono far convergere uomini e animali da altri nomi ; nel 197, esso concerne l'intera

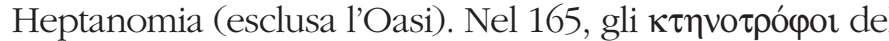
nomo Ossirinchite si erano presentati a lavorare al nomo Arsinoite coi loro asini, molti allontanandosene poi ; nel

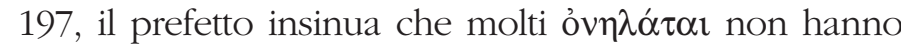
neppure gli animali che sono richiesti di possedere e, prima ancora di recarsi a lavorare in nomi diversi da quello di residenza, non lavorano neppure in quello.

3. Da quanto scrive Q. Aemilius Saturninus non si deve però dedurre che fino all'11 luglio 197, nell'intera Heptanomia, assolutamente non fosse stato incamerato grano : i trasportatori erano pochi, ma c'erano ed erano attivi. Essi, probabilmente, non riuscivano a incamerare grano al ritmo desiderato. La trasmissione del grano pubblico egiziano prevede infatti che il

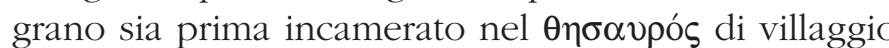
e sia poi di lì portato al Nilo o ai canali. È pertanto ovvio che deve esserci un equilibrio, variamente determinato in base alle diverse distanze da percorrere,

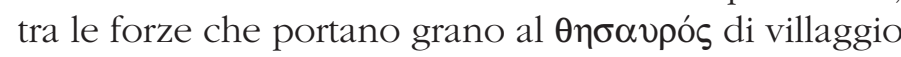
e quelle che di lì lo portano al punto di imbarco. Una campagna militare in corso o imminente può allungare i tempi dell'incameramento del frumento pubblico sia

149. Secondo Oertel (op. cit., p. 116, nt. 6 : « [...] Transport zum

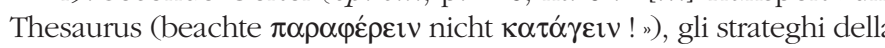
Heptanomia si riferirebbero agli immagazzinamenti ai $\theta \eta \sigma \alpha v \rho o ́$ di villaggio e non ai trasporti da questi ai punti di imbarco. Per l'uso di

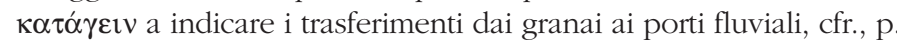
es., BGU 607, 11. 15-16, citato supra, nt. 137 ; oppure PGraux 30

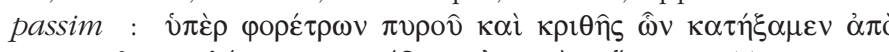

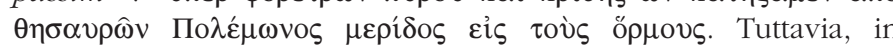

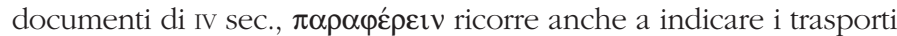
fino ai porti fluviali, cfr. BAGNALL R.S., PCol VII, p. 94. perché può richiedere a una forza lavoro oltre un certo limite non incrementabile la movimentazione di un più cospicuo prelievo fiscale (e ciò deve essere accaduto negli anni della campagna partica di Lucio Vero) sia perché può reclamare il rapidissimo invio di una prima quantità di cereali a essa assolutamente indispensabile, ciò che potrebbe essere accaduto nel 197, quando l'inizio della seconda campagna partica di Settimio Severo, avviata qualche mese dopo la circolare inviata da Q. Aemilius Saturninus, dovette richiedere il tempestivo invio, prima della fine dell'estate, di un notevole quantitativo di grano.

C'è da ritenere che col suo zelo, e malgrado la scarsa navigabilità dei canali, Saturninus fosse riuscito a far arrivare ad Alessandria prima del 17 Epeiph (= 11 luglio) una parte del grano necessario. Quel parziale successo, però, dovette essere pagato con un ritardo delle operazioni di incameramento, tale che i $\theta \eta \sigma \alpha v p o i ́$ di villaggio dell'intera Heptanomia, a un certo punto, risultarono inopinatamente vuoti. Ciò potrebbe illuminare un sottinteso nelle giustificazioni con cui gli strateghi cercano di discolparsi di fronte al prefetto. Nel comunicargli di non avere grano per lo scarso numero di trasportatori, essi volevano probabilmente anche alludere allo squilibrio tra i relativamente pochi animali che trasportavano grano ai $\theta \eta \sigma \alpha v \rho o ́$ e i relativamente molti che lo portavano ai punti di imbarco : la necessità di portare subito al Nilo il grano da mandare in Siria doveva aver costretto a ritardare le operazioni di incameramento, lasciando sulle aie più grano del solito.

Merita, finalmente, di essere messa in particolare risalto l'estensione geografica del fenomeno considerato : i ritardi sarebbero stati meno sorprendenti, se si fossero limitati al solo nomo Arsinoite, dove l'urgenza di inviare comunque al Nilo dei quantitativi di grano doveva misurarsi con la temporanea impraticabilità di molte delle vie d'acqua laterali. Non spiegabile in questi termini è invece il ritardo nel resto della Heptanomia, le cui terre, assai più vicine al Nilo, sono oltretutto gravate da prelievi granari assai meno importanti. Se il 17 Epeiph 197, malgrado le misure e gli allarmi del prefetto, persino lì l'immagazzinamento del grano pubblico era in ritardo, dovremo dedurre che ciò è determinato da alterazioni profonde della società egiziana rispetto, p. es., ai tempi della campagna partica di Lucio Vero. 


\section{MeSORE 185, MERIS DI HERAKLEIDES : TRIBUTI PREVISTI E INCAMERATI}

1. In POxy 4527 col. I sono annotate una dopo l'altra due liste di derrate misurate in artabe, che entrambe cominciano con enormi quantitativi di grano, precisati fino a frazioni minime di artaba : 814,862 e 1/2 1/3 1/24 $1 / 48$ 1/96 e, rispettivamente, 223,581 e 1/3 1/12. L'identità delle altre derrate, che ammontano a misure assai più modeste, era precisata nella parte perduta della colonna. Dalle 1l. 2-6 si è giustamente dedotto che quelli elencati nella prima lista (11. 7-13) sono i tributi dovuti dalla meris di Herakleides del nomo Arsinoite per

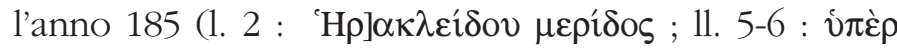

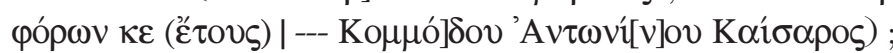
mentre, elencato nella seconda lista (11. 15-17), è quanto dei tributi dovuti risultava essere stato effettivamente incamerato (1. 14 : $\varepsilon \delta \eta \lambda] \omega ́ \omega \eta \eta \sigma \alpha \nu \mu \varepsilon \mu \varepsilon \tau \rho \hat{\eta} \sigma \theta \alpha \imath$ ) entro un arco di tempo delimitato da (un giorno de)l mese di Mesore (1. 15).

Questo documento è subito apparso di eccezionale importanza per almeno tre motivi : la vastità dell'imponibile cui si riferisce ${ }^{150}$, la quantità di grano che da quel pur vasto imponibile si dovrebbe prelevare nel $185^{151}$, l'enigmatica differenza tra quanto grano si dovrebbe prelevare dalla meris di Herakleides $(814,862$ e $1 / 21 / 31 / 241 / 48$ 1/96 artabe) e quanto (223,581 e $1 / 31 / 12$ artabe) risulta prelevato in un periodo di tempo delimitato da( un giorno de)l mese di Mesore.

L'altissimo numero di artabe di grano è stato spiegato da R.S. Bagnall con l'eccezionale predominanza, nel nomo Arsinoite, della terra pubblica $(\beta \alpha \sigma \imath \lambda \iota \kappa \hat{~ o ~}$ $\left.\delta \eta \mu о \sigma^{\prime} \alpha\right)$ e i considerevoli proventi granari che essa produceva in età altoimperiale ${ }^{152}$. Lo stesso Bagnall ha interpretato la notevole differenza tra le artabe di grano richieste e quelle che risultano effettivamente consegnate in un periodo di tempo delimitato da (un giorno de)l mese di Mesore riferendo queste ultime agli incameramenti di questo solo mese : se "comparable amounts" fossero stati immagazzinati nel mese di Payni e in quello di Epeiph, "the main threshing months ", la quantità complessivamente prelevata tra Payni e Mesore si sarebbe non di molto discostata da quella specificata a $1.7^{153}$.

P. van Minnen ha invece negato che i resti della 1. 15 possano consentire una restituzione nel senso ipotizzato da Bagnall ${ }^{154}$ e ha invece riferito la seconda quantità di grano a un diverso arco temporale, che andrebbe dall'inizio dei prelievi, nel mese di Pachon, fino all'ultima delle Epagomenai ${ }^{155}$, ritenendo che il documento fotografi lo stato delle entrate alla chiusura o quasi dei prelievi fiscali : assai poco grano resterebbe ancora da incamerare e il grande scarto che separa la quantità di grano richiesta da quella effettivamente versata fino ad allora darebbe la misura del "deep trouble " in cui si troverebbe il nomo Arsinoite nel 185.

Proiettate sul più generale dibattito sugli effetti della " grande peste ", queste due diverse interpretazioni di POxy 4527 hanno suggerito giudizi opposti circa le ricadute che l'epidemia avrebbe avuto sulle capacità produttive della meris di Herakleides : esse dovrebbero essere state assai limitate o addirittura nulle, se le 223,581 artabe di grano di 1.15 rappresentassero gli incameramenti del solo mese di Mesore 185 e se un all'incirca eguale numero di artabe fosse stato incamerato nel mese di Payni e in quello di Epeiph ; se invece le 223,581 artabe raffigurassero il totale delle entrate granarie tratte da Pachon all'ultima delle Epagomenai, si sarebbe portati a credere che quelle epidemie abbiano avuto conseguenze gravi sull'economia agricola almeno di questa parte dell'Egitto, non essendo facile ammettere, in assenza di ulteriori indizi156, che l'inondazione del 184 sia stata a tal punto disastrosa da consentire prelievi solo per

150. La superficie complessiva della meris di Herakleides è stat stimata in circa $600 \mathrm{~km}^{2}$ dall'editore P. Schubert, ad loc, 2001 , p. 193

151. 814,862 artabe sono oltre 3,600,000 modii italici, ciò che significa un prelievo medio " lordo " di oltre 6,000 modii per $\mathrm{km}^{2}$, se è appunto di circa $600 \mathrm{~km}^{2}$ la superficie della meris di Herakleides. Poiché l'estensione degli arativi soggetti a tassazione in grano sarà stata inferiore a $600 \mathrm{~km}^{2}$ (pensa a non piè di $430 \mathrm{~km}^{2}$ BAGNAu $\mathrm{R} S$. P.Oxy. 4527, 2000, p. 288-289) il prelievo medio per unità di superficie arata sarà stato ben superiore a quei, già altissimi, valori. 152. Bagnall R.S., op. cit., p. 289

153. Bagnall R.S., op. cit., p. 289 ; 291 : "Moreover, it appears from 1.15 as if some 223,581 artabas were declared to have been paid in Mesore ; if something like comparable amounts came during Pauni and Epeiph, the main threshing months, the total Pauni and Epeiph, the main threshing months, the
[sc. 814,862] would not have been far off being achievable ".

154. VAn Minnen P., P.Oxy. LXVI 4527, 2001, p. 175-177.

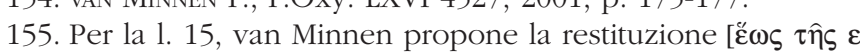

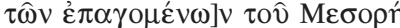

156. Bonneau D., Le fisc et le Nil, 1971, p. 251 
poco più del $27.5 \%$ di quanto normalmente dovuto $\mathrm{O}$ comunque preventivato.

2. Per parte mia, osserverei che a sostegno dell'interpretazione di Bagnall, si potrebbe ricordare la periodicità mensile di tanta parte della contabilità relativa al grano pubblico. In particolare, poiché POxy 4527 riassume le entrate di un'intera meris, si

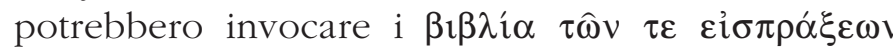

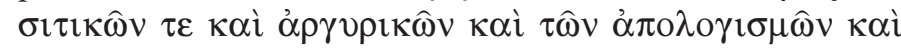
$\tau \hat{\omega} \nu \stackrel{\alpha}{\lambda} \lambda \lambda \omega \nu$ che strateghi e basilikoi grammateis erano tenuti a inviare mensilmente $(\kappa \alpha \tau \dot{\alpha} \mu \hat{\eta} v \alpha)^{157}$ ad Alessandria. Tale prassi è evocata in una circolare databile tra l'8 Thoth e lo Hathyr 194'158, in cui il procurator Neaspoleos Sallustius Macrinianus deplora il

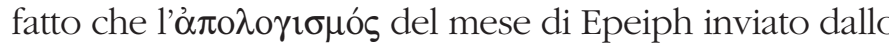
stratego del nomo Saita sia stato registrato nell'ufficio

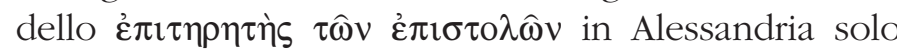
nell'ottavo giorno del mese di Thoth, ben oltre, si deve supporre, la $\pi \rho 0 \theta \varepsilon \sigma \mu i \alpha$ fissata dai precedenti prefetti per la registrazione mensile di tali atti.

L'argomento però non è decisivo, perché è possibile che nel 185 tale prassi non fosse stata ancora imposta : a essa infatti non potevano attenersi né i vertici amministrativi del nomo Ossirinchite nel 134, i quali soltanto l'ultimo giorno di Phamenoth ricevono dal sitologo di Sinkepha il rendiconto mensile del mese di Mechir ${ }^{159}$, né i vertici della meris di Themistos nel 154, i quali solo all'ultima delle Epagomenai

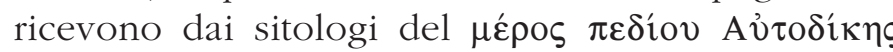

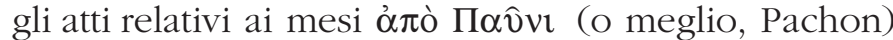

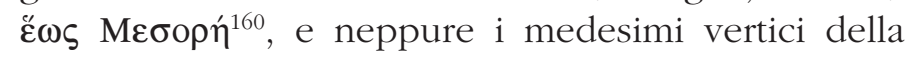

157. WilcKen U., APF, 4, 1908, p. 127 ; KRUSE Th., Der königliche Schreiber, 2002, p. $339 ; 650$.

158. $S B 13175$

159. POxy 515.

160. PAmb 69, 11. 1-19 (=WChr 190): 3 m. દ̉ $\pi(\alpha \gamma o \mu \varepsilon ́ v \omega v) \bar{\varepsilon} 1 \mathrm{~m}$.

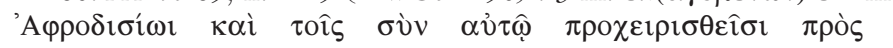

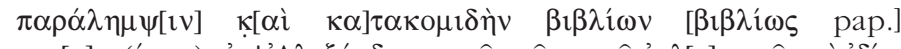

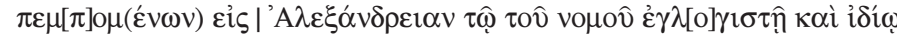

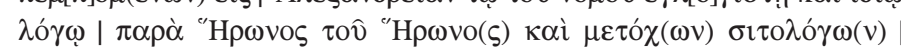

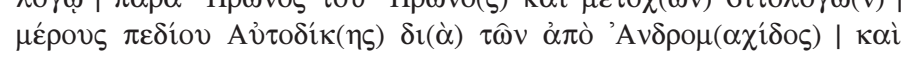

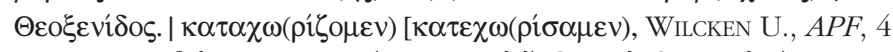

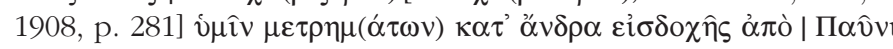

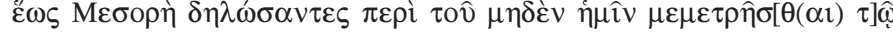

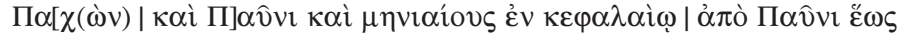

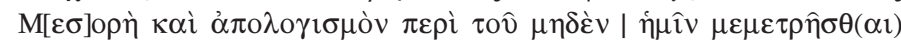

meris di Themistos nel 174, quando ricevono in blocco,

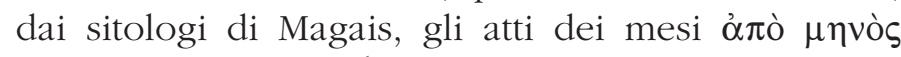

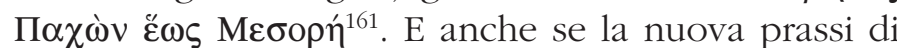
inviare rapporti mensili fosse stata istituita dopo il 174 ma prima del 185, sarebbe sempre possibile che essa avesse lasciato sopravvivere la più antica abitudine di

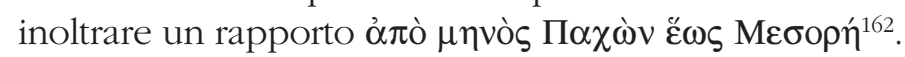

A favore della lettura di van Minnen, si potrebbe d'altra parte invocare il senso stesso del confronto tra la prima e la seconda lista di derrate, tra quali cioè dovrebbero essere i $\varphi$ ópo del venticinquesimo anno di Commodo e quante artabe invece $\dot{\delta} \delta \eta \lambda] \omega ́ \theta \eta \sigma \alpha \nu$ $\mu \varepsilon \mu \varepsilon \tau \rho \varepsilon \hat{\imath} \sigma \theta \alpha \boldsymbol{l}$ (1. 14) entro un certo periodo di tempo delimitato da un certo giorno di Mesore. Potrebbe infatti sembrare pleonastico e in definitiva poco logico che fosse confrontato con il totale dei tributi dovuti nell'anno venticinquesimo di Commodo il totale delle entrate dell'unico mese di Mesore, senza ricordare gli introiti dei mesi precedenti : quale utilità pratica potrebbe avere avuto un simile confronto ? Più funzionale e comprensibile, invece, sarebbe che col totale delle imposte dovute si confrontasse il totale dei prelievi al momento in cui il documento fu redatto. Tuttavia, neppure questo argomento mi sembra decisivo, potendosi ipotizzare che il totale degli introiti in natura da Pachon a Mesore fosse annotato nella col. II del papiro, la quale contava almeno 15 linee, quasi interamente perdute. Il testo potrebbe dunque aver riportato prima il totale dei tributi in natura dovuti, poi quelli incamerati nel solo mese di Mesore e finalmente quelli da Pachon a Mesore.

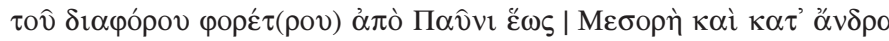

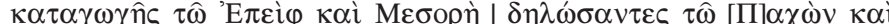

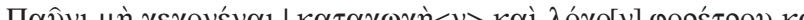

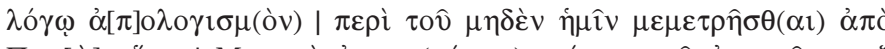

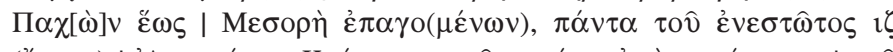

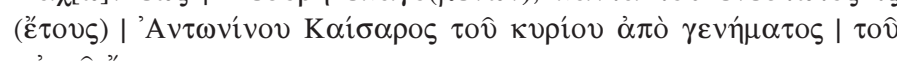

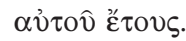

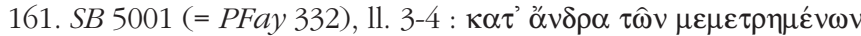

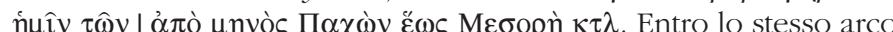
temporale dovevano iscriversi le registrazioni dei sitologi di Bernikis Aegialu nel 149: BGU 1893

162. Vale la pena di notare che in PBerlLeihg 12, del 210, i sitolog di Euhemereia riconoscono i versamenti eseguiti da Pachon a Phaophi, ma, prima del totale finale, elaborano due totali parzial (11. $14 ; 19)$, il secondo dei quali dopo Mesore e prima di Thoth. 
In attesa di un'auspicabile, ma non saprei quanto probabile scoperta che ce ne restituisca le parti mancanti, le nostre possibilità di interpretare $P O x y$ 4527 dipendono in ultima analisi da come prefiguriamo il contesto economico-sociale cui i quantitativi di grano lì registrati si riferiscono. È lecito cogliere nella differenza tra le artabe di grano da riscuotere e quelle già riscosse la prova e la misura di un crollo della produzione agricola della meris di Herakleides dopo le epidemie degli anni precedenti ? La stessa ampiezza del divario non corrobora invece l'obiezione di Bagnall, il quale ha insistito sulla difficoltà di ammettere che gli obbiettivi fiscali indicati nella prima lista siano solo " paper figures ", fissate prima della peste antonina e mai ritoccate dopo di essa ${ }^{163}$ ? E d'altra parte, però : è possibile che la meris di Herakleides da poco sommersa dalla seconda ondata di peste incamerasse grano pubblico a una velocità di circa 6,455 artabe al giorno $^{164}$ ? Se tale fosse stato il ritmo normale di incameramento negli ultimi anni di Commodo, avrebbe avuto bisogno Q. Aemilius Saturninus di aumentare

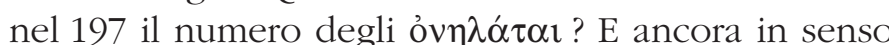
opposto: è possibile che delle campagne che producono introiti granari per 814,862 artabe portino

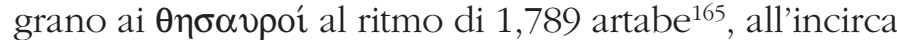
lo $0.20 \%$, al giorno ${ }^{166}$ ? A quella media, per incamerare l'intero quantitativo richiesto, ci sarebbe voluto più di un anno.

\footnotetext{
163. Bagnall R.S., P.Oxy. 4527, 2000, p. 291 : "Even if we were to assume that in the immediate aftermath of the plague the government resisted reducing assessments and ignored the abandonment of land, it is difficult to imagine that after nearly two decades and a second wave of plague the administration would have carried on, resolutely listing uncollectable amounts ".

164. Tante si ricavano dividendo per i 35 fiorni da Mesore 1 a Epagomenai 5 le 223,581 artabe di POxy 4527 col. I, 1. 15.

165. Tante risultano distribuendo sui 125 giorni che vanno da Pachon 1 a Epagomenai 5 le 223,581 artabe di POxy 4527 col. I

166. A tanto corrispondono le 1,789 artabe rispetto alle 814,862
} 1. 15 . totali.

\section{IL RITMO DI INCAMERAMENTO NEL NOMO ARSINOITE}

1. Occorre premettere una pregiudiziale metodica: neanche in Egitto il ritmo di incameramento e trasmissione del grano pubblico è un dato, per così dire, naturalmente stabile. Anche lì è una variabile dipendente dalle risorse che la società è in grado di mettere a disposizione dell'amministrazione imperiale. Abbiamo sopra rilevato come tra 174 e 194, i prefetti d'Egitto abbiano imposto l'obbligo a strateghi e basilikoi grammateis di inviare mensilmente dei rapporti sull'andamento delle entrate fiscali nelle unità amministrative di loro competenza. Questo più puntuale monitoraggio della velocità di incameramento del grano pubblico in tutta la valle del Nilo e non solo nel nomo Arsinoite tradisce un'ansia evidentemente prima non conosciuta dall'amministrazione imperiale, la quale ora vuole essere messa al corrente mese per mese dei progressi delle entrate fiscali della provincia. Il fatto che nel 194 sia il procurator Neaspoleos a richiamare strateghi e basilikoi grammateis a uno scrupoloso rispetto di queste norme dimostra che le preoccupazioni più precisamente riguardavano le entrate di grano pubblico da trasmettere fuori dall'Egitto : a Roma certo, ma, in quel momento, anche in Siria, dove Settimio Severo preparava già la sua prima campagna partica ${ }^{167}$

2. Di conseguenza, non mi sentirei di condividere un assunto comune alle peraltro opposte interpretazioni di Bagnall e van Minnen, e cioè che nel 185 le operazioni di immagazzinamento del frumento pubblico nella meris di Herakleides dovessero essere sostanzialmente concluse entro il mese di Mesore o non molto dopo. Ritenendo che la quantità di grano menzionata a 1.7 sia stata raccolta in quello stesso mese e che a essa si debbano aggiungere "comparable amounts " raccolti nei "main threshing months" di Payni ed Epeiph, Bagnall implicitamente assume che quasi tutto il grano della meris di Herakleides fosse incamerato prima della fine di Mesore. Dal canto suo, van Minnen afferma di aver l'impressione che la maggioranza delle ricevute

167. Halfmann H., Itinera principum, 1986, p. 219-220. 
dei sitologi sia datata agli ultimi tre mesi dell'anno egiziano, appunto Payni, Epeiph e Mesore, escludendo pertanto la possibilità che le operazioni di immagazzinamento si prolungassero in maniera significativa nei mesi successivi ${ }^{168}$.

In realtà, anche prima della grande peste o qualche decennio dopo di essa, le operazioni di incameramento appaiono prolungarsi oltre Mesore, quando le campagne militari facevano lievitare i tributi granari del nomo Arsinoite : considerevoli incameramenti di grano erano, p. es., ancora in corso a Euhemeria nel mese di Phaophi di un anno intorno al $163^{169}$; sempre a Euhemereia, nel mese di Hathyr 163, si registra l'ingresso di 2,436 artabe (una media di più di 81 artabe al giorno) $)^{170}$; a Karanis, nel mese di Hathyr 216, quasi 3,938 artabe risultano incamerate nei suoi

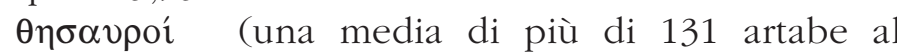
giorno $)^{171}$. Può presumersi che qualcosa del genere sia accaduto nel 185 ? Non escluderei che le res bene gestae $^{172}$ in Sarmatia nel 185 abbiano causato un qualche aumento dei tributi granari egiziani e una qualche dilatazione dei tempi del loro incameramento e neppure che la contemporanea requisizione di

\footnotetext{
168. van MinNen P., P.Oxy. LXVI 4527, 2001, p. 176 : "I have not made a thorough search of the extant "sitologus receipts" [...], but I have the impression that the majority are dated in the last three months of the Egyptian year [...] The percentage of wheat actually collected until the end of the Egyptian year is only $27.5 \%$ of the projected figure. I do not think it very likely that after the end of the Egyptian year the deliveries of wheat would continue unabated until they also reached $45 \%$ [...] Therefore I think that the figure for wheat eventually delivered by them need not be corrected upwards to $45 \%$, but rather to somewhat closer to $27.5 \%$, perhaps $30-35 \%$ at most

169. PStras 849. Con i seguenti numeri di artabe immagazzinate in singoli giorni : 73, 313, 116, 231, 434, 329 e 161. Il documento è da confrontare con PFay 86, di un anno imprecisato del II sec., dove nell'intero mese di Phaophi risultano incamerate da contribuenti provenienti da vari villaggi tra cui Theadelphia ed Euhemereia solo 432 artabe.

170. PStras 570

171. $B G U 2076$

172. H.A., C 6, 1 : eo tempore in Sarmatia res bene gestas per alio duces in filium suum Perennis referebat ; Cass. Dio LXXII 8, 1

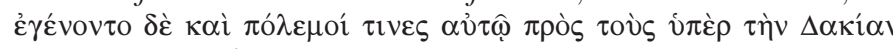

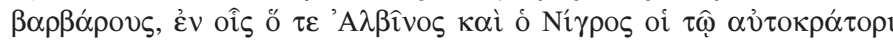

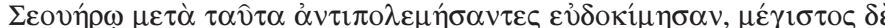

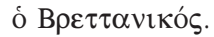

cammelli maschi nella meris di Herakleides ${ }^{173}$ abbia in qualche misura condizionato il trasporto del suo frumento pubblico. Tuttavia, si deve riconoscere che queste circostanze non bastano, da sole, a giustificare un ritmo di incameramento di solo 1,789 artabe al giorno per l'intera meris di Herkleides nel periodo che va da Pachon all'ultima delle Epagomenai.

3. Non saprei trarre indicazioni troppo precise dal confronto con dati parziali, relativi a singole sitologie, a periodi più brevi e ad anni anteriori alla seconda ondata della peste : $B G U$ 1893, che attesta come a Bernikis Aegialu nel mese di Payni 149 fossero immagazzinate 4,892 artabe $^{174}$ (per una media di circa 163 artabe al giorno) e il mese successivo 4,415 (1. 518 poco più di 147 artabe al giorno) ; PBerlLeihg 4 recto e verso (= SB 7196 recto e verso), che mostrano come a Theadelphia, nella meris di Themistos, nei diciotto giorni che vanno dal 16 di Payni al 4 di Epeiph 165 si fossero incamerate più di 5,400 artabe (con una media

173. In PPetaus 85, il komogrammateus di Kerkesucha Orus e altri villaggi, rispondendo allo stratego che gli aveva chiesto un

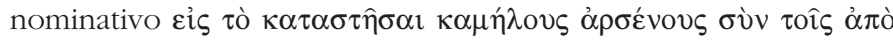

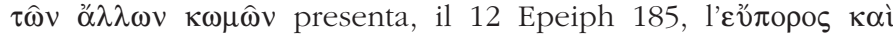
$\dot{\varepsilon} \pi \imath \tau \hat{\delta} \delta \varepsilon \iota \varsigma$ designato. L'ipotesi che i cammelli maschi richiesti dovessero servire all'incameramento e alla trasmissione del frumento pubblico non appare molto probabile, sia per il giorno in cui Petaus risponde allo stratego sia perché sappiamo che cammelli della meris di Herakleides potevano essere requisiti per diverse altre ragioni. Nel Mechir del 163, essi risultano impiegati,

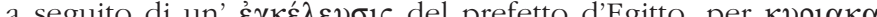

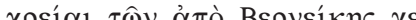

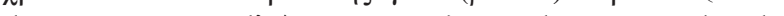

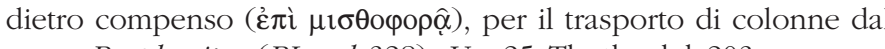
mons Porphyrites (PLond 328). Un 25 Thoth, del 203 con ogni probabilità, un'autorità militare con sede a Babylon richiede a una serie di nomi, tra cui quello Arsinoite, cammelli maschi in grado di resistere alle fatiche delle $\pi$ opeîa : il fatto che nell' Epeiph 185 siano stati espressamente richiesti cammelli maschi, proprio come

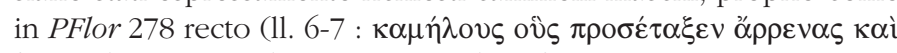

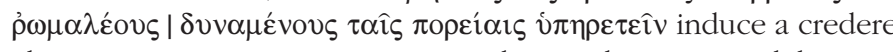
che essi servissero per scopi non legati al trasporto del grano pubblico, ma connessi, forse, a quelli che rendono necessaria la contemporanea requisizione di 20,000 artabe di orzo nel nomo Coptos: DarIs S., Carte dello stratego Damarion, 1992, p. 23-59. Requisizioni di cammelli per l'ala Herculiana sono presupposte, comunque si restituisca la 1. 7, da PBas 2, del 28 Thoth 190 cfr. Cuvigny H., Claudius Lucilianus, 2001, p. 171-174.

174. Così (1. 148) nell'edizione a stampa ; in DDBDP, viceversa, si legge 2,892 . 
di circa 300 artabe al giorno) e che quella media salisse a quasi 400 artabe al giorno dall'1 all'8 Epeiph ; PBerlLeihg 11, che mostra come dal 9 al 14 Mesore 168 a Theadelphia 857 artabe fossero incamerate (con una media di circa 143 artabe al giorno) ; PFay 86a, che mostra come a Theadelphia dall'1 al 10 Epeiph di un anno compreso tra il 161 e il 169 fossero incamerate 3,807 artabe (con una media di circa 346 artabe al giorno) ; PAmb 69, 11. 7-19 (= WChr 190), che mostra infine come nel 149 passassero mesi interi - Pachon e

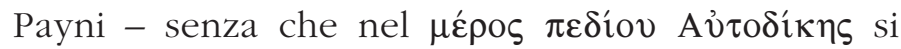
incamerasse una sola artaba ${ }^{175}$.

Che generalmente il ritmo di incameramento del grano pubblico nel nomo Arsinoite nel periodo che grosso modo va da Antonino Pio a Caracalla dovesse essere assai più rapido del poco più dello $0.20 \%$ al giorno da Pachon a Mesore sembra però certo. Infatti, se così non fosse, ci aspetteremmo che la documentazione a nostra disposizione, pur parziale, in qualche modo riflettesse un analogo sbilanciamento, con testimonianze di acquisizioni di grano nel periodo successivo a Mesore di gran lunga più consistenti, all'incirca triple, rispetto al periodo anteriore a quel termine. Al contrario, i rendiconti delle entrate granarie

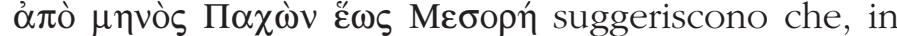
anni normali e almeno fino al 174, il grosso delle entrate granarie fosse incamerato in quei mesi, proprio come assumono Bagnall e van Minnen.

4. Ma vale anche tutto ciò per l'età di Commodo e, più in particolare, per gli anni più vicini al 185 ? Significative, anche perché pertinenti al periodo immediamente successivo alla seconda ondata di peste, mi sembrano delle ricevute di Sedment, se queste, come riterrei, sono state emesse nello stesso giorno in cui il grano trasportato è stato incamerato nei $\theta \eta \sigma \alpha v \rho o u ́$ di villaggio. Considerando i documenti datati, completi di mese, all'età di Commodo, di ventuno ricevute, undici risultano emesse prima di Mesore ${ }^{176}$, dieci dopo quel termine ${ }^{177}$. Se poi si raffina ancora l'analisi,

175. Cfr. supra, nt. 160

176. OWilck 1091 ; 1097 ; $1102 ; 1103 ; 1105 ; 1106 ; 1107 ; 1108$ $1109 ; 1110 ; 1111$

177. OWilck 1092 ; 1093 ; $1094 ; 1095 ; 1096 ; 1098 ; 1100$; 1101 ; $1112 ; 1113$. limitandola agli anni 181-189, si scopre che sono solo due le ricevute emesse prima di Mesore ${ }^{178}$ e invece otto quelle dopo quel termine ${ }^{179}$. L'indizio, va riconosciuto, è esile, ma concordante con quanto si deduce dalle rendicontazioni mensili delle entrate fiscali rese obbligatorie tra 174 e 194 e dall'esigenza, avvertita nel

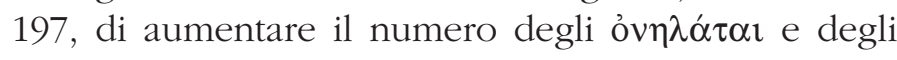
asini in tutta la Heptanomia.

Tutto ciò induce a presumere che negli anni intorno al 185 il ritmo di incameramento fosse a tal punto rallentato da far slittare a dopo Mesore la maggior parte delle acquisizioni e che nel 185, nella meris di Herakleides, gli incameramenti di grano pubblico non si concludessero con l'ultima delle Epagomenai : anzi, gran parte dei tributi granari del venticinquesimo anno di Commodo dovette essere stata incamerata a partire dal mese di Thoth. Pertanto, se le 223,581 artabe di POxy 4527 col. I 1. 15 sono state incamerate nel solo mese di Mesore, difficilmente quegli introiti saranno stati preceduti, nei mesi di Payni ed Epeiph, da incameramenti comparabili. Se invece esse sono state acquisite nel periodo che va da Pachon a Mesore, non per questo si dovranno presupporre dei crolli nella produzione agricola egiziana : nel 197, il prefetto d'Egitto Q. Aemilius Saturninus è in difficoltà non perché la provincia non riesca a produrre i programmati proventi granari, che in quell'occasione sono chiamati a sostenere tanto i consumi della città di Roma, che le necessità della campagna partica, ma perché, malgrado l'aumento del loro numero, la

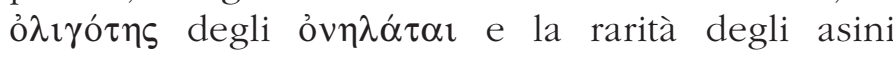
rallentavano in maniera preoccupante la mobilità di quei quantitativi di grano.

5. Finalmente, un confronto con un documento più lontano nel tempo, ma relativo a tributi di scala comparabile. BGU 802 mostra come, nel 42, dalle merides di Themistos e Polemon o da una parte di esse, si riuscisse non solo a incamerare, ma addirittura a portare al Nilo ben 270,808 artabe prima del 23 Epeiph, ciò che fa ritenere il ritmo di incameramento e trasmissione superiore alle 3,262 artabe al giorno. Lo stesso documento mostra come dal 23 Epeiph fino a

178. OWilck $1091 ; 1097$.

179. OWilck $1092 ; 1093 ; 1094 ; 1095 ; 1096 ; 1098 ; 1100 ; 1101$ 
oltre il 20 Mesore neppure un'artaba sia stata trasmessa. Evidentemente, in età giulio-claudia, la maggiore densità demografica e le dimensioni relativamente modeste del tributo granario all'annona di Roma dovevano consentire un'agilità di gran lunga superiore all'Egitto da poco uscito dalla " grande peste ", dove ci sono sì considerevoli surplus granari, ma anche assai pochi uomini e asini per trasferirli. Le 270,808 artabe di cui BGU 802 documenta il trasferimento sono all'incirca

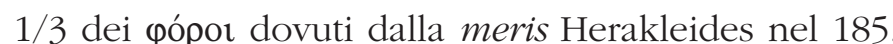
ma è probabile che esse rappresentino, se non la totalità, certamente il grosso dei tributi granari esportati

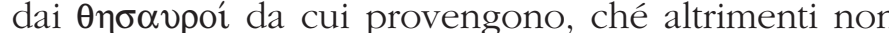
sapremmo spiegarci la pausa dei trasferimenti di grano sopraggiunta dopo il 23 Epeiph. Di quelle 270,808 artabe ben 267,896 , entro la stessa data, risultavano spedite ad Alessandria, pronte a essere imbarcate per l'Italia.

6. Il calo demografico sopraggiunto colla peste antonina non determina un catastrofico crollo della produzione agricola egiziana e neppure un'inadempienza fiscale assolutamente dilagante e incoercibile, sebbene anteriori tendenze in tal senso ${ }^{180}$ possano essersi, in quella congiuntura, in qualche misura accentuate. L'altissimo numero di artabe richieste alla meris di Herakleides dimostra, e Bagnall ha il merito di averlo per primo ravvisato, che la produttività non è precipitata nel 185 e che una quantità di grano pubblico considerevole, probabilmente molto maggiore che nel I sec. d.C., poteva di lì essere messa a disposizione dell'esercito e della città di Roma ${ }^{181}$.

I riflessi del depauperamento demografico provocato dalla peste, soprattutto dalla sua seconda ondata, diventano però evidenti quando si considerano i problemi del trasporto del grano pubblico : la lentezza con cui le campagne egiziane sopravvissute alla peste raccolgono e trasmettono le loro tasse in grano tradisce l'erosione demografica che in quegli anni - gli ultimi di Commodo, i primi di Settimio Severo - le debilita.

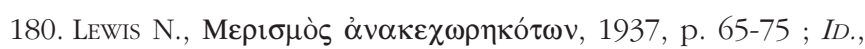
Reversal of a Tax Policy, 1993, p. 101-118

181. In questo contesto, con un accresciuto ruolo della flotta alessandrina, potrebbe meglio spiegarsi la devozione che i suoi

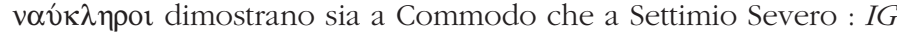
XIV $918=$ IPort $2 ;$ IG XIV $917=$ IPort 3.

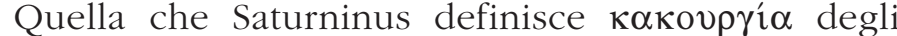

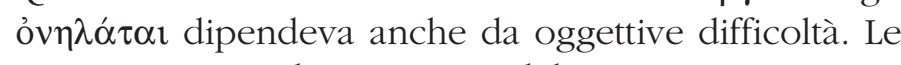
sue accuse, anche se in qualche misura potevano essere fondate, tradiscono piuttosto la cattiva coscienza di chi è consapevole della gravosità, in quel momento, della $\tau$ proví $\alpha$. La peste, lo abbiamo già detto, aveva

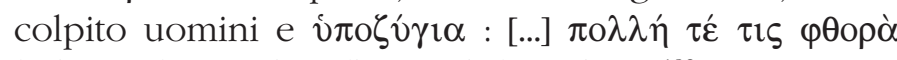

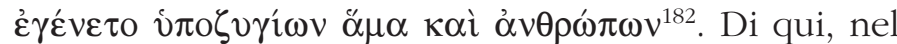
197, la necessità di reintegrare il numero degli

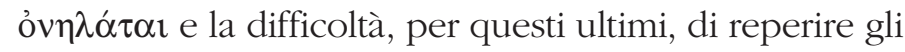
animali necessari.

Dalle gravi perdite di uomini subite nel 178/179 ${ }^{183}$, Soknopaiu Nesos avvertirà le conseguenze ancora nel 186 o 187, quando non solo i sacerdoti del villaggio sono 160 (erano stati 244 prima del 178), ma anche le esenzioni fiscali loro concesse appaiono scese, evidentemente a seguito della forte contrazione demografica, da 100 a $20^{184}$. Se la popolazione dei suoi cammelli, importantissimi per il trasporto del grano pubblico della meris di Herakleides e anzi di tutto il nomo Arsinoite, avesse subito analoghe decurtazioni, la lentezza del ritmo di incameramento che in qualche modo si riflette in POxy 4527 sarebbe meno enigmatica.

\section{SI FORTE ALEXANDRINA FRUMENTA CESSASSENT}

1. Come dimostra la già ricordata multa minacciata in caso di una spedizione da Alessandria dopo la fine di agosto, in età giustinianea, quando dal nomo Arsinoite si traeva molto meno grano che in passato, il grano

\section{Herod. I 12, 1}

183. Di 224 ö $v \delta \rho \varepsilon \varsigma$ ben 80 muoiono e solo 5 se ne aggiungono perché da poco adulti tra Choiak e Mechir : SB 12816. Seguo MesserI

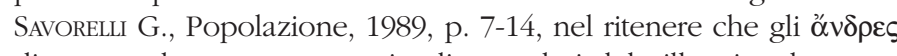
di questo documento sono i soli sacerdoti del villaggio ; la stessa studiosa ritiene che i 135 ö vopes di $S P P$ XXII $67+167$ (= SB 11715), del 208/209, rappresentino il totale dei maschi adulti non sacerdoti. Diversamente, secondo HobsoN D.W , PVindob.Gr. 24951+24556, 1984, p. 847-864, tanto i 169 di $S B 12816$ quanto i 135 di $S P P$ XXII 67 + 167 sarerebbero tutti i maschi potenzialmente tassabili.

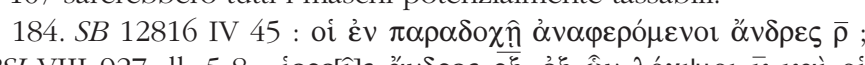

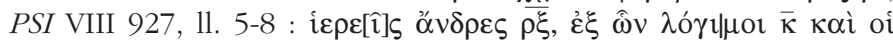

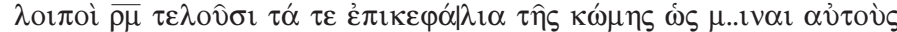

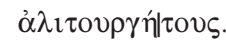


fiscale destinato all'annona di Costantinopoli doveva essere immagazzinato e trasmesso ad Alessandria nel periodo che va da Pachon a Mesore. Ciò però non era necessario in età altoimperiale, per il grano da trasferire a Roma. Allora i più lunghi tempi di navigazione obbligavano a spedire i tributi granari in due riprese : la prima, coincidente grosso modo con i tempi della spedizione giustinianea ${ }^{185}$, la seconda, alla riapertura della navigazione, la primavera successiva ${ }^{186}$. Pertanto, se una parte del grano egiziano destinato a Roma doveva comunque "svernare " in Egitto, poteva non essere considerato necessario affannarsi a immagazzinare e trasmettere tutto il grano pubblico prima della fine di Mesore. Tanto meno dal nomo Arsinoite, dove la distanza dal Nilo e la quantità di grano prelevata rendeva quelle operazioni meno semplici che altrove, soprattutto se tentate durante i mesi di Pachon o Payni, quando molti dei canali non erano ancora navigabili. Contenuti entro certi limiti, questi tardivi incameramenti non portavano pregiudizio al corretto funzionamento degli approvigionament granari di Roma.

Di per sé, il fatto che solo il $27.5 \%$ del grano fiscale fosse stato incamerato dalla meris di Herakleides alla fine di Mesore del 185 avrebbe potuto anche non arrecare danni al sistema di rifornimento granario della città di Roma : le quasi 600,000 artabe che ancora restavano da

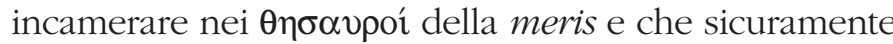
non sarebbero state spedite in Italia prima della chiusura della navigazione, sarebbero potute restare in Egitto per la semina dell'anno successivo e per i bisogni delle truppe di stanza nella provincia oppure essere inviate alla riapertura della navigazione. Ma se, insieme alle artabe della meris di Herakleides, anche altro grano pubblico egiziano fosse stato incamerato con un ritardo tale da renderne impossibile la spedizione in Italia prima della chiusura della navigazione, la stessa regolarità dei

185. Non è detto tuttavia che tutte le navi partite prima della chiusura della navigazione giungessero in Italia prima della primavera successiva, come mostra la navigazione di Paolo (Act. apostol. 27, 6-28, 13) e della Isis lucianea (Lucian., nauig. 7-9).

186. Le navi alessandrine che approdano in Italia nell'ultima decade di maggio (POxy 2191 ; PMich $490 ;$ 491) avranno portato frumento pubblico dell'anno precedente. Eccezionalmente, spedizioni di frumento pubblico potevano essere tentate anche nei mesi invernali : Tac., hist. IV 52. consumi di Roma durante i mesi invernali poteva essere messa a rischio.

2. Un passo della Historia Augusta attribuisce a Commodo l'istituzione di una classis Africana, quae subsidio esset, si forte Alexandrina frumenta cessassent $^{187}$. A limitare lo scetticismo con cui questa testimonianza è stata talvolta trattata ${ }^{188}$, si osserverà che malgrado il potente contributo dato dal frumento pubblico africano alla copertura del fabbisogno di Roma sin dal I sec. d.C. ${ }^{189}$ e malgrado i domini nauium Carthaginensium ex Africa e i domini nauium uniuersarum Afrarum noti, rispettivamente, per l'età di Antonino Pio e Marco Aurelio, dalla documentazione epigrafica da Portus e Ostia ${ }^{190}$, è probabile che non esistesse, nei porti del Maghreb, qualcosa di paragonabile a ciò che, sin dall'età giulio-claudia, era la classis Alexandrina ${ }^{191}$ : la dispersione geografica dei terminali portuali, i molto più lenti percorsi terrestri e i molto più veloci tragitti marittimi del grano africano rendevano poco funzionale una flotta granaria africana dalle dimensioni e dalle caratteristiche di quella alessandrina, costituita da grandissime navi, adatte a lunghi tragitti marittimi e a porti collegati all'entroterra per via fluviale.

3. Si possono avere opinioni diverse circa il concreto significato dell'" istituzione " della classis Africana ${ }^{192}$ : molto meno incerti credo si possa essere circa il collegamento tra il passo della Historia Augusta e alcune emissioni monetali di Commodo con leggenda PROVID AVG sul verso ${ }^{193}$. Certo, la celebrazione della prouidentia imperiale non era una novità, ma quando

187. H.A., C 17, 7 : classem Africanam instituit, quae subsidio esset, si forte Alexandrina frumenta cessassent.

188. Cfr., p. es., Pavis D’Escurac H., Réflexions, 1974, p. 397-408 189. Va abbandonata però l'idea, risalente al classico lavoro di PICARD G.Ch., Néron et le blé d'Afrique, 1956, p. 163-173, che già in età giulio-claudia il tributo africano fosse addirittura il doppio di quello egiziano : cfr. ntt. $83 ; 266$

190. ILS 339, dedica ad Antonino Pio ; ILS 6140, dedica del 173 a M. Iulius Faustus, notabile ostiense, mercator frumentarius patronus corporis curatorum nauium marinarum.

191. Sen., ep. 77.

192. Una rassegna in PAVIS D'EscuRAC H., art. cit.

193. Mattingly H., Coins of the Roman Empire, IV, 1940, p. clxiii clxxv ; clxxxi ; ALFÖLDI M.R., Providentia Augusti, 2001 [scr. 1955], p. 158. 
questa viene ripresa, in sestertii della undicesima $(185 / 186)$ e in aureii della dodicesima tribunicia potestas (186/187) di Commodo, in associazione all'immagine di una nave oneraria ${ }^{194}$, difficilmente l'allusione avrà riguardato qualcosa di diverso dai trasporti marittimi del grano fiscale destinato a Roma. E quando la legenda PROVIDENTIAE AVG torna sul verso di aurei e denarii databili al 191 o 192, dove campeggia un Ercole ritto con piede su una prua e una personificazione dell'Africa in atto di stringersi la mano sopra spighe di grano ${ }^{195}$, difficilmente quella dedica e quella raffigurazione potranno essere disgiunte dall'occasione in cui l'ultimo Commodo'196 avrebbe gratificato Cartagine e la classis Africana delle denominazioni, rispettivamente, di Alexandria Commodiana togata e Africana Commodiana Herculea ${ }^{197}$.

4. Quanto abbiamo sopra osservato a proposito del ritmo di incameramento del grano pubblico all'età di Commodo, può aiutare a sciogliere un'ambiguità relativa alle motivazioni della classis Africana. Secondo l'autore dalla Historia Augusta, essa avrebbe dovuto rimediare a eventuali cessationes (si forte Alexandrina frumenta cessassent) di grano alessandrino. L'ambiguità del passo è connessa all'oscillazione di significato del verbo cessare, che può valere cunctari, immorari, moram facere o anche deficere, desinere, deesse ${ }^{198}:$ le occasionali (si forte) défaillances degli Alexandrina frumenta potrebbero dunque consistere in ritardi (cunctari, immorari, moram facere) o in ammanchi (deficere, desinere, deesse). Se quanto abbiamo dedotto sopra dà una indicazione di tendenza per gli anni tra il 180 e il 197, siamo portati a ritenere che Commodo si trovi a fare i conti non tanto con un calo dei provent fiscali egiziani, quanto con un rallentamento delle operazioni di incameramento e di prima trasmissione.

194. RIC III p. 422 , n. 486 ; 487 ; p. 383 , n. 158 ; BMC Imp IV Commodus p. 808 , n. 588 ; p. 730 , n. 225

195. RIC III p. 396, n. 259 ; 259a. BMC Imp IV Commodus p. 755 , n. $355 ; 356 ; 357$.

196. In preda ormai a "commodianismo " : cfr. Grosso F., Lotta politica, 1964, p. 319-320; 341-342; 373-375.

197. H.A., C 17,8 : ridicule etiam Carthagine $<m>$ Alexandriam Commodianam togatam appellauit, cum classem quoque Africanam Commodianam Herculeam appellasset.

198. ThlL s.u.
Quello che si teme, insomma, tra il 180 e il 191/192, è che i rallentamenti delle operazioni di raccolta e trasmissione ad Alessandria del frumento pubblico egiziano, costringendo a posticipare l'invio in Italia di una parte troppo cospicua di esso, impediscano che si raccolga a Roma una quantità di grano sufficiente a far superare il periodo di mare clausum. Il fatto che si cercasse di risolvere il problema puntando sull'Africa tradisce il pessimismo dell'amministrazione circa la possibilità di riaccelerare i tempi di trasmissione del frumento pubblico egiziano.

5. I tempi dettati da Giustiniano per il trasferimento dell'є̇ $\mu \beta \supset \lambda \eta ́$ a Costantinopoli vengono da un'amministrazione che crede, a torto o a ragione, di poter contare su una forza lavoro, umana e animale, e su una dislocazione dei tributi granari lungo la valle del Nilo, tali da far ritenere possibile incamerare e trasmettere all'incirca 300,000 modii al giorno. Invece, un'amministrazione che sente il bisogno di essere informata mensilmente sui progressi delle entrate fiscali, che chiede inoltre alla disagevole meris di Herakleides ben 814,862 artabe $(=3,666,879$ modii $)$, ma, quali e quante ne siano le concause congiunturali, deve rassegnarsi a incamerarne parte cospicua dopo l'ultima delle Epagomenai, è un'organizzazione in evidente affanno. $\mathrm{E}$ in evidente affanno continua a essere negli ultimi anni di Commodo, quando i timori per i possibili ritardi del frumento alessandrino inducono a "istituire " una classis Africana. E ancora in affanno è nel 197, quando Q. Aemilius Saturninus, in previsione della campagna partica, è costretto ad

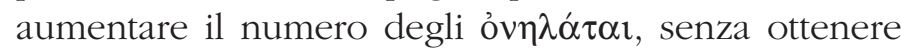
per questo la desiderata velocità di incameramento e trasmissione.

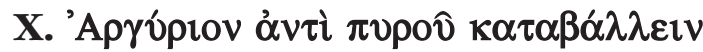

1. Iniziata poco dopo la circolare di Q. Aemilius Saturninus, la nuova campagna partica di Settimio Severo richiese, per tutta la sua durata, il prelievo e la movimentazione di più consistenti quantità di grano. Anche per il 198 e il 199 dovettero quindi riproporsi i problemi di trasmissione di frumento pubblico già 
emersi nel 197. Anzi, in quegli anni essi dovettero farsi più acuti per le latitanze degli ỏv $\alpha \kappa \varepsilon \chi \omega \rho \eta \kappa o ́ \tau \varepsilon \varsigma^{199}$, provocate forse da più attenti controlli circa il rispetto dell'obbligo della $\tau \rho$ ovía. Le pressioni dell'amministrazione imperiale per ottenere a qualsiasi costo un efficiente servizio di trasporto del grano pubblico sono suggerite, à rebours, da un giudizio emesso da Settimio Severo (e Caracalla) dopo la fine della seconda campagna partica, durante il suo soggiorno egiziano ${ }^{200}$, quando l'imperatore cercava di istradare la provincia verso una ristabilita normalità.

Uno dei primi atti in questa direzione fu il divieto, allora stabilito, di far gravare sulla stessa persona due liturgie contemporaneamente ${ }^{201}$. Deplorata anche in un passato non recentissimo ${ }^{202}$, l'attribuzione di una doppia liturgia doveva essersi fatta più frequente negli anni precedenti, in concomitanza con la stretta fiscale determinata dalla campagna partica e a seguito per un

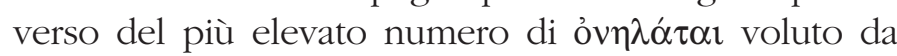
Q. Aemilius Saturninus e per l'altro del diffondersi, tra gli

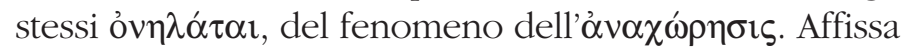
nel portico di Menfi il 9 dicembre 199, una sentenza imperiale liberava il ricorrente dall'obbligo della seconda liturgia, decretandone per sempre l'illegalità ${ }^{203}$. Se il ricorrente di cui gli imperatori accolgono la richiesta

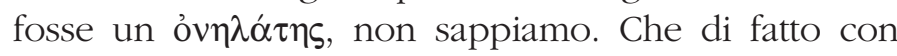
quella sentenza si riconosceva un diritto anche ai molti

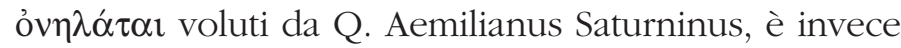
certo. La riprova la si coglie sia nella laconicità con cui Heron nel 200/201 espone il suo caso al prefetto d'Egitto

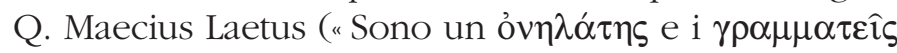
della città [mi hanno nominato a una seconda liturgia] "), sia nello stupore con cui il prefetto, dopo essersi accertato della natura della seconda liturgia, domanda al

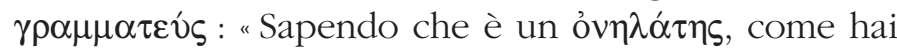
potuto chiamarlo a una seconda liturgia ? "204.

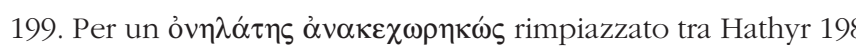
e Hathyr 208 : $B G U$ VII 1566 (da Philadelphia nel nomo Kynopolite).

200. Per la cronologia, cfr. ultimamente THOMas J.D. Oxyrhynchus Papyri Part LXVII, 2001, p. 174-175.

201. Cfr., ultimamente, THomas J.D., ad POxy 4593, ivi ulteriore bibliografia.

202. PSI XIV 1406, dell'età di Antonino Pio

203. POxy 4593, 11. 1-4

204. POxy 4593, 11. 19-20.
2. A non molta distanza di tempo dal divieto della doppia liturgia, gli imperatori fecero un ulteriore e più importante passo avanti nella stessa direzione : fu proclamata l'amnistia nei confronti degli $\grave{\alpha} \nu \alpha \kappa \varepsilon \chi \omega \rho \eta \kappa o ́ \tau \varepsilon \varsigma$, dei molti cioè che si erano resi latitanti negli anni duri della campagna partica ${ }^{205}$. Ma la comprensione nei confronti dei trasportatori di frumento pubblico e il perdono degli $\alpha$ $v \alpha \kappa \varepsilon \chi \omega \rho \eta \kappa o ́ \tau \varepsilon \varsigma$ non erano indifferenza nei confronti del problema della trasmissione di frumento pubblico ; né avrebbero dovuto essere scambiati, come invece probabilmente furono, per anticipazioni di una disponibilità ad accettare conversioni in danaro dei prelievi in grano. Pochi mesi dopo, il 20 Phamenoth (= 16 marzo) $200 \mathrm{fu}$ pubblicata la risposta degli imperatori alla richiesta, avanzata da Dioskoros figlio di Hephaestion, Pies(i)es figlio di Osiris e altri, di poter convertire in danaro le tasse in grano ${ }^{206}$. Anche in questa circostanza, la sentenza sul caso puntuale era destinata a chiarire l'indirizzo generale della poltica fiscale imperiale. Il fatto che l'ỏ d'affissione (la Stoa del ginnasio di Alessandria) e diramato nella provincia ${ }^{207}$ dimostra sia l'interesse dei contribuenti per gli orientamenti della politica fiscale imperiale sia il valore "normativo " che si annetteva a quella sentenza, in teoria non innovativa rispetto al precedente divieto cui peraltro si richiama.

La petizione doveva riguardare l'ormai imminente $\dot{\varepsilon} \mu \beta 0 \lambda \hat{n}$ del 200. La risposta data, richiamandosi a un precedente divieto ( $\varepsilon \kappa \omega \lambda \hat{\sigma} \sigma \alpha \mu \varepsilon v)$, intimato a degli i $\mu \varepsilon \hat{\imath} \varsigma$ che non saranno stati individualmente gli stessi Dioskoros, Pies(i)es etc., ma in generale tutti contribuenti egiziani, lascia intravvedere il succedersi di due opposte prassi relative ai prelievi fiscali in grano. La prima, ammessa fino un passato recente, prevedeva la facoltà, per alcuni contribuenti, di convertire in danaro una certa quota di tasse in grano ; la seconda, imposta da poco dagli stessi imperatori, quella facoltà escludeva.

205. Thomas J.D., A Petition, 1975 , p. 201-221.

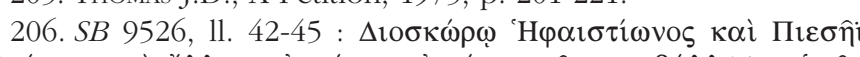

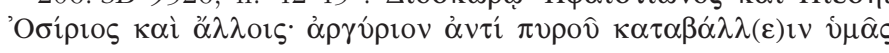
$\dot{\varepsilon} \kappa \omega \lambda \hat{\sigma} \sigma \alpha \mu \varepsilon v$

207. Coriat J.-P., Prince législateur, 1997, p. 624-627. 
3. Come si è detto, la prassi di convertire in danaro le tasse in grano potrebbe spiegare anche già il relativamente basso tributo granario egiziano alla Roma augustea e giulio-claudia. All'età di Commodo concedere o richiedere conversioni in danaro di tasse in grano poté sembrare un modo per limitare i danni all'erario e la pressione sulla società egiziana causati dalle difficoltà di trasporto del frumento pubblico. La possibilità di convertire in danaro i tributi granari egiziani potrebbe essere ancora prevista nel 194 quando il procurator Neaspoleos reclama il puntuale

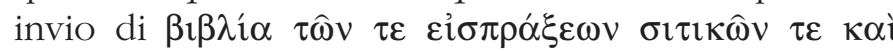

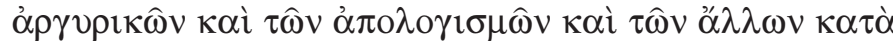
$\mu \hat{\eta} v \alpha^{208}$. Al più tardi nel 197, Settimio Severo inaugura una diversa politica fiscale. L'aumento del numero degli

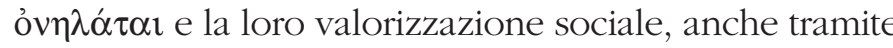

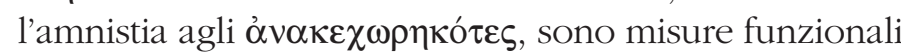
a una politica fiscale che vuole massimizzare i proventi in grano. La decisione di mantenere anche per l'ż $\mu \beta \lambda_{\lambda} \eta \dot{n}$ del 200 il divieto di convertire in danaro le tasse in natura, stabilizzando così le proporzioni tra prelievi in grano e prelievi in danaro fissate nel corso e in ragione della campagna partica, tradisce la volontà di trasformare in permanenti quegli equilibri fiscali che $i$ contribuenti egiziani, agli inizi del 200, potevano invece percepire come legati alle contingenze della guerra.

4. Negata la possibilità di convertire in danaro le tasse in grano, i tributi granari egiziani poterono allora lievitare, in qualche misura avvicinandosi ai livelli

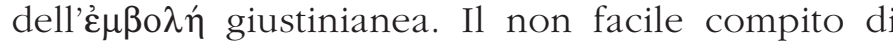

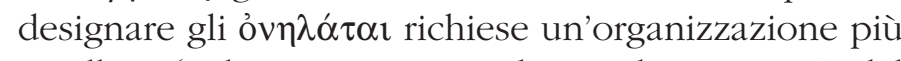
capillare (nel 207 a Ossirinco l'incombenza passò da

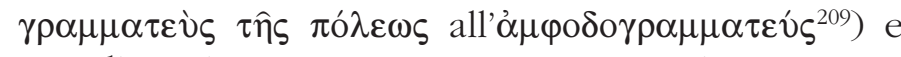
stimolò i più vari escamotages. Si continuò a ricorrere

208. KruSe Th., Der königliche Schreiber, 2002, p. 650 "Sicherlich auffalend ist dabei, daß der procurator Neaspoleos, der nach allem, was man weiß, vornehmlich mit der Verwaltung der alexandrinischen Getreidespeicher befaßt war, nicht nur mit Erhebungen von Natural-, sondern auch von Geldsteuern zu tun hatte. Für diese schon vom Ersteditor des Textes U. Wilcken $[A P F$, 4, 1908, p. 126] hervorgehobene Merkwürdigkeit habe ich auch

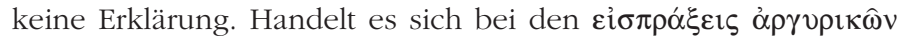
vielleicht um adaerierte Naturalzahlungen ?.

209. Thomas J.D., POxy 4593 Introd. al prefetto contro i tentativi di assegnare doppie liturgie $^{210}$; alcuni ebbero addirittura a protestare per essere stati indebitamente designati per un doloso scambio di identità da parte dell'ỏ $\mu \varphi о \delta о \gamma \rho \alpha \mu \mu \alpha \tau \varepsilon v ́ \varsigma$ di un altro quartiere. Nella sua petizione scritta in un greco fiorito e presentata il 25 marzo 207, Totoes nega di essere Sbichis figlio di Harmiusis e Taseus e di essere registrato nel quartiere della prima tribù, che in quell'anno il sorteggio dell'epistratego sottoponeva alle liturgie. Vittima dell'audace abuso dell'ỏ $\mu \varphi о \delta o \gamma \rho \alpha \mu \mu \alpha \tau \varepsilon v ́ s$, egli è solo un povero contadino registrato nel quartiere Hippeon Parembolé, che già è stato in passato assegnato alla liturgia della $\varphi v \lambda \alpha \kappa i \alpha$. Vive una vita tranquilla, paga annualmente le proprie tasse : proprio non ha il $\pi$ ópos di 1,200 dracme che gli è stato attribuito e assolutamente non potrebbe sostenere la $\delta \eta \mu$ oбí $\alpha$

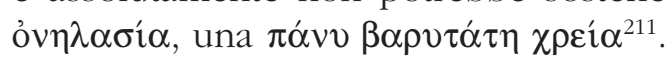

5. Oltre che alla volontà di aumentare la disponibilità di grano pubblico per Roma, il divieto di convertire in danaro le tasse in grano e la velocizzazione della trasmissione del grano fiscale egiziano si collegano anche al maggiore impegno militare connesso al nuovo assetto della frontiera orientale e, più in generale, a una politica estera più aggressiva su quel versante ${ }^{212}$. Gli effetti della cura con cui i Severi mettono a punto i meccanismi di prelievo e trasmissione del grano pubblico egiziano si colgono per un verso nel septem annorum canon, su cui più avanti torneremo, e per l'altro nell'efficienza con cui gli arativi egiziani assecondarono la campagna partica di Caracalla. Proprio mentre nella Mauretania Tingitana si condonavano i (difficilmente esigibili ?) debita fiscalia frumentaria, l'imperatore richiese, oltre quelli ordinari, contributi straordinari ai contadini egiziani.

L'aggravio di pressione fiscale sull'Egitto diventa donazione evergetica in Siria - concessioni necessarie, in realtà, per alleviare i disagi creati dal passaggio dell'imperatore e dai preparativi per la campagna

\footnotetext{
210. POxy 4593, 11. 5-13

211. POxy 2131

212. Cass. Dio LXXV 3, 2-3 ; WAGner J., Provincia Osrhoene, 1983, p. 103-123 ; KenNEDY D.L., Garrisoning of Mesopotamia, 1987,
} p. $57-66$. 


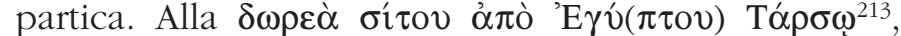
elargita probabilmente nel 215, come anche al grano assegnato a Laodicea in aeternum beneficium nel $216^{214}$, fanno da contrappunto le speciali liste per straordinari prelievi fiscali in Egitto negli anni 214/5, $215 / 6$ e 216/7 $7^{215}$ e fa da contrappunto, anche, la speciale contabilità con cui i sitologi di Karanis

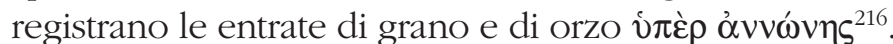

Di fronte alla necessità di mobilitare volumi di derrate senza precedenti, i comandati al loro trasporto giurano di portare a termine il loro compito : sulla $\tau \hat{\chi} \chi \eta$ di Caracalla giura Aurelius Musis, proprietario terriero nel villaggio di Sinary, nel nomo Ossirinchite, di portare ad Alessandria l'orzo da spedire all'esercito in Siria ${ }^{217}$; sulla $\tau \hat{\chi} \chi \eta$ di Macrino giurano, qualche tempo dopo,

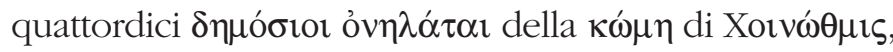
nel nomo Herakleopolite, impegnandosi a $\pi \alpha \rho \alpha \sigma \tau \eta \dot{\sigma \varepsilon \iota v}$

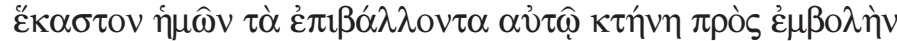
$\delta \eta \mu$ óíov $\pi$ voo $\hat{v}^{218}$.

\section{NAUICULARII MARINI ARELATENSES QUINQUE CORPORUM E PROCURATOR AD ANNONAM PROUINCIAE NARBONENSIS ET LIGURIAE}

Nella lunga storia del tributo granario gallico all'annona di Roma, l'evoluzione dell'organizzazione in cui sono inquadrati i nauicularii marini Arelatenses, che all'età di Settimio Severo risultano impegnati nell'espletamento di servizi annonari all'interno di una

213. Ziegler R., Münzen Kilikiens, 1977, p. 34-35.

214. Ziegler R., Antiochia, Laodicea, und Sidon, 1978, p. 507-511.

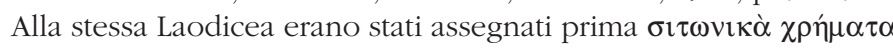
(nel 194) e quindi grano (nel 198) da Settimio Severo : Ibid., p. 501-507.

215. StudPal XXII 88 ; PStras VII 688 ; PYale III 137, dove alle 11. 2-5 le finalità dei prelievi sono chiaramente dichiarate : $\kappa \alpha \tau$

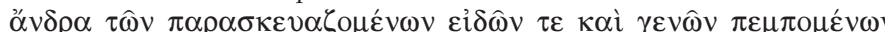

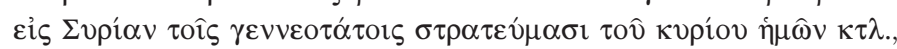
cfr. Schubert P., A Yale Papyrus, 2001, p. 3-9.

216. $B G U 529 ; 534=W C h r 191$

217. POxy 3091. Cfr. già POxy 3604, dove il 30 Hathyr 215 si giura di fornire asini per il soggiorno egiziano di Caracalla 218. PSI 1229. struttura articolata in cinque corpora ${ }^{219}$, mentre in un altro momento, secondo ogni probabilità anteriore ${ }^{220}$, appaiono riuniti in un solo corpus $^{221}$, rappresenta un segnale di discontinuità tanto più importante quanto più probabile è la sua coincidenza con la creazione della responsabilità amministrativa del procurator Augustorum ad annonam prouinciae Narbonensis et Liguriae. Tuttavia, circa la collocazione cronologica e il significato stesso di tale segnale non si registra unanimità di giudizio tra gli studiosi.

La pertinenza dei nauicularii marini Arelatenses a quinque corpora e l'esistenza di un procurator Augustorum ad annonam prouinciae Narbonensis et Liguriae sono entrambe attestate per la prima volta in una dedica arelatense posta appunto dai nauicularii marini Arelatenses corporum quinque a un Cominius Bo[ ?]o Agricola [ ?]elius Aper ${ }^{222}$, nel momento in cui questi lascia l'ufficio di procurator Augustorum ad annonam prouinciae Narbonensis et Liguriae per assumere, nella Mauretania Caesariensis, la prefettura di un'ala miliaria ${ }^{223}$. Alcuni studiosi riferiscono questa iscrizione al periodo compreso tra il 198 e il $211^{224}$ altri, invece, la riconducono già all'età di Marco Aurelio e Lucio Vero ${ }^{225}$. Le critiche incrociate hanno dimostrato malsicuri gli appigli individuati per tali ancoraggi cronologici. La grafia estesa procur. Augustorum, ritenuta da alcuni indice di probabile cronologia antonina ${ }^{226}$, è nondimeno presente anche in documenti d'età severiana ${ }^{227}$. L'ala miliaria in Mauretania Caesariensi, considerata da taluni un'innovazione

219. ILS 6987

220. Christol M., Naviculaires d'Arles, 1982, p. 10-11 ; diversamente, RougÉ J., Recherches, 1966, p. 253.

221. ILS 6986.

222. Per le diverse restituzioni del nome, cfr. Christol M. e Demougin S., Notes, 1984, p. 163-165; ALFÖLDY G., Zur Nomenklatur, 1986, p. 173-177.

223. ILS 1432

224. Christol M. e Demougin S., art. cit., p. 165-170 ; SiRKS B., Food for Rome, 1991, p. 97, nt. 170

225. CP 186 ; Pavis D'Escurac H., Réflexions, 1974, p. 428 ; 225. CP 186 ; PAVIS D'ESCURAC
ALFÖLDY G., art. cit., p. 177-179.

226. CP, p. 508 ; AlfÖLDY G., art. cit., p. 177-178.

227. Christol M. e Demougin S., art. cit., p. 166-167; per un altro esempio di grafia procurator Augustorum d'età severiana, cfr. CIL II, 1170. 
severiana ${ }^{228}$, è da altri ${ }^{229}$ identificata con l'ala I Neruiana Augusta fidelis miliaria, tra le truppe di stanza in Mauretania Caesariensis già nel $107^{230}$.

Quanto al significato della formula nauicularii marini Arelatenses corporum quinque, la sua ambiguità legittima interpretazioni molto diverse : da quella che presuppone che i cinque corpora siano tutti di nauicularii marini Arelatenses e che il passaggio da uno a cinque corpora rifletta un considerevole aumento dei trasporti da loro eseguiti, a quelle che ipotizzano che quelli riuniti nei cinque corpora non siano tutti nauicularii marini o tutti Arelatenses ${ }^{231}$.

Quanto infine all'ufficio di procurator ad annonam prouinciae Narbonensis et Liguriae, di cui andranno subito sottolineati il rango solo sessagenario, l'estensione spaziale, che riunisce una provincia e una regio italica confinante, e soprattutto le specifiche competenze ad annonam, esso è stato interpretato in maniera diametralmente opposta. Secondo alcuni, avrebbe dovuto facilitare trasferimenti a Roma di derrate annonarie ${ }^{232}$; secondo altri ${ }^{233}$, avrebbe cercato di porre rimedio, con importazioni di grano esterno, a difficoltà annonarie nella Narbonese e in Liguria, contemporanee e identificabili con quelle attestate per l'Italia dalla Historia Augusta ${ }^{234}$ e confermate, a Concordia e Ariminum, dalla documentazione epigrafica ${ }^{235}$.

Fortunatamente, quest'ultimo dilemma sembra essere di soluzione assai meno incerta dei precedenti. Gli argomenti in base ai quali si è negato che il procurator ad annonam prouinciae Narbonensis et Liguriae potesse sovrintendere a trasferimenti a Roma di grano pubblico prelevato nella prouincia Narbonensis e in Liguria fanno infatti riferimento per

228. Christol M. e Demougin S., art. cit., p. 167-168.

229. ALFÖLDY G., art. cit., p. 178-179.

230. CIL XVI, 56

231. Constans L.A., Arles antique, 1921, p. 206 ; Christol M., Naviculaires d'Arles, 1982, p. 13-14 ; DE SALVO L., Economia privata e pubblici servizi, 1992, p. 400-401 ; VIRLOUVET C., Naviculaires d'Arles, 2004, p. 361-362.

232. Pavis D'Escurac H., art. cit., p. 129-130 ; SiRKs B., op. cit. p. 97 ; VIRLOUVET C., art. cit., p. 345-6 ; CORBIER M., Les mesures et les hommes, 2006, p. 239

233. Pflaum H.G., op. cit., p. 508-509 ; Alföldy G., art. cit., p. 177. 234. H.A., MAnt 11, 3 : Italicis ciuitatibus famis tempore frumentum ex urbe donauit omnique frumentariae rei consuluit. 235. ILS 1118 ; CIL XI, 377. un verso alle vocazioni produttive delle aree geografiche in questione e per l'altro alla titolatura stessa dell'ufficio amministrato dal personaggio. Secondo lo Pflaum, infatti, la Narbonese e soprattutto la Liguria - "pays pauvre et montagneux" - mal si presterebbero a svolgere il ruolo di fornitrici di grano a Roma e il genitivo dipendente da ad annonam, di contro all'ablativo della titolatura procurator annonae Ostis, obbligherebbe a intendere la formula ad annonam prouinciae Narbonensis et Liguriae come "pour le ravitaillement en blé de la province de Narbonnaise et de la Ligurie " ${ }^{236}$.

Di questa argomentazione, alcuni passaggi e implicazioni sono già stati efficacemente criticati. P. es., è stato osservato che l'argomento grammaticale non è affatto dirimente, come mostra il confronto con la formula praefectus annonae Africae, che evidentemente non può riferirsi a un praefectus "pour le ravitaillement en blé de la province d'Afrique "237.

Pure rilevata è stata l'improbabilità che un mandato dell'ampiezza immaginata dallo Pflaum, che presuppone una crisi annonaria di assai larga scala, potesse essere affidato alla responsabilità di un personaggio del rilievo di Cominius Aper, tra l'altro scavalcando le tradizionali competenze del governatore di provincia ${ }^{238}$. Ad Antiochia di Pisidia, p. es., è toccato al legato L. Antistius Rusticus intervenire per risolvere la carestia che affligge la città in età domizianea ${ }^{239}$, mentre le crisi annonarie che colpiscono le città e le regioni dell'Italia settentrionale in età antonina non portano alla creazione di nuove strutture amministrative : tutt'al più ampliano (o solo esaltano) l'operatività di quelle esistenti ${ }^{240}$, talvolta coadiuvata (o supplita) dall'evergetismo delle élites locali ${ }^{241}$.

A guardar bene, il confronto tra Arrius Antoninus e C. Cornelius Felix Italus da un lato e Cominius Aper dall'altro mette in luce differenze più che affinità : i primi, onorati, rispettivamente, dall'ordo Concordiensium e dai

236. Pflaum H.G., op. cit., p. 508.

237. PAVIS D'Escurac H., art. cit., p. 132-133.

238. Ibid., p. 131-132. Vlp., Dig. XLVII 11, 6 pr.

239. $A E$ 1925, 126, su cui ultimamente Wiemer H.-U., Das Edikt des L. Antistius Rusticus, 1997, p. 195-215.

240. Cfr. supra nt. 236

241. ILS 6664 
uicani uicorum VII insieme al collegium fabrum, centonariorum, dendrophorum di Ariminum, si sono trovati a fronteggiare una situazione d'emergenza in una materia che doveva essere estranea oppure ai margini delle loro competenze di iuridici ${ }^{242}$; il secondo, invece, è stato inviato con specifici compiti ad annonam ed è onorato dai soli nauicularii marini Arelatenses corporum quinque, che, direttamente implicati nei servizi annonari per la città di Roma, riconoscono in lui un patronus optimus et innocentissimus, nulla di più. Soprattutto, si dovrà sottolineare che il pur lacunoso stato della documentazione disponibile lascia riemergere una procuratela annonae prouinciae Narbonensis nella carriera di C. Attius Alcimus Felicianus ${ }^{243}$. Se i due procuratori si fossero occupati dell'approvvigionamento granario della Narbonese anziché di quello di Roma, si dovrebbe dedurre che in quella provincia l'equilibrio tra disponibilità e consumi granari fosse a tal punto problematico da essere sottratto alla vigilanza de proconsole per essere stabilmente (o anche solo ricorrentemente) delegato a un apposito procuratore.

Come è stato più volte sottolineato ${ }^{244}$, ciò stride col fatto che un tributo granario gallico all'annona di Roma è attestato sia nel I che nel IV-V sec. d.C., circostanza che lascia presupporre, almeno relativamente ai periodi indicati e alla Gallia Narbonese, un equilibrio molto diverso tra produzione e consumi. Che anche a cavallo tra II e III sec. d.C. l'annona dell'urbe si giovasse regolarmente di grano gallico, pare logico ammettere

242. Giardina A., La formazione dell'Italia provinciale, 1993 , p. $54 ; 61$

243. CP 327. La procuratela annonae prouinciae Narbonensis segue i ruoli di aduocatus fisci prouinciarum XI, procurator alimentorum per Transpadum Histriam Liburniam, uice procuratoris quadragesimae Galliarum, procurator per Flaminiam Vmbriam Picenum, procurator priuatae per Salariam Tiburtinam Valeriam Tusciam, mentre precede i posti di procurator ferrariarum, procurator sacrae monetae, procurator hereditatium Romae e curator operis amphitheatri. Quest'ultima funzione si restauro del Colosseo dopo l'incendio del 217 : cfr. SABLayrolles R., Le Colisé brûle-t-il ?, 1990, p. 129-131.

244. PAVIS D'Escurac H., art. cit., p. 130, nt. 270, con opportuno riferimento a Plin., n.h. XVIII 66 ; VIRLOUvET C., Naviculaires d'Arles, 2004, p. 344, nt. 44 ; CORBIER M., Les mesures et les hommes, 2006 , p. 239 , nt. 36 . sia perché all'età di Marco Aurelio le proprietà imperiali in Narbonese erano così consistenti da essere amministrate da un procurator Augusti patrimonii prouinciae Narbonensis di rango ducenario ${ }^{245}$, sia perché all'età di Settimio Severo il praefectus annonae Claudius Iulianus allude ai nauicularii marini Arelatenses come a coloro che annonae deseruiunt ${ }^{246}$.

Tuttavia, se Cominius Aper sovrintende a trasferimenti di grano pubblico dalla Narbonese, trasferimenti che sono regolari già all'età di Plinio e lo saranno ancora in età tardoantica, come spiegare il fatto che la sua procuratela comprende anche la Liguria, che, oltre ad essere in larga parte poco adatta alla cerealicoltura, è anche, in quanto regio italica, esente da tributum ? In effetti, non abbiamo altre esplicite testimonianze di trasferimenti di grano ligure, pubblico o privato, a Roma e quando un ufficio simile a quello svolto da Cominius Aper riaffiora, esso si presenta semplicemente come procurator annonae prouinciae Narbonensis, apparentemente senza nessuna competenza sulla Liguria.

Nell'inclusione della Liguria nel campo d'azione di Cominius Aper H. Pavis d'Escurac ${ }^{247}$ ha letto la misura dell'eccezionale gravità della crisi in cui, a suo giudizio, doveva versare allora l'approvvigionamento annonario dell'urbe. B. Sirks ${ }^{248}$ ne ha invece dedotto che Cominius Aper fosse delegato ad acquisti non solo di grano, ma anche di olio. M. Corbier ${ }^{249}$ ritiene infine che malgrado

245. AE 1962, 183, cfr. Pflaum H.G., Une lettre de promotion, 1971, p. $349-366$

246. IIS 6987

247. Pavis D’Escurac H., Réflexions, 1974, p. 130-133 : “ En temps normal, la pauvreté en blé de cette région montagneuse qu'est la Ligurie n'en faisait certes pas une grande région exportatrice [... Mais les deux chevaliers sont chargés de missions extraordinaires. Lerr nomination en dehors des l'administration de l'annone prouve des conditions économiques exceprionnelles [...] Le fait même qu'à sa mission de Narbonnaise C. Cominius Bo... Agricola... elius Aper ajoute les terres de Ligurie, qui ne sont pas spécialement productrices, montre que, partout où un peu de blé pouvait être espéré, l'on dépêcha des envoyés de e Rome. Le maximum de blé devait être réuni et dans le temps le plus bref possible pour améliorer la situation frumentaire de l'Urbs".

248. SIRKS B., Food for Rome, 1991, p. 97 : "This procurator probably purchased grain and olive oil on behalf of the Prefect of the Annona ".

249. Corbier M., Les mesures et les hommes, 2006, p. 238 : “ Ne 
le diversità tra la titolatura di Cominius Aper (procurator ad annonam prouinciae Narbonensis et Liguriae) e di C. Attius Alcimus Felicianus (procurator annonae prouinciae Narbonensis) il raggio d'azione dei due procuratori sia stato identico, senza però che da ciò si capisca chiaramente se grano ligure a Roma sia stato trasferito da entrambi i procuratori o da nessuno dei due.

Per parte mia, farei osservare che l'eventuale omissione della regio italica dalla titolatura di C. Attius Alcimus Felicianus, comprensibile anche per la cronologia dell'iscrizione, alquanto posteriore all'ufficio menzionato, non sarebbe un caso senza parallelo ${ }^{250}$. Ma soprattutto farei rilevare che non appare evidente, come in altri casi ${ }^{251}$, che il compito del procurator ad annonam prouinciae Narbonensis et Liguriae e del procurator annonae prouinciae Narbonensis sia stato quello di realizzare acquisti o requisizioni straordinarie, imposte da eccezionali circostanze di emergenza. Né la doppia attestazione di una procuratela annonaria della provincia Narbonese deve necessariamente considerarsi, senza bisogno di ulteriore prova, la spia del ripetersi di tali situazioni ${ }^{252}$.

L'opinione che la procuratela ad annonam prouinciae Narbonensis et Liguriae sia stato un ufficio straordinario deriva dalla convinzione che l'amministrazione imperiale non potesse regolarmente trarre dalla Liguria introiti di grano pubblico. La IX regio italica, però, non è tutta povera e montuosa come si

déduisons pas du léger changement du titre que le rayon d'action du procurateurs'était véritablement restreint : pour naviguer de Narbonnaise à Rome, le cabotage des navires de mer se pratiquait toujours le long des côtes de la Ligurie (région dépendant administrativement de l'Italie)".

250. Cfr., p. es., le titolature di T. Aurelius Calpurnianus Apollonides (Pflaum H.G., CP, p. 715-717), che figura come $\dot{\varepsilon} \pi i ́ \tau \rho(\mathrm{o} \pi \mathrm{\circ} \varsigma)$

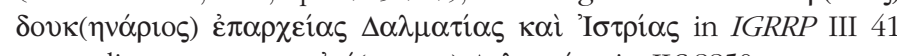

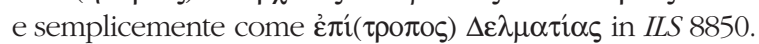

251. ILS 1435 (curator frumenti comparandi in annonam urbis) ; CIL VI, 41295 (procurator ad olea conparanda per regionem Tripolitanam).

252. Peraltro difficili da individuare, cfr. PAVIS D'Escurac H., art. cit., p. 133 : « La procuratèle annonae Galliae Narbon. de C. Attius Alcimus Felicianus, futur préfet de l'annone, se situe sous le règne de Sévère Alexandre ; il est impossible d'émettre la moindre hypothèse sur les circonstances particulières qui purent conduire à la nomination de cet envoyé extraordinaire ". vorrebbe. I suoi confini si estendono infatti fino alla sponda destra del Po e comprendono pertanto diverse centinaia di chilometri quadrati di pianura, certamente in grado di produrre considerevoli surplus di cereali, come tra l'altro testimoniano gli borrea Dertonensia di età ostrogotica $^{253}$. Va inoltre notato che introiti di frumento pubblico dalla $I X$ regio italica potrebbero spiegarsi con le proprietà imperiali comprendenti, a partire dall'età severiana, i multi agri acquistati da Pertinace ${ }^{254}$, ma forse anche causa dell'acquartieramento a Dertona di alcuni legionari tra II e III secolo d.C. ${ }^{255}$. Incardinata nella ratio priuata, parte almeno di quelle proprietà risulta affidata, durante la dodicesima tribunicia potestas di Settimio Severo (203/204), all'amministrazione di un procurator rationis priuatae per Flaminiam Aemiliam Liguriam $^{256}$, il quale potrebbe essersi egli occupato di raccogliere e trasmettere, attraverso le vie Postumia e Iulia Augusta ${ }^{257}$, il grano pubblico prodotto da quelle proprietà per depositarlo a Vada Sabatia, dove Pertinace aveva avuto

253. Cass., uar. X 27 ; XII 27.

254. H.A., P 3, 3-4 (presso Alba Pompeia, sembrerebbe) ; 9,4 (presso Vada Sabatia); cfr. 13, 4, per la mercatura esercitata a Vada Sabatia per homines suos anche da imperatore.

255. Cfr. Mennella G., Legionari del Donau, 2000, p. 645-653. La possibilità che queste presenze militari si spieghino con proprietà imperiali in zona mi è stata suggerita dal collega M. Maiuro, che qui mi è caro ringraziare.

256. IRT $395 ; 424 ;$ IG XIV $2433=$ ILS 8852. Che la procuratela rationis priuatae per Flaminiam Aemiliam Liguriam sia un'innovazione introdotta o nello stesso 204 o non molto prima può a mio avviso dedursi dalla procuratela priuatae regionis Ariminensium ricoperta da Ti. Claudius Zeno Vlpianus (CIL XI, $6337=$ ILS 1422) dopo essere stato, in seguito alle confische ai danni dei seguaci di Albino (Pflaum H.G., CP, p. 604), procurator bonorum damnatorum e quindi procurator silicum viarum sacrae urbis e subpraefectus uigilibus. Seppur non può dirsi, con lo pflaum, che la procuratela prinatae regionis Ariminensium sia solo "une dénomination différente du complexe per Flaminiam Aemiliam Liguriam" (Pflaum H.G., CP, p. 796, nt. 18), si dovrà riconoscere che la ratio priuata per Flaminiam amministrata insieme a quella per Aemiliam e per Liguriam, da D. Clodius Galba nel 204, include la priuata regionis Ariminensium amministrata da Ti. Claudius Zeno Vlpianus qualche anno prima. - Per l'accezione di Flaminia in riferimento all'ager Gallicus, cfr. THomsen R., The Italic Regions, 1947 , p. 168 . È peraltro possibile che all'amministrazione del procurator rationis priuatae per Flaminiam Aemiliam Liguriam fosse affidata anche la regio Rauennatium di cui è dispensator Herma (CIL V, 2385).

257. LUCCARDINI R., Vie romane in Liguria, 2001, p. 95-102 ; 133-152. 
le sue proprietà ed esercitato la mercatura, per homines suos, anche da imperatore ${ }^{258}$, oppure anche a Genua, dove è attestato un dispensator rationis priuatae ${ }^{259}$.

Se dunque può ammettersi che all'età di Cominius Aper e C. Attius Alcimus Felicianus si realizzassero regolari trasferimenti di grano pubblico ligure a Roma e cadono pertanto, anche per questo aspetto, le riserve dello Pflaum, resta però, lo si deve riconoscere, il paradosso che le aveva suscitate e cioè "le fait surprenant que nous n'avons aucune trace d'une organisation similaire dans certaines provinces comme l'Afrique, cependant bien plus importants [...] du point de vue du ravitaillement de Rome en céréales "260.

A mio avviso, il senso di questo paradosso deve cogliersi nella sua relazione con l'evoluzione della struttura in cui sono inquadrati i nauicularii marini Arelatenses. A seguito di una repentina e radicale riforma oppure attraverso un processo a più tappe, l'organizzazione dei servizi di trasporto di frumento pubblico gallico e ligure potrebbe essere passata da una fase in cui questi non richiedevano una speciale supervisione e i nauicularii marini Arelatenses erano inquadrati in un solo corpus a un'altra in cui si ritenne necessario istituire un procurator ad annonam prouinciae Narbonensis et Liguriae e inquadrare in una struttura di cinque corpora i nauicularii marini Arelatenses. Pur senza azzardare troppo precise ipotesi, è difficile sfuggire alla conclusione che in questo passaggio si rifletta la volontà di adeguare a esigenze nuove la velocità di trasmissione a Roma di frumento pubblico gallico e ligure.

Come in Egitto la riforma degli effettivi degli

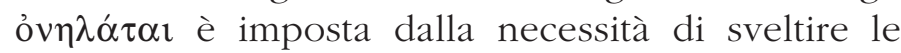
trasmissioni di frumento pubblico, così nella Gallia Narbonese e nella Liguria la necessità di mobilitare più rapidamente quantitativi di grano probabilmente più consistenti che in passato può aver improvvisamente reso necessaria una riorganizzazione dei nauicularii marini Arelatenses e l'istituzione di un procurator ad annonam prouinciae Narbonensis et Liguriae.

258. Cfr. supra nt. 255

259. CIL V, 7752 : Aureliae | Laudice | coniugi optimae | bene merenti Lupercus disp. rationis priuatae.

260. Pflaum H.G., Fastes, 1978, p. 168.
Per la cronologia di ILS 1432 - teoricamente databile o all'età di Marco Aurelio, con Lucio Vero (161169) oppure Commodo (177-180) Augusti, o in età severiana, a partire da Settimio Severo e Caracalla Augusti (198) - potrebbe osservarsi che l'ufficio di procurator ad annonam prouinciae Narbonensis et Liguriae più comprensibile (o, se si preferisce, meno sorprendente) sarebbe, se fosse posteriore all'acquisizione dei multi agri di Pertinace in Liguria e alle confische ai danni dei seguaci di Clodio Albino in Gallia ${ }^{261}$. Tra l'altro, se l'ufficio di procurator ad annonam prouinciae Narbonensis et Liguriae e l'inquadramento in cinque corpora dei nauicularii marini Arelatenses fossero posteriori alla vittoria di Lugdunum, essi si collegherebbero all'ampliamento del numero degli

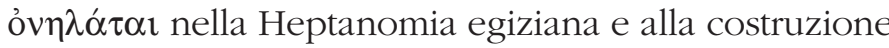
degli borrea di Cuicul, lasciando intravedere, nel brevissimo periodo che va dalla vittoria su Clodio Albino agli anni della seconda campagna partica, il dispiegarsi di una politica annonaria perseguita con grande energia e su amplissima scala.

Se, ciò malgrado, questa nostra presunzione dovesse risultare fallace, l'istituzione del procurator ad annonam prouinciae Narbonensis et Liguriae e l'inquadramento in cinque corpora dei nauicularii marini Arelatenses dovrebbero comunque essere considerati interventi strutturali finalizzati a rendere più agile la mobilità di più consistenti quantità di frumento pubblico. Essi quindi, più che essere spiegati con puntuali, episodiche carestie, dovrebbero essere accostati a realizzazioni come gli horrea di Caput Saltus Horreorum, anteriore al 193, o progetti come la classis Africana di Commodo.

\section{CANONe di SETTE ANNI : FRUMento Pubblico E FRUMENTO PRIVATO NEI CONSUMI DELLA ROMA SEVERIANA}

1. Le relativamente incerte cronologie degli horrea di Caput Saltus Horreorum e Thamusida, nonché dell'istituzione dell'ufficio del procurator ad annonam

261. H.A., S 12, 1-4 ; Herod. III 8, 2 ; 6-8. 
prouinciae Narbonensis et Liguriae e della creazione dei cinque corpora in cui sono inquadrati i nauiculari marini Arelatenses, rendono impossibili sia un'esatta ricostruzione dello sviluppo della politica annonaria imperiale dall'età di Marco Aurelio a quella di Settimio Severo sia una meno vaga valutazione delle variazion della quantità di grano pubblico messa annualmente a disposizione della città di Roma. Tuttavia, se è impossibile seguire la traiettoria ascendente della "curva " disegnata in questo periodo dal canon populi Romani, dalla quantità di grano pubblico cioè messa annualmente a disposizione della città di Roma, la stessa esistenza di quella "curva" non può essere revocata in dubbio : non ritengo si possa dubitare, in altre parole, che tra l'età di Marco Aurelio e quella di Settimio Severo la quantità di grano pubblico mobilitata dalle amministrazioni imperiali sia considerevolmente aumentata rispetto all'età precedente e che, nella misura in cui gli impegni militari lo permettevano, gran parte di quel grano fosse messo a disposizione della città di Roma.

2. I molteplici riscontri esterni che si rilevano nelle Mauretanie come in Egitto, in Numidia come nella Narbonese dissuadono infatti dall'aderire alle recenti (e meno recenti) proposte di derubricare a "mythistoria " le tradizioni sul canone di sette anni severiano ${ }^{262}$. Piuttosto, il confronto di quelle tradizioni con l'entità dei tributi granari destinati alla città di Roma alla metà circa del I sec. d.C. dà un'idea dello spessore del lungo processo evolutivo di cui qui abbiamo cercato di illuminare alcuni aspetti.

Prelevati dalle province di Egitto, Africa, Sicilia Sardegna, Betica, Chersoneso e Gallia, i tributi granari per la Roma giulio-claudia e flavia dovevano aggirarsi tra i 35,000,000 e i 40,000,000 di modii ${ }^{263}$. Ma sotto il profilo della contribuzione in natura, il Maghreb di età flavia è enormemente diverso da quello di età severiana. È assai dubbio, infatti, che in età flavia si

262. Cfr. ultimamente VERA D., Canon frumentarius, 2005, p. 273-304.

263. Deduco ciò dai 20,000,000 di modii inviati annualmente dall'Egitto dall'età augustea a quella flavia (cfr. infra), sommati a 6,000,000 di modii inviati dall'Africa (cfr. infra nt. 266) e al quantitativo di grano si può approssimativamente stimare inviassero le altre province (Plin., n.h. XVIII 66). traessero tributi in natura dalla valle del Sebou, dalla regione di Theueste, da quella di Cirta, da quella di Sitifis o di Cuicul ${ }^{264}$ : è comunque certo che se anche fossero stati prelevati, essi non sarebbero stati trasferiti al Mediterraneo né, tantomeno, messi a disposizione dell'annona di Roma. La parte dell'Africa che pagava

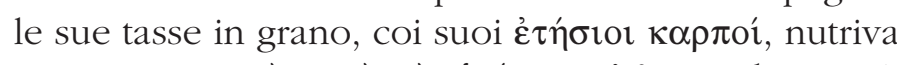

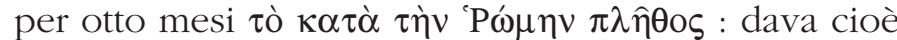
grano per otto mesi di frumentazioni alla plebs Romana $^{265}$

Secondo tradizioni raccolte dalla Historia Augusta, Settimio Severo, pur avendo trovato una res frumentaria minima, avrebbe lasciato un canon populi Romani "di sette anni "266, cosicché si sarebbero potuti erogare, secondo la lezione dei codici, 75,000 modii al giorno $^{267}$. Il canone di sette anni, inoltre, si sarebbe mantenuto almeno fino all'età di Elagabalo ${ }^{268}$. Dell'interpretazione di H.A., S 23, 2 che ho altrove ${ }^{269}$ proposto riassumo qui i punti essenziali.

a. Il fatto che il septem annorum canon sia condizione per una capacità di spesa temporalmente illimitata (ita ut cottidiana septuaginta quinque milia modium expendi possent) dimostra che con quell'espressione ci si riferisce non già a una riserva una sola volta accumulata, ma a un'entrata periodica. b. La periodicità del canon populi Romani è annuale, perché annualmente una parte delle tasse in grano prelevate nell'impero vengono devolute alla città di Roma.

c. L'annuale canon populi Romani si commisura o, approssimativamente, ai consumi dell'intera città di Roma $\mathrm{O}$, più precisamente, al ritmo delle

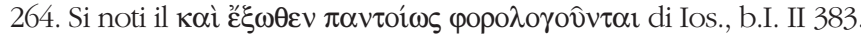
265. Ios., b.I. II 383. Come dimostra la terminologia e conferma una valutazione delle capacità contributive dell'Africa e del una valutazione delle capacità contributive dell'Africa e del
fabbisogno di Roma in età flavia, la formula usata da Flavio Giuseppe non può che riferirsi alla sola plebs frumentaria L'ammontare del tributo granario africano andrà calcolato a partire dalla razione individuale mensile di 5 modii moltiplicata per 150,000 beneficiari ammessi in locum erasorum, moltiplicata ancora per gli otto mesi : 5 × 150,000 x $8=6,000,000$ di modii Cfr. De Romanis F., Per una storia, 2003, p. 691

266. H.A., S 8,5 .

267. H.A., S $23,2$.

268. H.A., Hel 27, 7

269. De Romanis F., Septem annorum canon, 1996, p. 133-159. 
frumentazioni ${ }^{270}$ : il canon populi Romani severiano è "di sette anni" perché teoricamente sufficiente a sette anni di frumentazioni.

d. I 200,000 beneficiari del congiario del 202 comprendono, oltre i plebei che accedono al beneficio delle frumentazioni in locum erasorum ${ }^{271}$, i pretoriani, i vigili dopo il terzo anno di servizio, i magistri uicorum e altri eventuali beneficiari straordinari, tra quali anche, assai numerosi, coloro che hanno acquistato con la summula la loro tessera frumentaria ${ }^{272}$.

e. I plebei beneficiari del congiario testamentario di Tiberio (da identificarsi con i soli ammessi in locum erasorum : i uicorum magistri ne sono esclusi) sono 150,000 , non uno di più, non uno di meno ${ }^{273}$.

f. Il numero di modii giornalieri che, secondo la tradizione manoscritta, avrebbe consentito di erogare giornalmente il septem annorum canon deve considerarsi errato per due ragioni : a) perché altrimenti dovremmo ritenere $i$ tributi granari severiani all'annona di Roma più bassi addirittura di quelli giulio-claudi ; b) perché, non essendo 75,000 multiplo di 7 , dovremmo ritenere che il canone di un anno consentisse di erogare un numero di modii non intero, laddove il canone di sette anni, per mirabile coincidenza, consentirebbe di erogare un numero di modii tondo al migliaio.

g. Il riconoscimento di una corruttela del testo tràdito, pesantissima quanto al senso, ma facilissima a spiegarsi paleograficamente $(C L X X V$ (milia) $>L X X V$ (milia) $)$ permetterebbe di restituire una capacità di erogazione credibile : a) nel suo rapporto 7:1 con il ritmo delle frumentazioni (ai soli plebei ammessi in locum erasorum), b) nelle sue relazioni quantitative con i tributi granari di età giulio-claudia e c) col fabbisogno granario della città di Roma, che in età giulio-claudia doveva aggirarsi intorno ai 60,000,000 di modii ${ }^{274}$.

270. In maniera comparabile, il grano destinato a scopi militari si commisura ai consumi dell'esercito cui è destinato : Liu. VIII $2 ; 4$; IX 43, 21 ; X 5, 12 ; XXIII 21, 5 ; XXIX 3, 5.

271. Plin., pan. 25,3

272. Iuu. VII 171-175. Cfr. Virlouvet C., Tessera frumentaria, 1995, p. 201-216.

273. De Romanis F., Septem annorum canon, 1996, p. 146, nt. 49. 274. Cfr. supra, nt. 83.
3. Prima dell'età severiana, il rifornimento granario di Roma veniva assicurato da un equilibrio - certo non statico, ma un equilibrio - tra frumento pubblico e frumento privato. Altri imperatori, pur potendo aumentare la quota di frumento pubblico da destinare a Roma, avevano preferito conservare al grano privato una certa "quota di mercato " nell'urbe, dirottando altrove quote non insignificanti di grano pubblico. Adriano, p. es., come abbiamo già ricordato, permise di vendere in Oriente una parte dei tributi granari egiziani, quando il Nilo avesse prodotto una piena regolare e si fosse così sicuri che per la città regina ci sarebbe stato ő $\varphi \theta$ ovo $\pi v \rho o ́ s . ~ C e r t o ~ q u e l l ' a b b o n d a n z a$ di grano raccolto da ogni dove ( $\pi \alpha \nu \tau \alpha \chi o ́ \theta \varepsilon v)$ rendeva superflua per Roma una parte del tributo granario egiziano e logica la concessione di Adriano. Ma l'abbondanza di Roma, allora, non era fatta di solo grano pubblico : proprio negli anni in cui Adriano dirottava grano pubblico egiziano sulle città d'Asia, mercanti frumentari come T. Caesius Primus rivendevano a Roma grano privato fors'anche da oltremare, ma certo anche dall'Umbria e dalla Tuscia ${ }^{275}$

Anche all'età di Marco Aurelio e Commodo i consumi granari di Roma sono sostenuti da una concorrenza di grano pubblico e di grano privato, mentre parte dei tributi granari potenzialmente dirottabili sulla città vengono convertiti in danaro in provincia. Importazioni di grano privato trasmarino si intravedono dietro la dedica del 173 a un M. Iunius Faustus, notabile ostiense e mercator frumentarius da parte dei domini nauium Afrarum uniuersarum, cui si sono subito dopo aggiunti i domini delle navi sarde ${ }^{276}$. Da mercanti di grano trasmarino sarà costituito il corpus mercatorum frumentariorum autore di due dediche ostiensi, che si è proposto di datare all'età di Marco Aurelio $^{277}$ : questi commerci sono contemporanei alla prassi di consentire ai contribuenti egiziani di

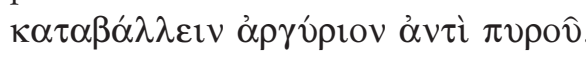

4. L'elevazione del canon populi Romani al livello di quello che era stato il fabbisogno della città in età giulio-claudia implica invece il forte restringimento, se

277. ILS 1427 ; CIL XIV, 4620. Cfr. CP 208. 
non adirittura la cancellazione, del commercio di grano privato a Roma in quegli anni o decenni. Riterrei essenzialmente politiche le ragioni di tale scelta. Le dimostrazioni contro la guerra civile nei Saturnalia del 195 o del $196^{278}$ avevano ancora una volta messo in evidenza, come già era stato in occasione dei disordini che precedettero la caduta di Cleandro, la tendenza della plebe romana a inserirsi nel gioco politico, fino a schierarsi, persino, contro l'imperatore. Questa tendenza andava limitata, accrescendo, innanzitutto, le capacità di repressione militare, con una maggiore concentrazione di truppe a Roma e nelle vicinanze, ma risolvendo anche, soprattutto ora che con un maggior numero di soldati si facevano più gravi, i problemi di approvvigionamento granario della città.

Sebbene il resoconto di Cassio Dione non consenta di comprendere esattamente in che modo e fino a che punto sia stata acuita dal praefectus annonae Papyrius Dionysius, la plebe non aveva riconosciuto in lui il responsabile della $\sigma \imath \tau o \delta \varepsilon i ́ \alpha$ del $190^{279}$. La res frumentaria minima degli ultimi anni di Commodo, con il bisogno di un consistente concorso di grano privato per coprire i consumi di Roma, aveva piuttosto reso credibili fantasie di enormi accaparramenti nelle mani di Cleandro ${ }^{280}$. Continuare a mantenere bassi livelli del canon populi Romani significava esporsi ai rischi derivanti dai mobili umori della plebe di Roma e dalla possibile buona sorte di qualcuno con credenziali migliori di Cleandro. Il septem annorum canon dissipava invece quegli incubi e contribuiva al mantenimento dell'ordine pubblico di Roma in maniera non meno efficace della legio II Parthica acquartierata nei castra Albana.

278. Cass. Dio LXXV 4, 2-7.

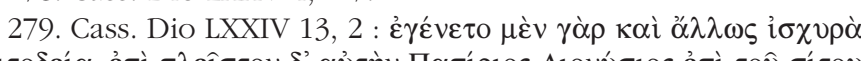

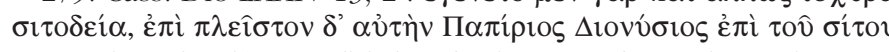

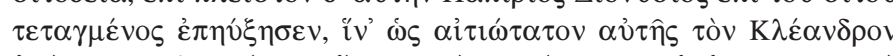

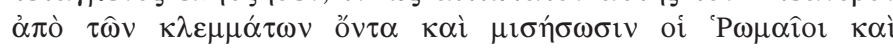
$\delta 1 \alpha \varphi \theta \varepsilon i ́ p \omega \sigma \tau$.

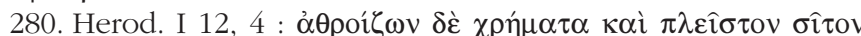

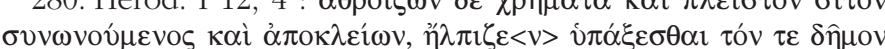

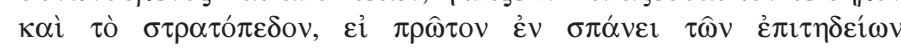

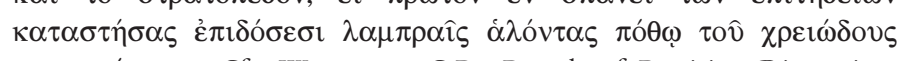

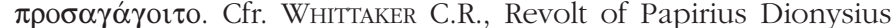
1964, p. 350 : "Guess-work and cook-shop gossip [...] but [...] people believed the story to be true ".
In parte, la lievitazione severiana del canon populi Romani derivava dalla necessità di assicurare le riserve invernali con un assai più largo concorso di grano extraegiziano, considerati sia il ritardo con cui il grano della valle del Nilo poteva giungere a Roma sia la possibilità che parte di esso fosse dirottato in Oriente per sostenere

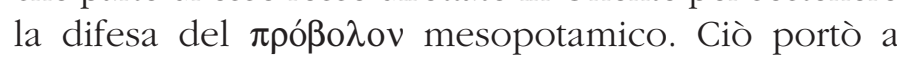
diversificare il più possibile le fonti di approvvigionamento e a sfruttarle tutte al massimo delle loro possibilità, come suggeriscono i debita fiscalia frumentaria accumulati dai contribuenti della valle del Sebou. In parte, però, il septem annorum canon derivava dalla scelta di non rinunciare comunque al grano egiziano, anche a quello che poteva giungere ad Alessandria solo dopo la chiusura della navigazione : come forse le 1,730 artabe di grano che dal 24 al 29 Phaophi (= 21-26 ottobre) 210 sono trasportate al porto di Alsos ${ }^{281}$ o le 2,662 artabe che nel mese di Mechir (gennaio-febbraio) del 211 erano inviate dal nomo ossirinchite agli horrea alessandrini di Neapolis ${ }^{282}$ o forse anche le x migliaia + 840 artabe che sempre dal nomo ossirinchite sono inviate dopo le Epagomenai del $211^{283}$.

E infine : il canon populi Romani cresce in età severiana anche in conseguenza della espansione della proprietà imperiale in Italia. Rari erano stati, in altri tempi, gli agri Caesaris in Italia ${ }^{284}$. Le carriere procuratorie di età severiana mostrano invece come essi allora si estendessero, per acquisizioni antiche, recenti e recentissime, su quelle zone che avevano alimentato, in altri tempi, il commercio di grano privato a Roma. Così Vlpius Victor, che dopo essere stato procurator ad bona Plautiani è procurator stationis priuatae per Tusciam et Picenum $^{285}$; così il già citato C. Attius Alcimus Felicianus che da procurator per Flaminiam Vmbriam Picenum diventerà procurator priuatae per Salariam, Tiburtinam Valeriam Tusciam e quindi procurator ad annonam prouinciae Narbonensis, approdando infine, dopo altri passaggi, alla prefettura dell'annona ${ }^{286}$.

281. PHamb 17

282. $S B 11272$.

283. POxy 1259

284. Tac., ann. IV 6. Sull'espansione della proprietà imperiale in Italia, è imminente la pubblicazione della tesi di M. Maiuro.

285. ILS 1370, cfr. CP n. 257

286. $C P$ n. 327. 


\section{BIBLIOGRAPHIE}

Adams C., 2007, Land Transport in Roman Egypt. A Study in Economics and Administration in a Roman province, Oxford.

AlfÖLDI M.R., 2001, Providentia Augusti. To the question of Limes fortifications in the 4 th century, in Gloria Romanorum. Schriften zur Spätantike zum 75. Geburtstag der Verfasserin am 6. Juni 2001, herausgegeben von H. Bellen und H.-M. von Kaenel, Stuttgart, [scr. 1955], p. 154-164.

AlFöldy G., 1986, Zur Nomenklatur und Laufbahn eines römischen Ritters aus Concordia, ZPE, 63, p. 173-177.

Allais Y., 1933, Les greniers publics de Djemila (Cuicul), $R A f$ 74, p. $259-268$.

Alquier P., 1928-29, Épigraphie latine et libyque du Département de Constantine (19326-1930), RSAC, 59, p. 361-400.

ARNAUd P., 2005, Les routes de la navigation antique. Itinéraires en Méditerranée, Paris.

Bagnall R.S., 1985, Agricultural Productivity and Taxation in Later Roman Egypt, TAPhA, 115, p. 289-308.

Bagnall R.S., 1996, Egypt in Late Antiquity, Princeton.

Bagnall R.S., 2000, P.Oxy. 4527 and the Antonine Plague in Egypt. Death or Flight?, JRA, 13, p. 288-293.

Bagnall R.S., 2001, A Heavy Artaba and its Ninety-six Loaves, in Alexandrian Studies II, in Honour of Mostafa El Abbadi, Alexandria (Bulletin de la Société d'Archéologie d'Alexandrie 46), p. 7-11.

Bagnall R.S e Frier B.W., 1994, The Demography of Roman Egypt, Cambridge.

Bastianini G., 1988, Il prefetto d'Egitto (30 a.C. - 297 d.C.) : Addenda (1973-1985), $A N R W$, II 10.1, p. 503-517.

Bastianini G. e Whitehorne J., 1987, Strategi and Royal Scribes of Roman Egypt. Chronological List and Index, Firenze.

Belke K., 2000, Prokops "De Aedificiis", Buch V, zu Kleinasien, AntTard, 8, p. 115-125.
BÉNABOU M., 2005, La résistance africaine à la romanisation, Paris (rééd.)

Bontwright M.T., 1992, Matidia the Younger, $\mathrm{EMCl}, 26$, p. 19-32.

Bogatrt R., 1995, Liste géographique des banques et des banquiers de l'Égypte romaine, ZPE, 109, p. 133-173.

Bonneau D., 1964, La crue du Nil, divinité égyptienne, à travers mille ans d'histoire (332 av. - 641 apr.J.-C.), Paris.

Bonneau D., 1971, Le fisc et le Nil. Incidences des irrégularités du Nil sur la fiscalité foncière dans l'Égypte grecque et romaine, Paris.

CAgnat R., 1903, Sabinius non Licinius Barbarus, in Mélanges Boissier, Paris, p. 99-102.

Camodeca G., 1994, Puteoli porto annonario e il commercio del grano in età imperiale, in Le ravitaillement en blé de Rome et des centres urbains des débuts de la République jusqu'au Haut-Empire. Actes du colloque international de Naples (1991), Naples-Rome, p. 103-128.

CARRIÉ J.-M., 2003, L'institution annonaire de la première à la deuxième Rome : continuité et innovation, in B. Marin e C. Virlouvet (ed.), Nourrir les cités de Méditerranée. Antiquité-Temps Modernes, Paris, p. 153-211.

Casanova G., 1984, Epidemie e fame in Egitto, Aegyptus, 64, p. $163-201$

Cavalier L., 2007, Horrea d'Andriakè et Patara : un nouveau type d'édifice fonctionnel en Lycie à l'époque impériale, REA, 109, p. 51-65.

Christol M., 1982, Les naviculaires d'Arles et les structures du grand commerce maritime sous l'Empire romain, $P H$ 32, p. 5-14.

Christol M., 1988, Rome et les tribus indigènes en Maurétanie Tingitane, in L'Africa romana. Atti del V convegno di studio (Sassari 11-13 dicembre 1987), Sassari, p. 305-337.

Christol M., 2005, Regards sur l'Afrique romaine, Paris

Christol M. e Demougin S., 1984, Notes de prosopographie équestre, $Z P E, 57$, p. 163-165. 
Constans L.A., 1921, Arles antique, Paris.

Corbier M., 1977, Le discours du prince d'après une inscription de Banasa, Ktèma, 2, p. 211-232.

Corbier M., 2006, Donner à voir, donner à lire. Mémoire et communication dans la Rome ancienne, Paris.

Corbier M., 2006, Les mesures et les hommes : les naviculaires d'Arles et leurs "règles de fer", in M. Corbier, Donner à voir, donner à lire. Mémoire et communication dans la Rome ancienne, Paris, p. 233-256.

CORIat J.-P., 1997, Le prince législateur. La technique législative des Sévères et les méthodes de création du droit impérial à la fin du principat, Rome.

Crawford-Thompson D.J., 1976, 'Imperial Estates', in M.I. Finley (ed.), Studies in Roman Property, Cambridge, p. $57-70$.

Cuvigny H., 2001, Claudius Lucilianus, préfet d'aile et de Bérénice, in T. Gagos e R.S. Bagnall (eds.), Essays and Texts in Honor of J. David Thomas, Oakville, p. 171-174.

Daris S., 1992, Le carte dello stratego Damarion, Aegyptus, 72, p. 23-59.

De Romanis F., 1996, Septem annorum canon. Sul canon populi Romani lasciato da Settimio Severo, RAL, s. 9 , p. 133-159.

De Romanis F., 2002, Gli horrea dell'urbe e le inondazioni d'Egitto. Segretezza e informazione nell'organizzazione annonaria imperiale, in J. Andreau e C. Virlouvet (ed.), L'information et la mer dans le monde antique, Rome, p. 279-298.

De Romanis F., 2003, Il pane di similago e i cinque modi mensili della lex Terentia et Cassia frumentaria, in S. Palmieri, Studi per Marcello Gigante, Napoli, p. 145-172.

De Romanis F., 2003, Per una storia del tributo granario africano all'annona della Roma imperiale, in B. Marin e C. Virlouvet (ed.), Nourrir les cités de Méditerranée. Antiquité-Temps Modernes, Paris, p. 691-738.

De SAlvo L., 1992, Economia privata e pubblici servizi nell'impero romano. I corpora naviculariorum, Messina.

Di Vita-Evrard G., 1988, L'édit de Banasa : un document exceptionnel ?, in L'Africa romana. Atti del V convegno di studio (Sassari 11-13 dicembre 1987), Sassari, p. 287-304.
Di Vita-Evrard G., 1992, La dédicace des borrea de Tubusuctu et l'ère de la province dans les Maurétanies, in L'Africa romana. Atti del IX convegno di studio (Nuoro 13-15 dicembre 1991), Sassari, p. 843-864.

Domergue Cl., 1963-64, L'arc de triomphe de Caracalla à Volubilis, Annuaire de l'EPHE IV section, 4, p. 283-293.

DreCOLL C., 1997, Die Liturgien im römischen Kaiserreich des 3. und 4. Jh. n. Chr. Untersuchung über Zugang, Inhalt und wirtschaftliche Bedeutung der öffentlichen Zwangsdienste in Ägypten und anderen Provinzen, Stuttgart.

Dupuis X., 1999, Cuicul, La Confédération cirtéenne et les Suburbures : des limites ambiguës, in Cl. Lepelley e X. Dupuis (ed.), Frontières et limites géographiques de l'Afrique du nord antique. Hommage à Pierre Salama, Paris, p. 129-138.

DupuIs X., 2000, Les IIII publica Africae, CCG, 11, p. 281-284.

ECK W., 1978, s.u. Matidia, in RE Suppbd. XV, coll. 131-134.

Eingartner J., 1998, Mopth(...) - Mons. Eine römische Straßenstation in der Mauretania Caesariensis zwischen ländlicher Tradition und urbane Fortschritt, in L'Africa romana. Atti del XII Convegno di studio (Olbia 12-15 dicembre 1996), Sassari, p. 309-320.

Euzennat M., 1976, in The Princeton Encyclopedia of Classical Sites, Princeton, p. 140-141.

Fentress E.W.B., 1990, The Economy of an Inland City : Setif, in L'Afrique dans l'Occident romain, Rome, p. 67-82.

FÉvrier P.A., 1964, Notes sur le développement urbain en Afrique du Nord : les exemples comparés de Djemila et de Sétif, CArch, 14, p. 1-47.

FÉVRIER P.-A., 1966, Inscriptions inédites relatives aux domaines de la région de Sétif, in Mélanges d'archéologie et d'histoire offerts à André Piganiol, I, Paris, p. 217-228.

FéVRIer P.-A., 1967, Aux origines de l'occupation romaine dans les hautes plaines de Sétif, $C T, 15$, p. 51-64.

Foraboschi D. e Gara A., 1982, L'economia dei crediti in natura, Athenaeum, 60, p. 69-83.

Galand L., 1949, Fouilles de Mons (Algérie), MEFRA, 61, p. 35-91.

GASCOU J., 1972, La politique municipale de l'Empire romain en Afrique Proconsulaire de Trajan à Septime Sévère, Rome. 
GASCOU J., 1982, La politique municipale de Rome en Afrique du Nord. I. De la mort d'Auguste au début du III ${ }^{\mathrm{e}}$ siècle, in $A N R W$, II 10, 2, Berlin-New York, p. 136-229.

Gascou J., 1992, Vici et provinciae d'après une inscription de Banasa, AntAfr, 28, p. 161-172.

GAscou Jean, 1989, La Table budgétaire d'Antaeopolis, in Hommes et richesses dans l'Empire byzantin, I. IV -VIT siècle, Paris, p. 279-313.

GERACI G., 2003, Alessandria, l'Egitto e il rifornimento frumentario di Roma, in B. Marin e C. Virlouvet (ed.) Nourrir les cités de Méditerranée. Antiquité-Temps Modernes, Paris, p. 625-690.

GIARDINA A., 1993, La formazione dell'Italia provinciale, in A. Schiavone, Storia di Roma. III. L'età tardoantica. I. Crisi e trasformazioni, Torino, p. 51-68.

GrÉGOIRE H., 1922, Recueil des inscriptions grecques chrétiennes d'Asie mineure, Paris.

Grosso F., 1964, La lotta politica al tempo di Commodo, Torino.

Gsell S., 1902-11, Atlas archéologique de l'Algérie, Paris $(=A A A)$

Halfmann H., 1986, Itinera principum. Geschichte und Typologie der Kaiserreisen im römischen Reich, Wiesbaden.

Hekster O., 2002, Commodus : An Emperor at the Crossroads, Amsterdam.

Hermansen G., 1982, Ostia. Aspects of Roman City Life, Edmonton.

Hobson D.W. 1984, PVindob.Gr, 24951+24556 : New Evidence for Tax-Exempt Status in Roman Egypt, in Atti del XVII Congresso Internazionale di Papirologia, III, Napoli, p. 847-864.

Houston G.W., 1988, Ports in Perspective : Some Comparative Materials on Roman Merchant Ships and Ports, AJA, 92, p. 553-564

JaCQues Fr., 1984, Le privilège de liberté. Politique impériale et autonomie municipale dans les cités de l'Occident romain (161-244), Rome.

Johnson A.Ch., 1959, Roman Egypt to the Reign of Diocletian, Paterson.
Jones C.P., 1986, Culture and Society in Lucian, Cambridge $\mathrm{Ma}$

KalÉN T., 1932, Berliner Leihgabe Griechischer Papyri, Uppsala.

Kambitsis S., 1997, Papyrus Graux III. P. Graux 30, Genève.

Katzoff R., 1986, Law as 'katholikos', in R.S. Bagnall e W.V. Harris, Studies in Roman Law in Memory of A. Arthur Schiller, Leiden, p. 119-126.

KenNEDY D.L., The Garrisoning of Mesopotamia in the late Antonine and early Severan period, Antichthon, 21, p. 57-66

Kruse Th., 2002, Der königliche Schreiber und die Gauverwaltung : Untersuchungen zur Werwaltungsgeschichte Ägyptens in der Zeit von Augustus bis Philippus Arabs (30 v. Chr. $-245 n$. Chr.), München.

Leglay M., 1982, Sénateurs de Numidie et des Maurétanies, in Epigrafia e ordine senatorio, Roma (Tituli, 5), p. 755-770.

Leunissen P.M.M., 1989, Konsuln und Konsulare in der Zeit von Commodus bis Severus Alexander (180-235 n.Chr.) Prosopographische Untersuchungen zur senatorischen Elite im Römischen Kaiserreich, Amsterdam.

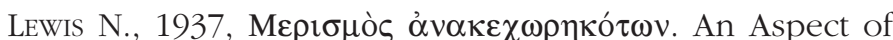
the Roman Oppression of Egypt, JEA, 22, p. 65-75.

Lewis N., 1993, A Reversal of a Tax Policy in Roman Egypt, GRBS, 34, p. 101-118.

Lewis N., 1997, The Compulsory Public Services of Roman Egypt, Firenze.

Lo CASCIO E., 1999, La popolazione dell'Egitto romano, SS, 40 , p. $425-447$.

LuCCARDINI R., 2001, Vie romane in Liguria, Genova.

Mattingly H., 1940, Coins of the Roman Empire in the British Museum, IV, London.

Mennella G., 2000, Legionari del Donau a Dertona e Ticinum una nuova testimonianza, in Y. Le Bohec (ed.), Les Légions de Rome sous le Haut-Empire. Actes du Congrès de Lyon (17-19 septembre 1998), Lyon, p. 645-653.

Messeri Savorelli G., 1989, La popolazione di Soknopaiu Nesos nel 178/9 d.C., AnPap, 1, p. 7-14. 
Miтthof Fr., 2001, Annona militaris. Die Heeresversorgumg im spätantiken Ägypten. Ein Beitrag zur Verwaltungsund Heeresgeschichte des Römischen Reiches im 3. bis 6 . Jh. n. Chr., Firenze.

Mratschek-Halfmann S., 1993, Divites et praepotentes. Reichtum und soziale Stellung in der Literatur des Prinzipatszeit, Wiesbaden.

MÜLLER A.E., 1993, Getreide für Konstantinopel. Überlegungenzu Justinians Edikt XIII als Grundlage für Aussagen zur Einwohnerzahl Konstantinopels in 6 . Jahrhundert, Jabrbuch der österrbeichischen Byzantinistik, 43, p. 1-20.

Nachtergael G., 2005, Papyrologica. II, CE, 80, p. 229-245.

Oertel F., 1917, Die Liturgie. Studien zur ptolemäischen und kaiserlichen Verwaltung Ägyptens, Leipzig.

OgGianu M.G., 1991, Contributo per una riedizione dei miliar sardi, in L'Africa romana. Atti dell'VIII Convegno di Studio (Cagliari 14-16 dicembre 1990), Sassari, p. 863-897.

Papi E. e Martorella F., 2007, Il grano della Tingitana, in E. Papi, Supplying Rome and the Empire. The Proceedings of an International Seminar Held at Siena-Certosa di Pontignano on May 2-4, 2004 on Rome, the Provinces, Production and Distribution, Portsmouth, p. 85-96.

Pavis D'Escurac H., 1974, Réflexions sur la classis Africana Commodiana, in Mélanges d'histoire ancienne offerts à William Seston, Paris, p. 397-408.

Pflaum H.G., 1971, Une lettre de promotion de l'empereur Marc Aurèle pour un procurateur ducénaire de Gaule Narbonaise, BJ, 171, p. 349-366.

Pflaum H.G., 1978, Les Fastes de la province de Narbonnaise, Paris.

Picard G.Ch., 1956, Néron et le blé d'Afrique, CT, 4, p. 163-173.

Pomey P. e Tchernia A., 1980, Il tonnellaggio massimo delle navi mercantili romane, Puteoli, 4-5, p. 35-45.

Rathbone D., 1989, The Ancient Economy and GraecoRoman Egypt, in L. Criscuolo e G. Geraci, Egitto e storia antica dall'ellenismo all'età araba. Bilancio di un confronto (Atti del Colloquio internazionale. Bologna 31 agosto-2 settembre 1987, Bologna, p. 159-176.

Rathbone D., 1990, Villages, Land, and Population in Graeco-Roman Egypt, PCPhS, 36, p. 105-106.
ReITER F., 2001, Vorschläge zu Lesung und Deutungen einiger Transportbescheinigungen, ZPE, 134, p. 191-210.

Rostovzev M., 1933, Storia economica e sociale dell'impero romano, Firenze.

Rougé J., 1966, Recherches sur l'organisation du commerce maritime en Méditerranée sous l'Empire romain, Paris.

SABlayrolles R., 1990, Le Colisé brûle-t-il ?, in Spectacula 1. Gladiateurs et amphithéâtres. Actes du colloque tenu à Toulouse et à Lattes les 26-29 mai 1987, Lattes, p. 129-134.

SAlama P., 1980, Les voies romaines de Sitifis à Igilgili. Un exemple de politique routière approfondie, AntAfr, 16, p. 101-133.

Salcedo de Prado I., 2006, Una familia de Cuicul y Cirta: los Claudii, in L'Africa romana. Mobilità delle persone e dei popoli, dinamiche migratorie, emigrazioni ed immigrazioni nelle provincie occidentali dell'impero. Atti del XVI convegno di studio (Rabat, 15-19 dicembre 2004), I, Roma, p. 539-554.

SALDERn F. von, 2003, Studien zur Politik des Commodus, Rahden.

SALOMIES O., 1997, Die Herkunft des numidischen Legaten Ti. Claudius Subatianus Proculus, ZPE, 119, p. 245-248.

SCHEIDEL W., 2001, Death on Nile : Disease and Demography of Roman Egypt, Leiden.

Schnebel M., 1925, Die Landwirtschaft im hellenistischen Ägypten, München.

Schubert P., 2001, A Yale Papyrus (P Yale III 137) in the Beinecke Rare Book and Manuscript Library III, Oakville.

Sena Chiesa G. e Arslan E., 1998, Optima via. Postumia. Storia e archeologia di una grande strada romana alle radici dell'Europa (Cremona 1996), Atti del convegno internazionale di studi, Milano.

SIRKS B., 1991, Food for Rome. The Legal Structure of the Transportation and Processing of Supplies for the Imperial Distributions in Rome and Constantinople, Amsterdam.

SIRKS B., 2003, Some observations on Edictum Justiniani XIII.8. A reaction to Jean-Michel Carrié, in B. Marin e C. Virlouvet (ed.), Nourrir les cités de Mediterranée. Antiquité-Temps Modernes, Paris, p. 213-219. 
Sommella P., 1978, Forma e urbanistica di Pozzuoli romana, Puteoli, 2, p. 1-98.

Thomas J.D., 1975, A Petition to the Prefect of Egypt and Related Imperial Edicts, JEA, 61, p. 201-221.

Thomas J.D., 2001, Oxyrhynchus Papyri Part LXVII, London.

Thomsen R., 1947, The Italic Regions. From Augustus to the Lombard Invasion, København.

Thouvenot R., 1941, Une colonie romaine de Mauretanie Tingitane: Valentia Banasa, Paris.

TSIPARIS C., 1979, Ostraka aus der Sammlung des Instituts fur Altertumskunde an der Universitat zu Lund herausgegeben und kommentiert von Christos Tsiparis, Lund (= O. Lund.)

Van Minnen P., 2000, Agriculture and the 'Taxes-and-Trade' Model in Roman Egypt, ZPE, 133, p. 205-220.

Van Minnen P., 2001, P.Oxy. LXVI 4527 and the Antonine Plague in the Fayyum, ZPE, 135, p. 175-177.

VERA D., 2005, Un canon frumentarius di sette anni gratifiche imperiali o 'mythistoria'?, in G. Bonamente (a cura di), Historiae Augustae Colloquium Barcinonense, Bari, p. 273-304.

Virlouvet C., 1995, Tessera frumentaria. Les procédures de la distribution du blé public à Rome, Rome.

Virlouvet C., 2000, Les denrées alimentaires dans les archives des Sulpicii de Pouzzoles, CCG, 11, p. 131-149.

Virlouvet C., 2004, Les naviculaires d'Arles. À propos de l'inscription provenant de Beyrouth, MEFRA, 116, p. 327-370.
Wagner J., 1983, Provincia Osrboene. New Archaeological Finds illustrating the Military Organisation under the Severan Dynasty, in Armies and Frontiers in Roman and Byzantine Anatolia. Proceedings of a Colloquium beld at University College, Swansea, in April 1981, Oxford, p. 103-123.

WhitTaker C.R., 1964, The Revolt of Papirius Dionysius A.D. 190, Historia, p. 349-369.

Wiemer H.-U., 1997, Das Edikt des L. Antistius Rusticus : Eine Preisregulierung als Antwort auf eine überregionale Versorgungskrise?, Anatolian Studies, 47, p. 195-215.

Wilcken U., 1899, Griechische Ostraka, I, Leipzig-Berlin.

Wilcken U., 1908, Aus der Straßburger Sammlung, APF, 4, p. 127.

Witcher R., 2005, The extended metropolis : Urbs, suburbium and population, $J R A, 18$, p. 120-138.

Youtie H.C., 1944, Oxyrhynchus Papyrus 2182, Classical Weekly, 37, p. 163-165.

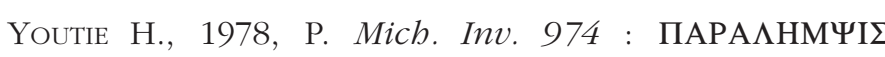
I $\triangle \mathrm{I} \Omega \mathrm{TIK} \Omega \mathrm{N}$ ON$\Omega \mathrm{N}, Z P E, 28$, p. 247.

ZIEgLeR R., 1977, Münzen Kilikiens als Zeugnis kaiserlicher Getreidespenden, JNG, 27, p. 29-67.

ZIEgLeR R., 1978, Antiochia, Laodicea und Sidon in der Politik der Severer, Chiron, 8, p. 493-514

Zuckerman C., 2004, Du village à l'empire. Autour du registre fiscal d'Aphroditô (525/526), Paris. 